\title{
AN EXAMINATION OF THE TSETSE PROBLEM IN NORTH MOSSURISE,
} PORTUGUESE EAST AFRICA.

By C. F. M. SwYNNERTon, F.L.S.

(Plates IX-XVII and Map.)

CONTENTS.

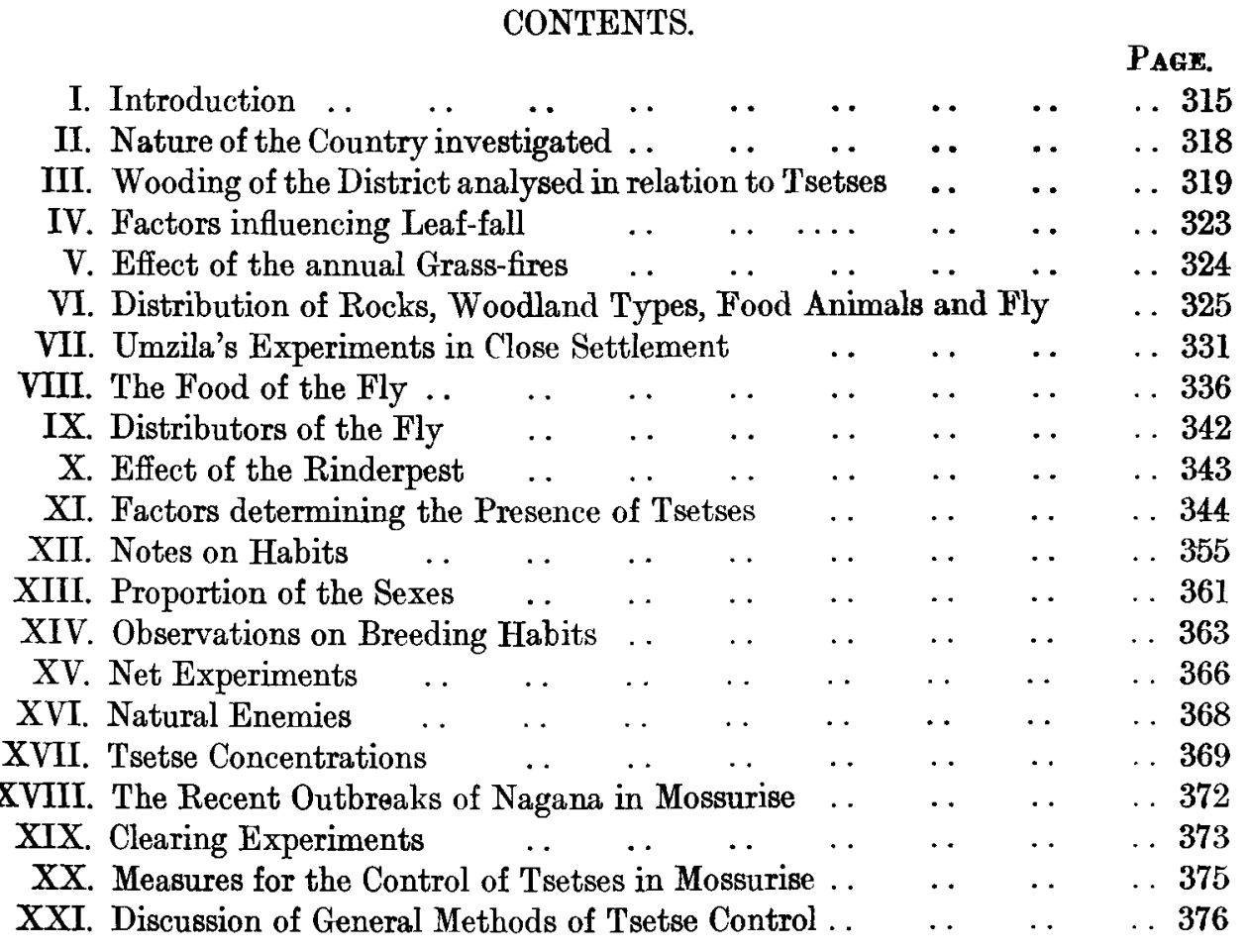

\section{I.-INTRODUCTION.}

In June 1918, I arranged to carry out a preliminary investigation of the habits and distribution of the tsetse-flies in the northern portion of the Mossurise district for a maximum period of three months on the understanding that the Mozambique Company would defray the general expenses of the expedition.

After a brief stay at Gogoyo's with little success I proceeded to the country east of the Sitatonga Hills. I had found tsetses in considerable numbers there in June 1900 , and hoped by commencing my work in a well infested area to gain at once a thorough acquaintance with the fly that would stand me in good stead during the rest of my expedition and enable me also to decide quickly on my requirements in the matter of bait and labour. I was fortunate enough to make a number of particularly interesting observations during this first part of my trip, east of the Sitatongas.

Having found that the large tsetse (Glossina brevipalpis) does not come readily to man or to goats, I applied for cattle to serve as bait. These reached me on

(737) 1,000. Wt.P2 154. 3.21. B.\&F.,Ltd. Gp. 11. 
28th July, and proved quite invaluable during the remaining six weeks. They revealed abundant fly in places in which the nature of the vegetation had previously been the only indication of its possible presence, and led to the suggestion that one reason why investigators have commonly met with so enormous a preponderance of nale flies is that insufficiently attractive bait has been offered to the sex that comes only to feed.

The part of my investigation already referred to, east of the Sitatonga Hills, was carried out with the help of my own farm natives only, and was concerned chiefly with the small flies, Glossina morsitans and $G$. pallidipes, which I there found mixed. I also then made my discovery, and commenced my study, of the Mtshanedzi-Buzi brevipalpis area, which at its other end affects Spungabera.

The second month (I was now being assisted in the matter of labour by Snr. Lamne) was occupied mainly with a fly survey of the northern part of the district. It included also the completion of my work on the breeding habits of $G$. morsitans and a week's study, south-west of Chibabava, of a typical piece of the surface-basalt country that constitutes so very large a proportion of the low-lying parts of the Mossurise district. At this period I sent a successful side-expedition round north of the entire Lusitu River in the Moribane district in order to gain some idea of the full extent and importance of the eastern fly-areas.

The third section of the trip was occupied with the completion of the above work, with experiments directed to ascertaining the effect and cost of particular forms of clearing for fly, a study of the habits of $G$. brevipalpis and a special study of the Spungabera problem. Spungabera being the official head-quarters of the district, and the seat of a herd of cattle belonging to the Mozambique Company that had lost heavily from trypanosomiasis, its protection from fly appeared to be of the first importance.

I returned home finally on 10th September, and afterwards I sent a small expedition to the Chinyika River, south of Spungabera, and completed my breeding experiments.

Four days had been spent near the British border examining the details of nagana outbreaks in Portuguese territory, two in trying to ascertain the maximum dry season elevation of $G$. brevipalpis, and two in all at Spungabera itself. Otherwise all the work was more or less far within Portuguese territory. I had had four working camps-one on the Umvuazi River east of the Sitatongas, one on the Buzi in the Gunye-Umpombo country south-west of Chibabava, one near the east end of the great southern brevipalpis area, and one at its west end at a point on the Buzi six miles from Spungabera.

The Mossurise fly problem quickly proved to be of quite extraordinary interest. Apart from the presence in the district of so many different tsetses, and the opportunity of studying them usefully that is offered by the very varied but welldemarcated conditions of vegetation, elevation, rock-formation, etc., that the district affords, the area west of the Sitatonga Hills was, under the Zulu domination, the scene of a particularly fine experiment in the banishment of tsetse. It was not difficult to obtain the details of this experiment, as most of the older natives had, incidentally or by compulsion, taken part in it. I made particular efforts to obtain information on this point, $(a)$ because a study of any successful campaign, 
by whomsoever carried out, is bound to add usefully to our general knowledge on the subject of controlling tsetse ; $(b)$ because the area cleared of fly was the very area which, in the Mossurise district, is best adapted to white settlement. This experiment affords a very clear indication that settlement, properly planned, is itself capable of clearing the country settled of the two flies here concerned-G. brevipalpis and G. pallidipes.

Other points to which I paid particular attention were an analysis of the vegetation in relation to tsetse, and a study of the distribution and local behaviour of the dangerous and less dangerous woodland types. The practical study of tsetse is, I am convinced, a matter for the botanist and œcologist rather than the unaided entomologist, and this point will be seen to be of the first importance. Each of the tsetses is dependent on particular, but different, shade conditions. Without a clear knowledge $(a)$ of the woodland types that provide these conditions, $(b)$ of those that provide them throughout the year, and $(c)$ of the dry season response of each of these types to elevational and edaphic conditions, exceptional seasons, burning, etc., any clearing operations that may be undertaken in the future for the extirpation of $\mathrm{fly}$, in connection with settlement or otherwise, will be lacking completely in the elements of precision and economy.

The main practical results have been, I think, the clear defining of the several fly-areas and of the situation at Spungabera, the lessons, both general and in relation to future settlement in Mossurise, to be drawn from the details of Umzila's success, and, in relation to $G$. brevipalpis in particular, the fact that the annual grass-fires can be made to play an important part by regulation of the time of burning. In primary forest the control of this fly is unfortunately rendered difficult by the presence of the Landolphia vines, which it may not be wished to sacrifice.

So far as G. morsitans is concerned, it seems to me that the possibility of taking advantage of its highly gregarious and localised habits is worthy of further study.

I conclude by expressing my very high indebtedness to Snr. Lanne and, in his absence, Snr. A. P. Monteiro for going out of their way to do all in their power to assist me in making a success of the investigation, and to my old friend Snr. Ferreira for his very cordial offer of help on learning that $I$ was working in his district also. I am likewise particularly highly indebted to Dr. W. T. Lawrence of Gogoyo, who not only gave me such information as he already possessed with regard to the fly and continuously collected tsetses for me locally, but also rendered my work east of the Sitatongas and south of the Mtshanedzi possible in this foodless season by lending me native food in considerable quantity. Mrs. Lawrence most kindly presented me with gauze for nets at a moment when it was particularly acceptable, and Messrs. J. W. Scott and G. D. Otterson, living in the mountains, were good enough to assist me in a test of the resistance of $G$. morsitans to cold in the pupal stage. For some of the literature of the subject, presented to me at different periods in the expressed hope that I would undertake tsetse investigation, I am indebted to my friends Drs. G. A. K. Marshall and A. G. Bagshawe, Directors of the Imperial Bureau of Entomology and the Tropical Diseases Bureau, London, respectively; and för copies of his own interesting publications, to Mr. R. W. Jack, Rhodesian Government Entomologist. I have also to thank the Rhodesia Museum and Mr F. P. Mennell, of Bulawayo, for the latter's identifications of a rock collection (737) 
made in connection with the tsetse work; Mr. E. C. Chubb, Curator of the Durban Museum, for his identification, still incomplete, of the small mammals trapped by me in a dry season breeding centre of $G$. morsitans; and the Director of Mines, Maçequeçe, for his kind loan of the Geological Survey Report. Mr. W. M. Longden, who spent many months with the Chief Gungunyana, has kindly sent me many interesting notes on Manikusa's and Umzila's wars.

Lastly, I have to thank His Excellency the Governor of the Mozambique Company's Territory for his sympathetic interest in the undertaking, and the readiness with which he provided for the expenses of the expedition.

\section{II.-Nature of the Country Investigated.}

The country investigated lies chiefly in the Mossurise but partly in the Moriban district, and in the main between the Buzi and Lusitu Rivers. East of the latter river's great southward bend it is bounded by the southern termination of the splendid Chimanimani massif with peaks of over 8,000 feet, and by that of the Mabiti highlands. Its most prominent physical feature is the straight, high, narrow Sitatonga Ridge that, pointing to the magnetic north, cuts at right angles to the two rivers and effectively shuts off the lowland plains east of it from the foot-hill and valley country to its west. The latter is divided further by two rivers, the Mtshanedzi and the Puizisi, which flow out from the direction of the political border, but turn off, the former to the Buzi, the latter to the Lusitu, shortly before reaching the Sitatongas. The valleys are low and broad, as is that flanking the Sitatongas on that side, and it was these valleys that were the site of the guard-area employed by Umzila for the protection of the enclosed country-a successful measure against fly which I shall describe below.

Between the Lusitu and Puizisi, between the latter and the Mtshanedzi, and again between the Mtshanedzi and the Buzi, are three hill systems, the first twe backed by and rising strongly to the highlands of the British frontier (see Map), the other consisting of independent second-rate heights rising from broken country that falls away gradually to the eastward-flowing Buzi.

The elevation varies from well over 4,000 feet (1,220 metres) on Mount Umtareni and the Sitatonga crests, and 3,700 at Spungabera, to 2,000 and 1,000 feet and less in the lower valleys between the Sitatongas and the British border. East of the Sitatongas the general elevation would be nearer 500 to 600 feet. Indirectly at any rate, elevation is an important factor here in relation to the permanent distribution of tsetse.

I had no means of taking altitudes, but the following aneroid readings, taken by him in 1917, have very kindly been given me by Mr. R. W. Jack.

\begin{tabular}{|c|c|c|c|c|c|c|c|}
\hline \\
\hline \multicolumn{8}{|c|}{ 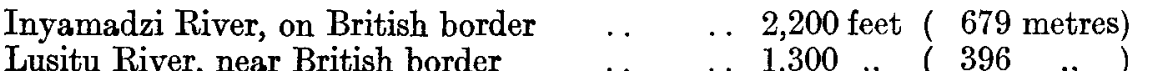 } \\
\hline Lusitu, near Haro & ii Junction & & & 1,100 & & 335 & \\
\hline Mossurise River or & Spungabera & -Masan & jena Road & 950 & & 290 & \\
\hline Gogoyo, Dysart C & ncession & & & 1,200 & & 366 & ", \\
\hline Mtobe's Kraal & . & & about & 1,000 & , & 305 & $"$ \\
\hline Mafusi's Kraal & $\cdots$ & & 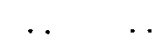 & 2,200 & , & $(670$ & ", \\
\hline Spur & $\cdots$ & & & 3,700 & , & $(1,137$ & ,. \\
\hline Jersey homestead & $\cdots$ & & . & 2,800 & , & 853 & $\because$ \\
\hline
\end{tabular}


The last figure, though obtained in British territory, gives an idea of the higher altitudes in the lower part of Gwenzi's country, about the Chinyika River south of Spungabera.

\section{III.-Wooding of the District Analysed.*}

A classification of woodland types in relation to tsetse would properly be founded on the degree to which and the length of period during which they lose their leaves in winter. It so happens that the division between evergreen (or with high, dense, heavy undergrowth and lianas) and deciduous coincides here in the main with the natural division of the wooding into two principal types.

These are:-(1) primary forest, pyrophobic or fire-fearing, dominated either by evergreen or deciduous trees; (2) secondary, pyrophytic or fire-supporting forest of various sub-types. The latter replaces the former where that is burnt out. Bark adaptations enable it to withstand fires, and it is burnt through annually. Where it so thickens up as to reduce the grass growth, and consequently the severity of the fires, it tends to be re-invaded by the primary forest. A large proportion of the finer rubber forest in the area investigated consisted of secondary forest in course of re-invasion, and this harboured the large tsetse (Glossina brevipalpis).

Primary forest (Pl. ix ; Pl. xiii, fig. 2) consists of lofty, densely growing trees that support many woody lianas and shade lower tiers of evergreen shrubs and mall trees, with a carpet and fringe that do not readily burn. Primary forest of the "rain-forest" type exists in the highlands, mostly in small patches at Spungabera and elsewhere, and is characterised by such splendid trees as Khaya nyasica (East African mahogany or mubaba), Chrysophyllum fulvum (large muchanja) and Piptadenia buchanani (umfomoti). The last-named species dominates most forest of this type seen in the Lusitu-Sitatonga rubber country. It gives it almost the character of " monsoon" forest, for it differs from the others in being regularly deciduous; but the period of leaflessness is not very long, and the lianas and high close-packed evergreen shrubs (Pl. xiii, fig. 2) continue to afford the requisite shade for the forest fly, $G$. brevipalpis, and to favour its activities at all hours of the day.

There is much striking evidence in favour of the view that primary forest once covered this country, and that during very many thousands of years past it has gradually been reduced to its present small dimensions through the agency of burning and cultivating man. From this and from the analogy of the distribution of our other forest animals, quite apart from the results of the movements of game, would follow the comforting deduction that primary forests that to-day lack the large tsetse possess some advantage, elevational or otherwise, in regard to it, and are likely therefore never to harbour it for long. Such forests are those of Spungabera, Mount Silinda and the border generally.

Apparent primary forest here has three sub-types, "mountain," " heavy" and " ravine." The first does not concern us; the second (Pl. ix) is characterised by the shrubs, Conopharyngia usambarensis and Dracaena fragrans, and the liana,

*These descriptions"of woodland types are necessarily greatly condensed, but their recognition will be facilitated by reference to the accompanying illustrations. 
Landolphia swynnertonii; and the third (specially common in the area investigated) is often dominated by the Piptadenia, by the shrubs, Craterispermum laurinum and Dracaena gazensis, and the liana, Landolphia kirkii ( $f f$. Pl. xiii, fig. 2). It seems to be the most important in relation to G. brevipalpis, though I have also taken this fly in some numbers in the heavier type.

$A$ river-bank association that is worth mentioning specially owing to its ubiquity is that which consists mainly of tall, clean-stemmed trees of mowana (Adina microoephala) and mubaba (Khaya nyasica) growing on the immediate edge of streams and, so long as the moisture supply remains ample, resisting the action of the fires. Except where it has been associated with lower woody growth, I have not found it to harbour fly. However, it frequently is thus associated.

Secondary formations-deciduous in varying degrees-present several very clearly defined sub-types varying from savannah to close wooding, and each somewhat closely confined to a particular geological formation. With "wooded pasture " of one or other of these sub-types it covers the bulk of the country.

The local "formations" are as follows:-

(1). Very highly deciduous types, such as Pterocarpus sericeus (mumbhnigu), Pterocarpus angolensis (bloodwood or mubvangazi) - the earliest shedder and latest reclother of all (Pl. x, fig. 1)-Acacia natalitia (ihlofunga), A. caffra (iguwha), Bridelia micrantha (mushungunu) and others. Considerable stretches of country are covered almost exclusively with bush of these species-open or dense, pure or mixed. Fly spreads in during the rains, but I failed completely to find tsetse in wooding purely of this type during the leafless period even in such shade as there was, and as it is quite unlikely that they can exist there then, it follows that such areas are cleared each year for from one or two to many months at a time. The country carrying these more sensitive types of wooding is characterised by good soil and permanent streams, and much of it by high elevation. It is particularly. suited to settlement.

(2). Lowland bush savannah (PI. $\mathrm{x}$, fig. 2), comprising many tree species, but with the mupoza (Combretum near leonense) dominant on the drier parts and the musekesa (Bauhinia reticulata) on those that are wetter in the rains. The bush is mostly sparse and, the fires being early and the trees and shrubs low, the shade is destroyed at an early date in a normal year. Rare scattered fly, G. morsitans and pallidipes, was to be found in this type of country up to the time of burning, that is in 1918 the end of July, but permanent fly was near by in a more suitable type of wooding-Brachystegia, with vleis. I found no trace of the existence of permanent breeding centres in this type of country-the basalt.

(3). Brachystegia wooding, here known as "tondo-bush" or "itondo" and evidently identical with what Jack calls "gusu." This again contains a variety of trees and shrubs, but different species of Brachystegia dominate, such as $\dot{B}$. glabiflora, the mutondo (which gives its native name to the type of wooding), and the mutsatsas, B. randii, B. bragaei and B. spicaeformis, the trees of the red spring foliage. Uapaca also-U. kirkiana (munjanje) especially in the highlands, $U$. sansibarica (mutongoro) below-is common and in many places forms pure wooding. Diplorhynchus mossambicensis (mutowa), with its weeping 
foliage, creviced stem and branches and furrowed, protectively coloured bark, is a particularly useful tree to the tsetse and is abundant in Brachystegia bush at low elevations. It is the foreground tree in Pl. xvi, fig. 1.

Tondo-bush is the tsetse bush par excellence. Brachystegia-Uapaca wooding in our present connection is divisible into three varieties, two of which carry each its own tsetse. It is divisible into $(a)$ high " itondo," characterized by the greater size of the trees and generally denser wooding and forming fine " savannah " forest (Pl. xvi, fig. 1); (b) lower, more open "itondo," still mostly savannah forest, but poorer and intermixed with more definite savannah (Pl. xv, fig. 1). It is (with other conditions correct) the special haunt of $G$. morsitans. The former, finer variety is divisible further into (1) clean itondo, devoid of woody undergrowth and of the large fly (Pl. xiii, fig. 1), and (2) itondo with woody undergrowth, inhabited by $G$. brevipalpis (Pl. xii, fig. 2 ).

This undergrowth, usually patchy, consists for the most part of saplings of the trees themselves, often in close-packed clumps (Pl. xii, fig. 2; Pl. xvi, fig, 1), and of large scattered shrubs such as the umtunduluku (Ximenia americana) and the chigwenderes (Bauhinia galpini and B. petersiana); but in parts of the high itondo may be found numerous clumps of "ravine" type primary forest undergrowth, extensive or small, of bird and baboon-carried genera that have made a start and maintained themselves where the ill-regulated fires have enabled them to do so. Pl. xiv, fig. 1, gives some idea of their nature.

Two highly important points about itondo in relation to tsetses are these :(a) The grass-growth in general below high tondo-bush is sparser than in some of our other secondary sub-types and does not burn really effectively till late in the season; (b) itondo as a whole, under our local conditions of rainfall, tends to retain its leaves through the winter better than any other of our secondary formations. The mutsatsas (Brachystegia bragaei, etc.) have often regained their leaves before the associated mutondo trees ( $B$. globiflora) have lost theirs, and the Uapacas only lose theirs (and that not completely) when nearly all the other species are busy regaining their leaves. This tendency to keep in leaf without some s'ight interregnum is less marked at high elevations, in particularly cold and dry winters, and in the drier parts of the lowland areas; but on the Buzi, and in the "Oblong" (see Map) generally, it was sufficient in 1918 to carry G. brevipclpis in numbers everywhere through the winter, and it is probable that in most if not all years it would do so in most parts of this piece of wooding.

(4). Dense secondary forest includes especially $(a)$ the very fine type of wooding dominated by musara and musunganyemba (Milletia stuhlmanni and Pteleopsis. myrtifolia)-definite " monsoon forest"; and (b) a more mixed type. In places, owing often to the coppicing effect of unthorough native cultivation with the good seed-bed offered by old gardens to seeds from the surrounding bush, and to the relative exclusion of fire consequent on the absence of grass, the ordinary trees of the savannah form more or less dense thickets (Pl. xvii, fig. 1). Eventually trees and shrubs that are normally found on the outskirts of primary forest introduce themselves and finally dominate. Such are the munjerenshe (Albizzia fastigiata chirindensis), the large umkadhlo (Rauwolfia inebrians) and the fine shrubs Vernonia 
podiocoma (mudambasese) and Brachylaena rhodesiana (ipahla). The annually burning grasses tend to disappear, the live carpet may become sparse or it may become composed in part of the non-burning grasses that occur in the primary forest of the same locality. Clumps and stretches of the handsome ribbon-like izeya grass (Setaria mauritiana), beloved of buffalos, also of Amomum (good shade for brevipalpis) are exceedingly common, and thickets occur of such tall, more or less herbaceous plants as Isoglossa mossambicensis and the unpleasantly smelling Mellera lobulata. Woody undergrowth is usually more or less scarce excepting when the wooding is under invasion by primary elements.

In the simple coppice stages (Pl. xvii, fig. 1) these woods are highly attractive to G. pallidipes; in the older stages where the overwood is tall and heavy, as on the Sitatonga base, and some underwood is present, they shelter G. brevipalpis. In the Mtshanezi-Puizisi area especially a large proportion of the groves of this type are of relatively low growth and are characterized by the presence of the very beautiful climbing fern, Lygodium subalatum, which carpets the ground and curtains the trunks up to a considerable height, affording low shelter and additional shade where the shrub growth is poor. This variety of the type is perhaps more commonly frequented by pallidipes than by brevipalpis. "Dense mixed secondary" occurs here chiefly on the dolerite and, like Milletia bush, tends readily to be replaced by primary elements (which are more suitable to brevipalpis) where it is in contact with them. Thus Albizzia chirindensis and Piptadenia buchanani (umfomoti) are at present sharing the dominance of the Mafusi rubber forest, and the shrub growth shaded by them is already largely primary. The musara (Milletia) is rather specially deciduous, and I have found relatively little dry season fly in this variety of dense secondary excepting where it was under incipient primary invasion.

(5). Bauhinia and Erythroxylon-Landolphia thickets. Two species of chigwendere (Bauhinia galpini and B. petersiana), large and densely foliaged shrubs that lose their butterfly-shaped leaves more or less late in the season, occur from the British border to the Sitatonga Hills. $B$. petersiana continues to be present east of the hills. They are found in every type of secondary wooding, especially on ant-heaps, but in places they form almost pure coppice of their own. When well-grown and in leaf, their coppice is more attractive to $G$. pallidipes. Where, however, the Bauhinias occur isolated under higher shade, G. brevipalpis is attracted and rests under their coils-for under these conditions they tend to assume the habit of lianas.

Low dense thickets of Erythroxylon emarginatum, Pleuroridgea zanguebarica and other erect shrubs, with a few rubber vines, have invaded (for the most part) Pterocarpus wooding at high elevations on Mount Umtareni. I found no fly there, for reasons probably of elevation and also of situation; for between this and the permanent fly-bush (Brachystegia) lower down the slopes lay a belt of highly deciduous trees (formation 1, above). Lowland rubber forest (PI. xi) is not essentially different. It also contains much of the Erythroxylon, but the invasion of Landolphia and other lianas has progressed further than on Umtareni and here fills the thickets. The trees of the highly deciduous and other (Brachystegia) types that have been invaded still in many places stand out above the new shrub growth, just as on Umtareni. I refer particularly to the Madanda forests, which I did not 
visit on this trip, but which (from what I saw of them in 1906-7) I should quite suspect of being capable of harbouring $G$. pallidipes and, in many places, G. brevipalpis.

\section{IV.-Factors Influencing Leaf-Fall.}

I have described above the relative deciduousness of our various types of bush. We have seen that primary forest (PI. ix), and bush which it is seriously invading, is never leafless enough here to discourage its special fly-brevipalpis; and that of the secondary types, Brachystegia wooding (Pl. xvi, fig. 1) and particular varieties of the "dense secondary" formation tend to retain in this district sufficient leaf to carry fly through the year.

However, within any particular type of wooding actual leaf-fall is hastened locally, and the gaining of the leaf correspondingly deferred, by several factors. It is true that some of the differences are apparently individual, though unseen root disabilities might account for them. It is at any rate of frequent occurrence to see two trees of the same species and size (e.g. of Pterocarpus) standing together, one of them leafless the other not. Ficus subcalcarata (the mutowetowe fig, an isolated large specimen of which will sometimes harbour fly) is an extraordinarily erratic leaf-shedder. But general rules are apparent also.

(1). Season affects leaf-fall. After the abnormally heavy rains of 1917-1918 $(2,514.5 \mathrm{~mm}$. at Spungabera) leaf-fall generally took place, I should say, quite three weeks later than usual, where frost was absent. A low rainfall (such as that of 1913), or early and severe cold, hastens the phenomenon. It must be remembered further that rainfall, hence leaf-fall, varies with locality, particularly in relation to the mountain ranges. The rainfall appears to be distinctly lower east of the Sitatongas than on them or even west of them, and is lower here again than on the hills of Spungabera, the "Jihu" (Gwenzi's) and the British border.

(2). Proximity of moisture in the soil affects leaf-fall in two opposite ways. On damp low-lying ground liable to frost the leaf-fall is hastened, and even where there is no actual frost, trees bordering on ill-drained, cold, swampy ground tend annually to lose their leaves earlier then those of the same species that stand back on well-drained soil. But trees standing on warm, damp soil lose their leaves later than the latter. These differences are to be clearly seen in fly-harbouring Brachystegia woods, but the particular illustration I shall quote is concerned with some scattered wooding of Pterocarpus angolensis (mubvangazi-Pl. x, fig. 1) that is under my continuous observation. Here not only is there, in May, an increased leaflessness as one approaches the cold, damp lower valleys, but of the trees within the latter, those with their roots raised on ant-heaps are practically in full leaf when those on the general ground-level are completely leafless.

(3). Differences in the amount of humus present has appeared to account for a difference in leaf-fall between woods of the same species-e.g. of Pterocarpus sericeus (mumbhungu) on the dolerite-and it is to be noted that ant-heaps exert an influence in this direction also. It is probably again mainly a matter of relative moisture retention.

(4). Geological formation affects leaf-fall once more on the same lines. I have noticed that Pterocarpus sericeus loses its leaves a good deal later on the fertile 
(and moisture retaining) upland dolerite than on the sandstone-shale formation at the same elevation. The Brachystegia-Burkea groves of the far drier, deeply cracking, compact basalt soils of the plains, effectively drained by the low-flowing Buzi and highly insolated, were losing their leaves earlier than those of the granite, especially on stony outcrops; while similar wooding on a quartzite strip on the Buzi, at the same elevation and distance from the river and only half a mile away, was far later than the latter, as was the Brachystegia wooding (doubtless with better rainfall, however) of the sedimentary area of the higher Buzi.

(5). Altitude, other things being equal, makes a difference. Travelling between Maruma and the escarpment at Makwiana's kraal on 11th August I saw no Albizzia (munjerenshe) or other secondary wooding that was not completely leafless. On approaching the foot of the descent I began to find some in leaf-and at once found fly, both brevipalpis and pallidipes. I have come across' many other examples both in our individual tree-species and in our woodland types that were thus reminiscent of the instance of the plane tree-simultaneously leafless at Innsbruck, yellow-leafed at Garda, dark green at Palermo and in parts of Greece evergreen; and I have little doubt that latitude must also count for much in this connection.

Altogether it is certain that no unqualified statement disregarding rainfall, soilmoisture, frosts, elevation, latitude and exceptional seasons can be made for particular types of wooding as regards the period for which they will be without leaves and inhospitable to tsetse. It is, I think, equally certain that an exhaustive study of these factors may be of great assistance not merely in the explanation of local outbreaks, but in the actual control of the fly. Certainly no investigator can at present lay down the law for another area than his own as to the behaviour of particular types of wooding and, therefore, for the seasonal behaviour there of the fly.

A point that cannot be too greatly emphasised is that, if we are to fight the fly economically as well as effectively, we must base our measures not on the normal ' but on the exceptional season. I do not refer to the season that is so exceptional as to occur only once in 50 years-as the great droughts of 1860 (approximately) and 1913 ; nor to cases in which haste is vital ; but, let us say, to the driest or coldest season in ten.

The effect of the factors that I have mentioned above may be seen even when leaf-fall has been brought about artificially, as by a fire.

\section{V.-Effect of the Annual Grass-fires.}

These very commonly anticipate leaf-fall. Except in the loftier bush, and to some extent there, they scorch and wither even the higher leaves and defoliate the saplings and shrubs, destroying the shade. The very factors, local and seasonal, that accelerate or retard the date of the normal leaf-fall hasten or postpone that of the fires also. In 1918-except on the uplands where the frosts were considerable and dried the grass-the earlier fires were a month or more later than usual ; in 1913 they were exceptionally early (after a deficient rainfall) and provided some excellent instances of what might be accomplished by severer annual fires towards the destruction of tsetse-haunted bush. The Buzi flats with their cracking basalt 
ooil (PI. $x$, fig. 2) are stated always to burn earlier than the granite gneiss near them (Pl. xiv, fig. 2 ; Pl. xv, fig. 1) with its impervious underlying bed, and the sandstone-shale areas of the uplands west of Spungabera definitely do burn considerably earlier than the dolerite beside them. The type of bush also influences the date of burning. High canopy-forming Brachystegia, such as occurs in Mossurise on the upper Buzi, burns effectively much later than the same bush where it is lower and more broken, and some types (as high dense secondary, including Milletia) burn, if at all, late yet tamely.

It is stated that under the Zulus burning was the subject of regulation for hunting purposes, a late, thorough burn being aimed at and usually achieved. Under the white man everyone burns when he pleases. It thus comes about that the first fires take place when the grass is but half ready to burn and there is relatively little recent leaf-litter on the ground. They attract but little wind to swirl the flames into the tree-tops and the thickets, and they are very small in extent, so that the flies driven from them find ample refuge all round. When later fires take placeat various dates-the areas burned earlier are already becoming fit for the reception of the fly and the latter suffers no inconvenience. A still worse effect of unregulated burning, from the point of view of tsetse control, is the encouragement given by too early burning to the wooding and particularly to the formation of the thickets on which $G$. brevipalpis rather specially depends (Pl. xvii, fig. 2). Late burning on the other hand finds the grass and fallen leaves at their driest and most abundant, and is so extensive as to draw in great wind. It achieves much actual destruction of young growth, and a temporary destruction of much high shade as well, at a hot, dry time that must be relatively critical for the tsetse.

A failure to burn, again, may be made the means of destroying thicket growth if the next year's burning is late, owing to the additional amount of inflammable material present. The fire no longer stops at the outskirts.' This result actually followed the temporary effort to keep fires from the rubber forests, and I was shown where pieces of these forests (in Umtobi's country-of the type shown in Pl. xiii, fig. 2) were completely destroyed in consequence.

\section{VI.-Distribution of Rocks, Woodland Types, Food Animals and Fly.}

\section{Geological Formations.}

Geologically, the country investigated is divisible into four clear-cut blocks, two of them east of the Sitatongas, two west. The two to their east are a granitegneiss and a basalt formation. The two to their west are $(a)$ a sedimentary formation of shale, sandstone and quartzite; $(b)$ dolerite, breaking through and capping the medimentary formation, which in the dolerite area is visible only in places.

The granite-gneiss country consists of lowland plains, flat to undulating. ${ }^{*}$ It is bounded on the west by the Sitatongas, on the north (I believe) by the Mabiti hills across the Lusitu and by their north-easterly continuation, on the south by a fairly well demarcated line a few miles south of the Umvuazi and apparently

* My rocks, identified by Mr. Mennell as mica granite, gneissose granite and Muscovite granite or gneiss, show more or less foliation, and the area appears to be that, east of the Sitatongas, described by Theile and Wilson as metamorphic. The general characteristics are those of the granite. 
following the same general direction as that river. The surface soil is a coarse, loose, whitish sand, and numerous vleis, still wet in the dry season, indicate the presence below of the usual impermeable layer.

The basalt plains (Pl. $x$, fig. 2) adjoin the granite-gneiss on its south. They cross the Buzi and cover a great extent of country to the south of it. The ground, reddish where the rock is exposed, browner or blacker in the interleaved alluvial patches, dries rapidly after the rains and shrinks and gapes. In the country actually investigated by me it is possible that the Buzi, flowing between fairly high banks, determines the height of the water-table.

The sedimentary area - or rather the area where this stratum is continuously exposed, for it underlies both the basalt and the dolerite-fills the great oblong tract enclosed between the Mtshanedzi and Buzi rivers (see Map). A broad strip of the same formation runs thence up the Buzi to the British border. It is hilly throughout, the solls are mostly compact, and the rock frequently outcrops. Except in the strip just referred to, it is not well supplied with permanent streams.

The sub-ophitic dolerite, as dyke or cap, dominates largely between the Mtshanedzi and the Lusitu, and especially at and south of Spungabera in Gwenzi's country. It is accompanied by a red, rather clayey, yet well drained and highly fertile, typical "trap" soil, and abounds in excellent permanent streams.

The Sitatongas themselves are of quartzite, flanked by schists, trap, etc.; apparently (Thiele and Wilson) the schists dominate to the north of them, in the area traversed by my native expedition.

\section{Distribution of Woodland Types.}

The granite-gneiss carries open (mixed) Brachystegia bush usually of a rather poor type (Pl. xiv, fig. 2). Its vleis are nearly bare of wooding, except for the fine trees on the ant-heaps that stud both vleis and dry land. The finer vleis in particular are lined by a short green sedge (Fuirena). The male tsetses are found in rather special connection with this.

The basalt, as might be expected from the above description, tends to carry a very poor type of bushy (Pl. x, fig. 2), mixed, but commonly more or less stunted and very open woods-the "lowland bush savannah" of my classification (p. 320). Thorn groves occur in places; elsewhere, on exposed or nearly exposed sedimentary rock, Brachystegia patches. The grass, short in some places, is long in others. Fires are earlier here than anywhere else.

The sedimentary rock of the "Oblong" and its northward extension carries itondo (Brachystegia-Uapaca forest) of a particularly fine type, with a good deal of sapling undergrowth and, in places, patches of invading primary shrub formation (v. p. 320 and the figures there referred to). The mutongoro (Uapaca sansibarica) often forms close groves beside vleis. The grass growth is seldom dense or very high, except in open places (Pl. xiii, fig. 1), but great and annoying burr areas, of four semi-herbaceous species of Triumfetta (dzunzu), occur. They dry up and are leafless in the winter.

The dolerite carries (a) wooding of the dense mixed secondary types, largely composed of highly deciduous species, and including Bauhinia thickets; $(b)$ open 
Pterocarpus sericeus (mumbhungu) wooding, highly deciduous. It is also, however, the chief seat of the surviving primary forest (Pl. ix; Pl, xiii, fig. 2). A high-forest area composed of primary forest (largely ravine type), tall, dense, mixed secondary, and invasions of the latter by primary forest, covers much of the broad strip of country that comprises the Mafusi and Maronga rubber forests, and stretches interruptedly from somewhat near the British border at beacons 76-77 eastwards to the Musapa, crossing the Lusitu on the way. It is roughly bounded on the south by the Puizisi, but sends two broken, narrow extensions southwards along the eastern and western base respectively of the Sitatongas. Between the Puizisi and the Mtshanedzi, and again in the Gwenzi country, lighter dense secondary types dominate, copse-like groves (Pl. xvii, fig.1), and fern-entwined wooding alternating with open, highly deciduous wooding of Pterocarpus sericeus and its Acacia and other associates. This more open wooding dominates rather specially at the higher elevations, though scattered close Albizzia groves, losing their leaves in the cold weather, are also somewhat prominent there. Narrow primary-type thickets -fringing forests (Pl. xiv, fig. 1)-often occur along the small streams, and harbour fly permanently at the lower elevations. The grass-jungle growth, except in the dense wooding, is immense and tangled. The fires are normally more or less late and, when postponed further till the grass is dust-dry, they are of extraordinary severity.

\section{Distribution of the Game.}

This again is most simply stated in terms of rock-formation. The lower-lying Mtobi-Gogoyo dolerite-dyke country that is bounded by the Mtshanedzi on the outh, the lower Chikambwe on the west, the Mtobi piece of the Lusitu on the north, and the Sitatongas in the east, forms an area that is poorly stocked with game, and is surrounded by the heavily stocked areas of the gneiss, basalt, sedimentary rock and (latterly) the higher elevation dolerite. Of these well-stocked areas the basalt only (Gunye's, etc.) is somewhat unattractive to the buffalos, though they wander into it in small parties in the rains. Their distribution is chain-like, the new buffalo colonies of the dolerite connecting occasionally with the herds of the sedimentary "Oblong," these with the herds of the Umvuazi-Lusitu Brachystegia-morsitans area (the gneiss), these with further herds in the Moribane district (at Muchamba's, etc.), and these again, it is said, with those of Cheringoma. With them are found elands and elephants in numbers, animals that are also rather specially attracted by Brachystegia bush, yet have latterly invaded the dolerite also.

Bush-pigs are exceedingly and increasingly abundant on the sedimentary rock and the dolerite, far less so on the gneiss and basalt, where they are largely replaced by wart-hogs. Herds of sable antelope are distributed through the country generally. Lichtenstein hartebeests are present in numbers throughout the two formations east of the Sitatongas, also (but much less so) on the sedimentary rock, but not at all on the dolerite with its jungly grass-growth. Waterbucks occur in small herds on the large rivers. Bushbucks, reedbucks and duikers are present throughout, where the conditions are suitable, and little blue duikers (Cephalophus monticola) are in some numbers in the dense forests and thickets. 
Baboons are abundant everywhere, especially perhaps in the Sitatongas, in the mountains of Spungabera and parts of the British border, and in the dense Lusitu wooding. The forest monkey, Cercopithecus albogularis beirensis, is to be found wherever high dense forest is present, and the bush monkey, C. pygerythrus, is ubiquitous, in smallish numbers.

\section{Distribution of other potential Hosts of Tsetses.}

I shall refer sufficiently to man and the smallest mammals below under "Food of the Fly." But facts to be referred to also, and particularly Lloyd's results from his examinations of the gut-contents of $G$. morsitans, show that in considering the fly's dependence on the local game population we cannot leave out of account the local bird and reptile population. Guineafowls and francolins, the former particularly, both crested and horned (Guttera edouardi and Numida mitrata), are everywhere abundant, the crested guineafowl especially frequenting dense forest. Of doves, all ground-feeders, two of five common species occur in dense forest, three throughout the other woodland types. Each of these two main woodland divisions boasts also its own considerable low-searching insectivorous bird population and its common touraco. The smaller seed-eaters-waxbills, whydahs, weavers, canaries-are a very important item in the bird population everywhere except in dense forest, and even there (as I noticed in the Madanda) in the open spaces that are covered with grasses that burn. They are nearly always found on or near the ground, and commonly in great flocks. They are most abundant in the non-forested, heavily seeding dolerite areas-with less permanent fly. Quails were seen everywhere in grass-country and much on the borders of the morsitans vleis.

Another bird that haunts every type of woodland and has been recorded as being attacked by tsetses (Lloyd) is the ground hornbill (Bucorax cafer), purely a groundsearcher. It walks in smıll spread-out parties and (in common with the insecttivorous birds) makes up somewhat for any lack of numbers by adopting a definite beat, most parts of which it revisits at intervals of a few days. In common with them also it probably does the fly more harm than good, for it destroys many snakes and the young of ground-nesting birds. Secretary birds and the various storks may be classed with it in this respect and are found in rather special association with the two formations about to be mentioned.

The water-haunting birds are found mainly on the basalt (on the Buzi) and granite-gneiss. Jacanas, egrets, bitterns, hammerheads, moorhens, rails, grebes, and occasional herons are found at the larger pools of the vleis of the latter formation, constantly but in small numbers and in contact with some of the dry season centres of $G$. morsitans. The two largest rivers and such fine series of pools as those east of Chibabava boast a far larger water and waterside population, but, so far as I have seen, it does not come into really intimate and essential contact anywhere with the main tsetse populations. The ground-running birds-the various bustards and coursers, dikkops, sandpipers, plovers, etc.-are particularly addicted for many spring and summer months to the shorter-grassed and sparingly wooded basalt, and certainly also to the granite-gneiss, though I have not seen them there when the grass has been recently burnt. 
The main reptile-population follows closely the two biggest rivers and is not sufficiently intimately connected with the big permanent fly-belts to be worth discussing. In the fly areas I noticed more snakes, including several puff-adders, on the granite-gneiss than elsewhere. Other reptiles were a large arboreal Varanus, which occurs in various types of secondary wooding, including Brachystegia, but of which I have seen few individuals. in all, and some not very abundant Agamid and smaller lizards in the Brachystegia areas.

\section{Distribution of the Fly in relation to the Geological Formation.}

The granite-gneiss, with its open-stemmed Brachystegia covering and frequent vleis, is the special home of $G$. morsitans, which in the dry season is still to be found in numbers and breeding actively beside particular vleis. $G$. pallidipes is also plentiful there, and $G$. brevipalpis is found in small numbers where the shade is particularly heavy.

The basalt, with its sparse stunted bush, was still carrying an extremely thin sprinkling of $G$. morsitans and pallidipes in late July, when burning was barely beginning. I am inclined to regard it as, in the main, an overflow area from the gneiss, and it is quite likely that any measures that banished fly from the latter formation would incidentally banish it from the adjoining basalt.

The sedimentary rock arca, with its fine Brachystegia forest and considerable if patchy undergrowth, is apparently more or less heavily infested almost throughout with $G$. brevipalpis. G. pallidipes also occurs, but in small numbers, said to be greater in the rains.

Of the two woodland sections of the dolerite area the Mafusi-Musapa high-forest section, with its extensions, appears to be more or less heavily infested throughout, at any rate in the dry season, with $G$. brevipalpis, G. pallidipes also occurring. Pupae of $G$. austeni were taken in numbers near the Buzi-Mtshanedzi confluence.

In the Puizisi-Mtshanedzi area on the other hand $G$. pallidipes, though in small numbers seems rather specially in prominence, perhaps in part owing to the relative absence of the bigger fly. The latter does occur here and there in small numbers wherever the shade is suitable. Behind the Makwiana escarpment the country appeared to be clear of the fly by early August and had probably been so for some weeks, though it would still doubtless be possible occasionally to encounter there an odd straggler carried from below, particularly on the Chikambwe's tributaries, where leaf was present. At the lower elevations, where also the bush of the dolerite retained more leaf, fly was still met with; but judging from the observations that Dr. Lawrence has most kindly carried out for me since my departure, it would seem that it must become specially scarce there also towards the close of the dry season, though not extinct. It is in part a matter of leaf-fall, for at his station (Gogoyo) pallidipes showed itself once more in some numbers with other biting flies when the leaves were well in evidence again in the hot weather shortly preceding the rains. Glossina brevipalpis was taken in small numbers here and was seen by me also on the Buzi below Spungabera.

An expedition sent by me to the Chinyika in late September failed to take any tsetses, though it brought back numbers of other biting flies. 
There ore three great permanent fly-areas in the country investigated :-(1) The morsitans-pallidipes area of the granite-gneiss; $(2)$ the brevipalpis area of the Lusitu rubber forests ; (3) the brevipalpis area of the "Oblong."

Between the last two is sandwiched an area of more deciduous foliage. Out of the higher parts of this such fly as has got there is ousted in the cold weather by the leaf-fall, and in its lower parts the fly becomes scarcer and more localised before the rains, reappearing with the leaf in October. These last remarks refer to G. brevipalpis and pallidipes, the latter fly occurring throughout the area.

Finally, there is a narrow strip along some of the frontier, widest at Spungabera and on the hill-mass enclosed by the Puizisi-Muchamba confluence, that may be regarded as quite fly-free, excepting in so far as travelling parties of male flies may on occasions be carried into it during the rains and early dry season by buffalos, etc. Nearly all the country on the British side of the frontier may be regarded as falling within this category.

G. austeni was taken only near the junction of the Buzi and Mtshanedzi. The type of wooding in which it occurred is not uncommon on lowland streams, and there can be little doubt that further investigation will show it to have a more extended local range.

More generally it may be concluded that each fly is confined closely to particular woodland types, which, in turn, are confined to particular geological formations, the conditions that suit pallidipes being the most widely distributed. But the distribution of the permanent fly is by no means thus conterminous with that of either the buffalos, the big game generally, or any particular species of mammal, though abundant mammalian life of some kind is present in each of the areas, flycarrying or otherwise. Man is relatively scarce (except on the Lusitu), and very small mammals are abundant everywhere in the fly area. The dominant bird elements of the brevipalpis areas are insectivorous and gallinaceous. The morsitans area has in addition a stronger bustard-plover element and, at some of the permanent fly centres, a very limited water-bird element, as well (apparently) as a somewhat larger reptilian population than the other areas. I may add that various moth larvae, numerous, gregarious and often immense, are much more in evidence in Brachystegia areas than elsewhere ; but, for reasons to be stated, it is doubtful in spite of Roubaud's results whether they are of great use to the fly. The fact that brevipalpis does not come readily to man makes its presence difficult to detect unless one is lucky enough to come across a male queue some evening. However, my conclusion that the "Oblong" was well infested was come to after I had seen only two flies. Their hum in flying struck me as being identical with a sound I had been hearing continually since I came there. I then made a point of disturbing all large flies of any species I saw and made my natives bring me for a day or two all they could catch for release close to me, but I failed completely to match the sound, which I therefore concluded to be that of $G$. brevipalpis. I continued to hear it, often on the part of large flies which I could not then identify visually that came out to us and turned back, evidently rejecting us, and of flies that flew away from the shady sides of tree-trunks when these were beaten. An observation on pigs of a day or two later and subsequent results from cattle abundantly justified the conclusion. 


\section{VII.-Umzila's Experiments in Close Settlement.}

\section{Earlier History of the District.}

About ninety vears ago, following immediately on the invasion of Bulindhlela or lower Gazaland (the Delagoa-Inyambane country) by the Zulu chief Manikusa, what are now the Mossurise and South Melsetter districts became the scene of three invasions. First came that of "the Bulindhlela chiefs, who, though defeated by Manikusa, refused to submit to him. . . . They retired in a north-westerly direction, over-ran this country, seized all cattle (then plentiful) and later proceeded north to Hatoko's." Secondly, these fugitives were "followed by Uncaba (alias Mosani) as far as Chiamiti-now the farm Schaapplaats in South Melsetter. Here Uncaba and his people settled." Uncaba was a brother of Manikusa's father, Isigode, and he and his people were part of the Zulu invading force under Manikusa.

"Uncaba became unpopular here, one of the principal grievances being that he would not allow members of his crack regiment, the Amakanda, to marry until their heads were grey. Representations were made to Manikusa and he was induced to come up here. Fighting occurred and Uncaba, forsaken by his best fighting regiment (the Amakanda) retired with a following up the Sabi valley, and subsequently in a north-westerly direction" (letter from Mr. W. M. Longden). I do not know whether the view is correct that this "impi" founded the "Angoni" tribe near Lake Nyasa.

Manikusa (who returned to lower Gazaland) died in 1861. His second son, Umzila, disputed the claim of his elder brother, Mawewe, to the throne and, at first defeated by him, went north and settled in succession at Umpombo's on the Buzi, and Dongonda north of the Lusitu (see Map). Mawewe eventually followed him thither, but was defeated with the aid of the Portuguese, and Umzila took possession of lower Gazaland. He himself remained at his northern capital, which he shifted more than once. From Dongonda he moved to Gandwa, on what is now the writer's farm "Gungunyana" in South Melsetter, and thence, later, to the neighbourhood of the Chinyika River in Gwenzi's country, south of Spungabera. Here he made his longest stay, eventually moving to Mwayamuhle's, just south of the Mossurise in Garawha's country; and here he died.

His son Gungunyana shifted the headquarters across the Mossurise to the foot of Mount Singuno, but later, in about 1889, he returned to the old southern capital Bileni, near Lourenço Marques. The population of Mossurise and South Melsetter was forcibly collected and taken thither. Soon after-in 1895-the Portuguese Government had to bring Gungunyana to account, and with his capture in the following January (Theale), the Zulu native domination ended. Since then the Mossurise natives have gradually drifted back from Bileni to their old homes, but it is stated on all hands that only a small proportion actually has come back, and that the population of the district does not at all approach its former size.

In 1893, the land on the British side of the border was occupied and settled by Europeans, that on the Portuguese side, in part depopulated of natives as I have stated, remaining wild to this day. In 1896-7 the rinderpest swept through the country and, missing small areas here and there, decimated not merely cattle, but in particular buffalos, kudus and elands. 


\section{Fly and Cattle before Umzila's Time (say 1820-1861).}

There can be little doubt that ever since the arrival of the Bantus particular pieces of country have been subject to local concentrations of population, and that where other circumstances have been sufficiently favourable, these concentrations have resulted, while they lasted, in the opening-up to cattle-farming of the piece of country involved.

The " old people" had told my various native informants that previous to Uncaba's massacres of about 1830, farming went on successfully even close to the Sitatongas, where they had shown them the old cattle pits. The country was very densely settled. The chiefs Mafusi and Mtobe have both told me that at that time cattle were kept in those portions of their countries in which all subsequent attempts to keep them have failed, and Gunye has stated that it had been handed down that in the days before Uncaba cattle-farming, accompanying a concentrated population, took place even in his country, but that many used to die. But when Umzila came here (in 1861) the whole country had reverted to wooding and game as the result of the depopulation arising from Uncaba's massacres. It was much as it is now ; fly had become plentiful, and the mountains of the present political border were the boundary, then as now, between the fly and such cattle as existed.

\section{Umzila's Experiments (1861-1889).}

Both when at Umpombo's, and later at Dongonda, Umzila made a determined attempt to keep cattle, but in each case he failed. The concentration of population was not so great as in his later attempts; it was short-lived, and close by was a great belt of $G$. morsitans-a fly which follows man.

The Zulus, it may be mentioned here, knew the fly well, and the disease caused by it, and they regarded the proximity of game as dangerous for cattle. But why did they place their cattle amongst the fly? They said, "this whole country is full of it-where shall we put our cattle ?" However, cattle had always thriven in the open hilly country which is now South Melsetter; they were being captured at this time (after Umzila's defeat of his brother) in great numbers in raids on the Mashonas, and Umzila at last sent them all to Gandwa. Later he said "I cannot live away from my cattle," and it was thus he left Dongonda.

From Gandwa, Umzila sent an order to sondela enkosini (draw near to the King). Thereupon an immense compulsory movement of the population took place. The country to the east of the Sitatonga Hills, particularly in and south of Gunye's, was at that time more fully populated than that to their west, but almost the whole of this population was deported, territorial chieftains and all, to the lower parts of the tract between the Sitatongas and the present British border, to Spungabera and Gwenzi's country, and (with Umzila's further movements) to the Umswirizwi (Mossurise) valley, to Zinyumbo's Hills and Chimbiya's, and even eventually to the Sabi east of this area. The chief Gunye told me that he himself was compelled to settle at Chimbiya's.

\section{The Effect on the Wooding.}

Every one of my informants has described most graphically the result of this concentration. The bush simply disappeared and the country became bare, except 
for the numberless native villages and a continuity of native gardens. This complete clearing was confined to the lower-lying areas. The Puizisi-Mtshanedzi hill-mass, as Makwiana told me himself, was relatively little affected by the new settlement, and the bush was never at all completely cleared. It was, however, surrounded on three sides by a broad cleared cordon, and on the other, backed by the highlands.

In Mtobe's and Mafusi's the bush was never fully cleared; the rubber forests already existed and they continued to do so, although, according to Mafusi and others, they then consisted merely of umfomoti wooding (Piptadenia) that was chiefly confined to the ravines. In Gungunyana's time they had already spread greatly (under encouragement), and many Landolphia vines existed throughout the new areas not yet wrist-thick. They were a valuable asset to the Zulus, who traded the rubber for cloth on the coast, and used the latter in turn in the barter of cattle. Again, away from the neighbourhood of the Mtshanedzi and the Buzi the "Oblong" remained completely uninhabited and uncleared.

Zinyumbo's area, like Gogoyo's, was very completely cleared- " right to the Mwangezi it was gardens only," as was Gwenzi's country, the Mossurise valley and portions of the Sabi.

\section{The Effect on the Game.}

Large mammals became very scarce-not merely big game, but pigs and baboons. "The Mangoni (Zulus) are killers of everything, men and animals." Drives with nets were organized across the entire country, and game, pigs and baboons were thus killed wholesale. If a herd of buffalos was reported subsequently anywhere west of the Sitatongas, it was at once hunted; if pigs appeared in a garden, they were at once tracked down to their retreat, and, the people round having been called out, were surrounded and killed. Except on its fringes the "Oblong," then as now, was a great uninhabited game reserve, The game in it was thinned, it is true, and was kept well driven within its borders, but there still remained enough to attract the Mangoni hunting parties. In the heavily settled areas a few bushbucks, duikers and pigs were still to be found throughout the period.

\section{The Effect on the Tsetses.}

There were still plenty of int-hesi (tsetse) in the tondo-bush on the granite-gneiss, and fly never disappeared in the " Oblong." In neither place could cattle ever be kept. In Mtebe's country too and the eastern part of Mafusi's-that is, within a short distance of rubber forest-they could never keep cattle. Mafusi told me that he remembered the fly there, with the same distribution as now, from the time he was a child, except that it has spread with the spread of the forest. At Maronga's and beyond-that is, in the continuation eastward across the Lusitu of the rubber forests_cattle could never be kept, though Usele and other Zulus settled there and made the attempt. In such places the cattle required for ceremonial purposes used to be brought, as needed, from the safe areas. Cattle also continued to fail in Gunye's country and south of the Buzi from the Mwangezi eastwards, though persistent and prolonged attempts were made to keep them in this area of sparse fly, the losses in some cases being made up time after time from outside. 
In Zinyumbo's hills and even just on the Mwangezi cattle succeeded, as they did thence westward through the Mossurise valley and northward to Spungabera. This tract was full of cattle. But few deaths took place, and these always along its extreme eastern margin, on the borders of the " Oblong."

In the Gogoyo-Makwiana tract cattle were kept right under the Sitatongas both at and opposite the Rupisi and from the great bend of the Mtshanedzi to its source, also in the hills behind the cleared guard-area between the Mtshanedzi and Puizisi and up to and beyond the present British border. Many of the herds were large.

On the Sabi (present British territory) the results were particularly interesting, for this had previously constituted a separate fly-belt, which was eventually almost completely wiped out by native cultivation. The rinderpest may have given the coup de grâce to the surviving remnant or two (recent events render this doubtful), but at any rate cattle were already being placed and kept successfully all over the old fly area in the seven years between Gungunyana's departure (with all the cattle he could take) and the advent of the rinderpest (W. M. Longden and others).

When the country was closely settled, cattle were kept successfully in places where they had always died before; and when the settlement was well established, they succeeded where in its earlier days they failed, though fluctuations still took place with successive shifting of the population. It is true that herds actually abutting on the fly still suffered small and occasional losses, as they are doing to-day to a greater extent on the present fly boundary.

\section{What drove the Fly out?}

From the failure throughout the 25 years or so of this experiment to keep cattle near the Mafusi rubber forests, well settled and well cleared of large mammals though they were, it is likely that it was not the mere destruction of its food supply that cleared the Zinyumbo, Gwenzi and Puizisi-Mtshanedzi areas of fly. We may compare also Mr. Pollard's statement with regard to the Munshi division of Northern Nigeria (Bull. Ent. Res. iii, 1912, p. 221). "It is interesting," he writes, "to note that the Munshis are great hunters and that they have practically destroyed all the wild game in their district, and yet, in spite of this, the trypanosomiasis of cattle and horses is rampant."

But the game does not merely feed the fly ; it also carries it, each year, from the permanent fly-areas into the more deciduous areas adjoining them as soon as these have sufficiently regained their leaves. The heavy settlement of the broad river valleys and the base of the Sitatongas, by clearing the bush, not only rendered those areas themselves inhospitable to the fly, but also opposed a barrier to the passage of game, and so protected from the fly the large enclosed piece of chiefly deciduous bush behind the guard-area. Previous to the establishment of the guardarea it had been impossible to keep cattle in the area behind it, as it is now again impossible, and the broad guard-area itself, to judge from the descriptions of the bush cleared, had probably harboured even more permanent fly then than it does to-day. That the fly-population itself was diminished by the Zulu system of late burning is also by no means unlikely.

The case is most instructive and points the way for future measures. It must be remembered that the flies concerned-brevipalpis and pallidipes, especially the 
former, which is more abundant_-are not such great followers of man as is morsitans, and that the chance of success in such a case, without wholesale clearing of the bush, is greater than where morsitans is concerned. On the Saivi it was different. Here the permanent fly-bush itself was destroyed to a far greater extent and the fly in most parts exterminated.

\section{Was the Experiment intentional ?}

These concentrations of population round the King were not primarily flymeasures; they took place whether the country was fly-infested or not. But their effect in fly-country was well known to the natives, and I was informed that Umzila entertained considerable hopes in relation to the keeping of cattle from his successive concentrations at Umpombo's, at Dongonda, and west of the Sitatongas. Success was attributed to the effect on the game rather than to that on the shade, and Umzila's measures against the game were stringent. His intention of colonising the "Oblong" was frustrated by the depredations of lions on the settlements placed there (e.g. in the Budu country), and there were difficulties connected with water and an immemorial and bloody feud with regard to the Dengaza tract between the chieftains Makwiana and Gogoyo;* but he settled its borders very heavily and kept the game well driven within them by means of frequent hunts.

\section{The Effect of the subsequent Depopulation.}

Before Gungunyana carried off the population to Bileni (near Lourenço Marques) in about 1889, he had already commenced to protect the game. He had decreed azi-zale (let them multiply), and game had become more abundant both outside and inside the cattle-keeping areas. The guard-areas still opposed its passage into and out of these areas and no harm resulted to the cattle. When the population left, the game (in the words of my native informants) just "burst forth" (zadabuka). At the same time the wooding was let loose and soon re-established itself throughout the previously settled country.

In a very few years (by 1896 according to native information) the fly had more or less regained its old wet season limit-not many miles east of the present political boundary-though the bush capable of supporting it was not then so ubiquitous as it is now. I myself lost a beast from fly on "Scott's Hope" (a Portuguese farm on the British border) in 1900, and a tsetse was taken south of Spungabera, on the tondo-covered hills west of the Buzi (spot shown on map), in the same year by Drs. Wilder and Lawrence.

The fly caused little trouble then, but two things have happened since-a progressive invasion of the upland dolerite $(a)$ by the deciduous wooding, and $(b)$-more important still-by game of wandering species. Buffalos and elands especially, decimated by the rinderpest, are now extremely abundant, and having spread from the sedimentary area into the hills, wander much more frequently than they used to into the highlands. It is only in the last three years that buffalos have reached the Puizisi country in any numbers. They have there tapped another brevipalpis area, and the consequence has already been visible in the destruction of the cattle of the Muchamba-Puizisi valleys.

* Not that this was allowed to continue actively under Umzila. He decreed "Ther" must be no more war. We are the only King (Si'nkosi sodwa)!" 


\section{VIII.-THe Food OF THE Fuy.}

Observations by numerous workers elsewhere have shown that tsetses living in contact with large reptilian and avian populations very freely utilise the former, and perhaps also the latter as food. Gut examinations even of $G$. morsitans have shown in some cases (Lloyd) a remarkable proportion of non-mammalian contents ; the same fly has been seen to feed on the bare neck-wattles of an unconfined ground hornbill (also Lloyd); a case is on record (Ensor) in which a fly, " almost certainly morsitans," was observed through glasses trying to get under a perched hawk's wing; and in the Entebbe laboratory Glossina palpalis "fed readily on captive fowls, creeping under the wings to reach the poorly protected parts" (Bagshawe). It follows from this last and extraordinarily important observation (which does not surprise me when I remember that morsitans rather reminded me of Olfersia in its low poise and clever sidelong movements in response to attempts to catch it) that birds are not necessarily protected against tsetses by their armature of feathers, though many of them certainly are by their agility and insect-eating habits. Yet young birds, whether nestlings or runners both in the nest and for a time after leaving it, are defenceless-and abundant just when the fly is abundant. Also the fly (as met with on this trip) retires to rest later than do most diurnal birds, the latter being thus relatively unprotected from it during a very brief portion of each day when the fly is particularly active-but the bird (it must be admitted) less conspicuous.

Such facts, with the way in which birds, including ground hornbills, keep to definite beats, the whole of which they work every few days, and the fact that nearly. the whole bird-population searches for its food and breeds either usually or very commonly within a few feet of the ground, the search being conducted with much bustle and conspicuousness on the part of the large combined parties of small birds, must be taken into account when we attempt to explain such cases as Umzila's failure to keep cattle near the then much smaller rubber forests (in spite of a great hunting population and a strenuous effort to exterminate game) and when we consider the question of destroying game to starve the fly. At the same time, so far as small birds are concerned, it seems to me that the fly's habit of choosing harmoniously coloured surfaces to rest on suggests that its effort will be to evade rather than attack them during their active hours and stages of existence. I feel also that the very striking connection between the fly's breeding habits and game must be given its full weight.

My own observations dealt only with mammals.

\section{Mammals from the smaller Ungulates downwards.}

The natives of the morsitans area were unanimous in their statement that tsetses feed freely on baboons, and that " wherever you find baboons you will also find fly." They gave me many instances in which baboons driven from their gardens had left numerous replete flies behind and others in which flies were attracted in numbers to baboons that were killed. Simpson's similar personal observations and native statements on the Gambia and Gold Coast will be recalled, as will Lamborn's indirect evidence. Monkeys (Cercopithecus pygerythrus, which lives in lower bush than C.albogularis beirensis and raids natives' gardens) were stated more rarely 
to have done the same, and-an important statement if true-it was stated that replete tsetses were occasionally found where cane-rats (abundant in much of this country and very largely diurnal) had been many together.

Pigs were as universally incriminated as baboons, and here I obtained a quite excellent instance myself. In the "Oblong" (east end) in cloudy weather we walked right on to four bush-pigs sleeping. In their hasty rush they left the flies behind, and these streamed after them in great numbers and with quite a hum. We captured nearly twenty that through repletion could scarcely fly; all but one were brevipalpis, the exception being a pallidipes, and more than half were females. Austen records both morsitans and brevipalpis as feeding freely on wild pigs and quotes Dr. Hearsey's statement that $G$. morsitans was seen to settle literally in hundreds on the carcase of a wart-hog, behind which animal I also took these flies.

My indirect evidence of the value of such animals as pigs to the fly was also interesting. In a mile-wide patch of primary forest east of the Sitatongas, in which I saw much brevipalpis, both native information and a careful search for spoor showed that it could have been feeding on nothing but pigs, baboons and smaller fry. The same applies to a piece of high, dense, secondary forest on the western foot of the hills, into which according to the owner of a kraal on the spot (confirmed by the usual search for spoor) no big game had entered for some months. It also applied, I am certain, to much of the rubber forest area in which pigs and little blue duikers-and these only-are abundant. In one place a length of about 300 yards for a very great width was continuously turned up by the pigs and looked like a hoed plantation. It made me wonder whether one of the forest hogs (Hylochaerus) may not occur in these forests.

Finally, working for over a fortnight round my camp on the Buzi east of Spungabera, in an area in which game is relatively abundant, I made a special point of studying the daily spoor in relation to the distribution of $G$. brevipalpis. To sum up the result, there was a considerable area that I am certain was not entered by big game during my stay, or for some days before it. There was a smaller, inner area, immediately round certain kraals, that had probably not been visited by such animals for many weeks or months. In general the spoor showed much less movement of the big game now than in the wet season, yet the fly was equally present throughout, lurking in all the thickets to attack passing animals.

The only "passing animal" that showed a similar ubiquity was the bush-pig, and I was convinced from the evidence that the fly was living practically entirely on bush-pigs at the time of my visit. Man was not being attacked. My friond Mr. G. D. Otterson spent a few days with me here, and declared on leaving that the evidence of the fly's independence of the bigger game in the matter of food was a "complete eye-opener" to him.

I conclude from these observations that any attempt in north-west Mossurise to destroy the fly by starving it in its permanent haunts is doomed to failure if the bush-pigs, and perhaps the baboons also, are not destroyed; and the destruction of the pigs in this type of country is not easy.

Two species of lemur occur in the fly areas. The larger of these, Galago crassicaudatus, is abundant in most of the brevipalpis country and sleeps exposed (but perhaps protected by its fur) in the daytime. Bats, including the largish fruit-bat, 
Epomophorus crypturus, are abundant, and insectivorous species were found sleeping in great numbers in hollow trees of Sterculia triphaca on the ant-heaps of vleis frequented by $G$. morsitans and $G$. pallidipes. Bushbucks and duikers are more or less common -and hard to exterminate. The little blue duiker (Cephalophus monticola), more or less abundant in thickets and dense forest, is less hard to reduce by fence-trapping. It has a habit of resting under logs and between tree-buttresses that might bring it into additional contact with the fly. It was one of the animals least liked by my carnivorous mammals. Of yet smaller mammals two species of Tatera came in great numbers to my traps at a spot where male clusters of morsitans were present all the time on the grass and females in the wooding (Pl. xiv, fig. 2). Lloyd has suggested that nocturnal mammals, including MurIDAE, are perhaps liable to the attack of tsetses owing to the latter's habit of resting in similar holes. I have myself taken morsitans puparia from holes made by animals in a bank, and noted that brevipalpis and pallidipes rest in holes in trees. Nevertheless, an argument exists against this view in the fact that some of the bats at any rate are very easily disturbed, and the part played by the small nocturnal mammals, including bats, needs far fuller testing than it has received. Species of Arvicanthis, Otoniys, Myosorex and Petrodromus are largely diurnal, but their small relative size suggests both their ready perception and intolerance of the fly and their less ready detection by it.

Dassies or rock-rabbits (Procavia) may be of much use to the fly, but very locally and only in rocky places. I found them in the coarse quartzite rocks that form the crest of the Sitatongas and support Brachystegia; and I spent many hours with several workers trying to find wet season tsetse puparia in the humus under raised and overhanging rocks, but without success. I searched similarly in the Maruma forest, frequented by dassies, but Maruma, I judge, in spite of the outbreak of trypanosomiasis there, is seldom if ever reached by the fly.

\section{The larger Ungulates.}

I have thought it well to give prominence to the evidence favouring the view that the pigs, aided doubtless by the smaller buck and perhaps yet more by the baboons, will continue to support a fly population in parts of north Mossurise eren if the larger game is banished. At the same time it goes without saying that the larger the permanent game population the greater will be that of the fly; and I obtained abundant indirect evidence that, as things stand now, the bigger ungulates present in the fly-areas are taking an important part in the feeding of the tsetse. As I shall describe elsewhere, I found numerous batches of puparia-mostly of morsitans, a few of brevipalpis - associated with spots where larger mammals had been lying down. Buffalos were incriminated the most frequently, but Lichtenstein hartebeests, wart-hogs and other species were concerned.

My finds of pupae in the morsitans area seemed rather to suggest a preference for the buffalo on the part of the fly. I found this definitely asserted by some of the natives and denied by others. My guide in the morsitans area, a very observant native, was particularly convinced of it. Questioned as to a connection between the two animals, he replied that one may find fly where there is no buffalo, but that where there is a choice it follows the buffalo. "The buck," he said, "are much 
more restless under its attentions than the buffalo, the hartebeests especially keeping up their dance when tsetse are about them; so that the fly can feed more easily on the buffalo." Neave has already made a suggestion to this effect.

I shall discuss this subject further under the next heading. Elephants were stated by the natives to be attended by tsetses when the latter are numerous, and I took a male brevipalpis waiting on a much used elephant path. Roubaud and Bouet (referring to $G$. longipalpis) are both quoted as speaking of a special association between tsetses and the elephant and hippopotamus.

\section{Man - and the Fly's Preferences.}

Using cattle as I did, I obtained abundant and excellent evidence that $G$. morsitans and $G$. pallidipes attack these animals more readily than they attack man, that G. morsitans attacks man more readily than does $G$. pallidipes, and that the latter, in turn, attacks man far more readily than does $G$. brevipalpis. It constantly and everywhere happened that the carriers passed through a place without drawing fly and that the cattle coming just afterwards attracted many. A dozen to twenty carriers are more conspicuous than two or three head of cattle and their scent is overpoweringly stronger. Similarly I have seen a fly (pallidipes) on a leaf beside the path allow carriers to pass it unmolested and then at once fly out to my donkey. Another piece of evidence was afforded by a fly (brevipalpis) that I found perched on a projecting slab of shale in the path, facing away from me. I stopped short (about two yards away) and had the cattle (immediately behind me) turned into the grass. After about two minutes the fly flew back to me and, without alighting, returned to its perch. I then had the two cattle immediately brought up, the leading ox standing nearly level with me in the path. The fly shortly flew back again, first to myself, then, swerving off, to the ox, under which it at once settled and began to feed.

A point that struck me in the morsitans area was that whereas when we were digging for puparia there was often delay before a fly attacked us (one fly was actually seen watching on a tree-trunk for a time before it came), the cattle were attacked quickly.

Man is attacked by all these flies much more frequently in the rainy season, but the increased attacks are probably not more than proportionate to the great increase in the number of the flies at that time of year. Dr. Lawrence has sent me records of occasional attacks on natives at his homestead at Gogoyo's even by brevipalpis, and as for morsitans (no doubt in company with pallidipes), I was informed by the natives across the Sitatongas that they become at times unbearable, forcing every man to carry a leafy twig with which he continuously switches his back and shoulders. G. pallidipes (it is stated) also becomes a nuisance in places west of these hills.

Concerning the practical question, "if other sources of food were eliminated, could the tsetse still keep going with the aid of man?" it is certain from the observations of Lloyd, Maugham, Stephenson-Hamilton, myself and others that the tsetses would then attack man much more. Tsetses (as I have seen) constantly obtain full feeds from man and escape unscathed and, where the bush comes up to a village, so far from avoiding it, morsitans and pallidipes - but not brevipalpis appear to become rather a nuisance. 
It is doubtful whether brevipalpis, a relatively easily detected and easily caught fly, would readily adapt itself to man. With regard to morsitans it may be said that the conditions favouring its dry season centres would have to be present as well as the villages. I only saw one such apparent coincidence here, but there is no reason why it should not be common. The size of the human population and its effect on the bush when really large are further factors to be considered.

Of our fly areas here the "Oblong" is uninhabited and the higher Mafusi and morsitans areas are not thickly inhabited. I believe it is very different on the actual Lusitu, but there brevipalpis would be the fly permanently present.

I was myself bitten by morsitans far less than my natives, but this was presumably a matter of skin-colour and clothes; Mabuzana, living near the Mtshanedzi south of Grogoyo's, volunteared the information that tsetses were specially attracted by a black coat. I said "How do you know that?" "Bacause I have one!"

Perhaps more surprising than the preferences shown in relation to man are those shown with regard to his domestic animals. I had three female native goats with me throughout the trip and in about the fifth week added a male; and until I obtained cattle, about a week later still, I used these goats continuously for bait. They proved most unsatisfactory, and although they were occasionally bitten, I bave little hesitation in saying that even man was much preferred to them both by morsitans and pallidipes and was not liked worse than they were by brevipalpis. Put ahead of the cattle they failed to draw fly where the cattle would draw many. A dog that was with me throughout the trip and still remains healthy was relatively little bitten. Healthy-looking native dogs and goats were present throughout the fly-areas and were stated to be much bitten in the rains. I regularly fed my flies on the goats and once they bit they fed fully, but a relative reluctance to bite was distinctly seen, and this reluctance extended to a sheep on which I fed the flies that I finally brought home with me. The relative reluctance shown by Dr. J. W. S. Macfie's flies to feed on guinea-pigs, dogs and cats is worth recalling, also the preference of Lloyd's flies for monkeys as against goats.

Experiments that I carried out on AsILIDAE showed that those flies possess graded preferences along the same lines as carnivorous vertebrate animals experimented on, so that there would be nothing extraordinary in the tsetses doing the same. Experiments on carnivorous animals, including lions, showed the following order of preference :-(1) Pig, wild and domestic ; (2) beef (nearly equal to pig); bushbuck and sable antelope were liked very nearly as much ; (3) goat, sheep, dog, man, blue duiker. These last were liked far less than (2). It seems probable from the evidence I obtained on this trip that the preferences of the tsetses I had to do with would follow much the same general lines.

AsILIDAE often attack the highly nauseous Acraeine butterflies and tsetses attack man, but their preferences are very real nevertheless, in view of the fact that after a feed they do not wait till hungry enough for Acraea or man before feeding again should anything better turn up. Lloyd and others have shown, and my own observations confirm them, that when there is nothing better to turn up, the fly will at last "occur in such quantities "- that is to man-"as to be a source of the greatest annoyance" (Maugham). At Kanyezi's vleis, with some game about 
but buffalos absent, we saw a good deal of fly and were often attacked by "feeders" (as distinguished from "followers"). In the Masando vleis in 1900 with game temporarily very scarce and buffalos absent I was very greatly pestered. This time, in the same Masando vleis, with buffalos present, I found few flies, and at a series of vleis a few miles further east which the buffalos had just reached in numbers I found none, though the natives stated that they had been there in great quantities up till then. At first at these places I had not the cattle, and it was legitimate to suppose, as the natives did, and it was doubtless true of the males, that the tsetses were "away following the game." But the female fly is a feeder, and apparently follows little, and the cattle quickly showed that flies were present, but that they were being kept too well fed to show themselves to less acceptable man.

It is easy, understanding the working of the fly's preferences, to see that a failure to find non-mammalian blood in an examination of its blood-contents is quite compatible with the possibility that it might live on birds and reptiles were mammals removed.

It follows also from my observations on this expedition that the old idea that tsetses possess a preference for the buffalo may be perfectly correct, though it will show itself strongly only where, and while, buffalos are so abundant as to make the fly comparatively independent of less favoured food. The special enthusiasm I saw shown for an actual congener of the buffalo seems to be highly significant in this connection.

Unfortunately there would seem to be no very practical method of utilizing the flies' preferences except by using cattle to draw them out. With its favourites destroyed it will live well on the next best and so on. Arsenic-tolerant cattle, sufficiently saturated, might be worth experimenting with as bait.

\section{Drinking of Water by Tsetses.}

My flies frequently applied their proboscides to grass-stems put into the tube wet (to simulate the effect of dew), never to those inserted dry. My native informants on the Umvuazi agreed in asserting that they frequently saw tsetses in numbers "drinking" on the wet sand of the river in very hot weather. I have watched Tabanus on the wet mud of pig wallows at the Amanzimhlope head-waters with its proboscis in definite contact with the moisture, as were those of non-biting Muscid flies of several species that were also present, and this habit of drinking is a common one in hot weather on the part of both Diptera and butterflies. Kinghorn and Lloyd have both noticed tsetses at the edges of puddles ; Moiser obtained records of it from his natives, and saw his captive flies insert their proboscides into the wet soil of their bottles; and Lloyd obtained the same result from moistened sponge and moistened blotting paper that I obtained from wet grass. Carpenter has gone further, for he has traced the presence of the liquid inside the fly. The point is not merely of importance in relation to the hot-weather needs of the fly ; it may also be important, it seems to me, in relation to the possibility of poisoning the highly localised male swarms of $G$. morsitans by spraying the grass they rest on.

Lloyd's positive results from slices of water-melon go to confirm Maugham's observations (under natural conditions) as to the sucking of vegetable juices. It is probably moisture rather than real nourishment that would thus be sought and obtained. 


\section{IX - Distributors of the FIY.}

Game not only helps $(a)$ to feed the $\mathrm{fly}$, and $(b)$ to provide the trypanosome, but $(c)$ it helps to distribute the fly, carrying it back each summer into the areas from which the fall of leaf had driven it.

That the fly does definitely spread at each rainy season, over the latter type of area is shown by native statements, by nagana outbreaks, and by my finding in the highly deciduous country a mudstained pupa-case of $G$. brevipalpis, one of our most shade-loving tsetses. That the fly wanders back into these areas partly without the aid of game is possible enough; but without their aid I doubt if it would have re-occupied much country by the time the leaf fell again. The tsetse is a distinctly sedentary insect, and throughout reminded me much of a tick, excelling it mainly in flying a little distance to its prey instead of waiting to be brushed off by it. This, with the details of some of the outbreaks of trypanosomiasis, the fact that tsetses actually do follow animals for long distances, and the cogent indirect evidence I shall refer to on page 358, support the view that the game is of the first importance to the redistribution of the $\mathrm{fly}$.

Accepting the hypothesis, the most important point to note is that the fly's chief distributors will be by no means necessarily identical, in a given area, with its chief food animals. The individuals, pairs or herds of most of our antelopes have definite circumscribed haunts and grazing grounds that they keep to. In the case of bushbucks and duikers these are small, and parties of pigs also for long periods together rootle and depredate from particular lairs or lair-areas. Hartebeests also have relatively small beats, and herds of sable antelope and kudu have their permanent grazing grounds, larger than these others, though the kudu is sometimes a wanderer. Animals with this localised habit may be regarded as the fly's most reliable food-supply in its permanent haunts, even though some other animal may temporarily become more important through sheer numbers.

Elands, on the contrary, are great wanderers; elephants cover much ground; and the buffalo, if it is on the whole less of a wanderer individually, and in the matter of long purposeful "treks" than the eland, nevertheless covers, with its great herds, very large grazing grounds, is continually wandering back and forth between its various centres inside and out of the permanent fly-areas, and breaks up into parties and individuals that, to judge from the spoor, leave little ground in the general range unvisited in the rainy season. Also, as I shall show elsewhere, the buffalo more than any other animal has been increasing its numbers and range here at a great rate for many years past.

I believe then that these animals, and the buffalo in particular, are mainly responsible for the annual spread of the fly, and that so far as we are concerned, in and near Mossurise, our main grievance against the game is not so much that it feeds the fly (which would be fed and contaminated in any case by the pigs) but that it carries it far and wide in the rainy season and so brings it into contact with the cattle.

The effect of the difference in the travelling habits of the male and female flies must of course be duly taken into account. 


\section{X.-EFfect of the Rinderpest.}

The effect of the rinderpest is of practical importance in relation to the question of destroying the game to starve the fly.

In reply to my question, addressed to many natives, as to whether the fly became less after the rinderpest, I received two answers, one from south of the Lusitu, the other from north. It may be stated at once that both buffalo and fly are said to be much more abundant, and to have been so before the rinderpest, in the Brachystegia area north of the Lusitu than in that to its south (both of them on the gneiss and carrying both morsitans and pallidipes), so that the difference in the replies may perhaps be genuine.

The reply from the former area (from the countries of Muchamba, Usambai and Udombe) was that the rinderpest was followed for two seasons only by a definite reduction in the numbers of the fly. In the second of these seasons it was already more numerous, in the third season and subsequently it was as numerous as ever. The buffalos were still scarce, so that if this statement is correct and there were also any real connection between the rinderpest and the fly's reduction, one explanation might be that the fly had previously become specially dependent on the buffalo, owing to the latter's immense relative numbers, and took a season or two to adapt itself completely to the habits of the other larger mammals. Wart-hogs and baboons were stated to have been particularly abundant. Another explanation will be suggested below.

The answer I received from south of the Lusitu, in the fly-areas both east and. west of the Sitatonga Hills, was that the rinderpest was followed by no noticeable reduction of the fly at all. One man stated on the contrary that they then bothered the natives terribly. Another made the quite sound suggestion that perhaps with their other food destroyed they attacked men more, so that, though fewer, they seemed as many as ever. All insisted that, though certain abundant species of game were killed off, plenty of other food remained, in the form of bush-pigs, warthogs, baboons and part of the larger game.

To the above evidence I am able to add a little of my own. In 1900 I passed with carriers through a portion of the morsitans fly-area. Hunting on 31st May and 1st June in and near the large wood and series of adjoining vleis called the "Mahloka" or "Masando " near the Umvuazi we were beset by very great numbers of tsetses, which also kept with us for considerable distances-far heavier attacks and "followings" than any I experienced in 1918. At that time buffalos were still exceedingly rare as the result of the rinderpest of four years before. I saw no trace whatever of them during that trip-a shooting trip-and local natives I have consulted have confirmed the fact of their absence. I have already mentioned the loss of a beast beyond the limits of the present fly in 1900 , and the capture in the same year of a tsetse south of Spungabera, just inside the edge of the present permanent fly.

On the other hand, my information from north of the Lusitu, if reliable (it was given to the members of my native expedition thither, not to myself), certainly seems to suggest that in some fly-areas an effect may have been produced. The real, dense, busily breeding centres of a morsitans belt may in the dry season at 
any rate and under certain local conditions, be exceedingly localised. It is a fact. also that the two animals that I have suggested to be the fly's most important carriers are amongst the three that suffered worst from the rinderpest. It is possible, therefore, that the actual effect of the rinderpest in certain areas may have been not directly to starve the fly, but to confine it the year through to a far greater extent to its dry season centres by the destruction of its chief carriers. The narrowing in this way of the area tapped for food in the wet season might react also on the numbers of the fly. The suggestion is tentative and perhaps may not be borne out in the belts actually reduced, especially if man, a carrier of morsitans, was present in numbers, living or passing, about the dry season centres.

The failure of the rinderpest to destroy the fly here to any appreciable extent tells decisively against the view that the rinderpest blood was in some way poisonous to the fly-for all my informants agreed as to its severity everywhere, except in a portion of Makwiana's highlands. The animals sometimes died "whole herds together," and I myself can witness indirectly to the effect on the buffalos.

Its failure tells also against the hope that we may exterminate the fly in the Mossurise district by destroying the bigger game only.

\section{XI.-Factors determining the Presence of Tsetses.}

\section{Shade and Undergrowth.}

It would appear from the present and other observations that the fly must be - protected from the drying effect of continuous sunlight either by a sufficient supply of shade, or by a readily accessible moisture supply, or by both ; and that this, with food, is its primary desideratum.

Glossina brevipalpis, so far as I have seen (and I was with it for some weeks in all), relies very greatly indeed on shade and is rarely found away from fairly heavy shade. The requisite degree of shading is provided by wooding with leafy undergrowth. This may be either primary forest (in which the undergrowth is sometimes such as to give sufficient shelter alone (Pl. xiii, fig. 2) or secondary bush in leaf with thickets and sapling clumps below ( $\mathrm{Pl}$. xii, fig. 2). Of these types the primary forest (Pl. ix ; Pl.xiii, fig. 2) and, in many places and most seasons, heavy Brachystegia bush are the best capable of carrying this tsetse through the dry season. It is not at all dependent on the presence of vleis, and I have found it waiting in all the thickets at some distance from water of any kind and in hot weather in September with the ground baked. It is true that it was in greater numbers near certain little streams than in the Brachystegia thickets, but (as results from the same type of forest away from streams appeared to show conclusively) this was only because those streams were lined with fringing forest of primary type.

So dependent does the fly appear to be on good shade that, except in the early morning, after sunset and on dull days, it will leave animals it is on as soon as they emerge from the shady bush into the sunlight. On dull and rainy days it will follow freely into the most open country and at high noon, so that the term " crepuscular," which has been applied to this $\mathrm{fly}$, is not altogether justified by my observations. Thermometer readings taken at the same time in primary forest, primary forest with its undergrowth cleared, and, thirdly, in a sapling thicket in Uapaca wooding along- 
side, were identical, yet brevipalpis had deserted the cleared piece (v. Expt. 1, p. 373). This, with a failure to take brevipalpis in some high, dark secondary wooding on the Sitatonga base, excepting at the occasional thickets, suggests that extra shade may not be the only advantage gained from thickets. Protection from drying winds, additional protection from the eyes of enemies (such as the thickets very definitely afford) and some advantage to the pupae are the three that occur to me, but I am convinced that shade is the chief consideration.

Glossina morsitans was found in a very different kind of country. It was very obviously far less dependent on good shade than $G$. brevipalpis, and I failed to find even stray individuals in the densest forest types - but the stray individuals taken were in any case very few. It occurs both on the granite-gneiss and the basalt of the lowlands, the latter usually with very poor bush indeed (Combretum, etc., Pl. $x$, fig. 2) and the former with savannah forest of a poorer type than that of the sedimentary area, though in each of these two it is Brachystegia. On the basalt and on most of the gneiss this fly occurred during my visits only as very rare individuals, and on the basalt and away from vleis only males were taken. The granite-gneiss, however, carries (as I have related) very numerous vleis, many of them with permanent water, and in spite of much painstaking search elsewhere, it was only at these vleis (and then only at some of them) that morsitans was found in great numbers together and its breeding going on with some vigour in the dry season.

Here the male flies occurred in the usual bands, containing in some cases at least d. few hundred flies at a time on the short or shortish grass and sedge. They were sometimes out in the sunlight amongst or beyond the scattered chidsgwati shrubs and stunted Parinariums that separate the open vleis from the Brachystegia bush surrounding them, sometimes a little way in the Brachystegia bush itself, never very far from the vleis. Some of these vleis with well populated fly-pockets consisted of mere glades in the bush, in which there was now no definitely exposed water and in some of which, had I not dug, I would hardly have expected water; but bigger vleis were part of the general series to which they belonged, and even in the glades experimental digging always showed moisture near the surface and actual water not many feet below. Some places would be moist on the surface, especially in the early mornings, when dew also was present in such glades generally. The flies were found in rather special association with a low, heavily-headed sedge (Fuirena), with which I found the local natives had also learned to associate them. This remained green after the grasses generally were dry and, with one or two low-growing associates, covered considerable areas at the edges of certain vleis. Almost the only low-growing plant that was transpiring at the time of my visit, and doubtless cooler than the dried-up species, it possibly offered a greater certainty of the deposition of dew.

The stray flies, of which I took fewer of morsitans than of pallidipes, appeared (as I shall indicate for pallidipes) to be finding their way to the vleis and rivers by the end of July, with leaf-fall already producing a visible effect in dry areas and at the actual vlei-edges, which latter, however, were also coming back into leaf. The natives described to me the increase of the fly in the hot weather, its spread in the early rains and its abundance then at places where, even with game temporarily absent, one now found few or none. In general it would be difficult 
to find a more fitting description of this morsitans-pallidipes area than has been given by Dr. Shircore of the "proclaimed area" of Lake Nyasa (Bull Ent. Res. v, pp. 87 and 88); although, owing to the lateness of the season in 1918 and the fact that grass-fires had now barely begun, I am not in a position to judge of the completeness and duration of the stripping of the drier country of the stray fly of which I seemed to have seen the beginning. This type of wooding comes back into leaf again very readily after the weather has warmed up, and it possesses an early element in the mutsatsas. The return of the leaf does not await the rains and the country is sometimes already very shady when it is otherwise absolutely at its driest. The relative value of these two factors - shade and moisture-in relation to the fly's fresh redistribution should be interesting to study.*

I did not find that $G$. morsitans appeared to be at all dependent on the presence of undergrowth. The bush in which it occurred was for the most part devoid of such growth, though some of it was itself low. I may add here that in consequence of the very late fires of 1918 , and of the fact that I worked the normally late-burning areas last, the whole investigation was carried out in unburned country (except for a few odd patches). Nevertheless I obtained no evidence in favour of the view, but much against it, that any of the flies concerned will live in open grass-country devoid of bush. Even the attacks of morsitans on the basalt were always in or beside shade, were it only that of a large shrub or a semi-leafless tree, and when noted definitely resting, either in my experimental net or in the field, this fly was always in the shade-under a $\log$, on the shady side of a trunk, etc. A replete resting morsitans female that I disturbed repeatedly always settled again on the shady side of trees. I have seen waiting male clusters furthest from bush in large vleis. but there was some reason to suppose that the individual flies did not stay with the cluster indefinitely.

Glossina pallidipes is distinctly more catholic here in its genera] tastes than either of the other two. It occurs both in the country favoured by brevipalpis and avoided by morsitans and in that favoured by morsitans and avoided by brevipalpis, as well as in wooding of its own; nor do the stray individuals, at any rate, avoid the extremes. Males were taken on the sparsely shaded basalt ( $\mathrm{Pl} . \mathrm{x}$, fig. 2$)$ in dry windy weather and with the leaf falling freely, and occasional individuals of both sexes were taken in primary forest dominated by Khaya nyasica in full leaf (Pl. ix).

I do not feel that I disentangled its habits sufficiently from those of $G$. morsitans on the granite-gneiss. Here, in the Brachystegia bush, it appeared to occur in every place in which we found morsitans ( $\mathrm{Pl}$. xiv, fig. 2 ; $\mathrm{Pl}$. $\mathrm{xv}$, fig 1 ). It was in great numbers only where morsitans was also numerous-namely at particular vleis and glades; it was very sparse elsewhere, but less so than morsitans, and both flies (and once brevipalpis too) were on us or the cattle together. When pallidipes puparia were taken at all, they were under the same log as those of morsitans.

* Mrs. Lawrence, writing for her husband well on in November and sending me flies, speaks of the pleasant and cooling effects of the first light rains-" but" (she adds) "the tsetses : they are abundant." Tsetses had reappeared with the return of the shade, but the advent of the rains would seem to have led either to their freer breeding out or (as I think, by making more general the conditions under whioh they could exist in comfort or safety) to their freer dispersal from their breeding centres. 
A fact that is possibly of interest is that in my first week spent at the Kanyezi morsitans centre (28th June-6th July) I saw and secured numbers of morsitans but relatively few pallidipes, though a good sprinkling of this fly was present. During my second stay there (27th July-1st August) pallidipes had apparently been heavily reinforced and was now taken (both males and females) in greater numbers than morsitans. It did not seem that emergences could account for this difference ; the puparia, living and empty, taken in large numbers on each visit, contained an extraordinarily small proportion of those of pallidipes-perhaps one per cent.though the bush generally was well searched. On the other hand the adult flies of both sexes, which at my first arrival were scattered more through the country generally, had latterly, with only two or three exceptions (these being on the basalt where moisture would be harder to find), been taken only at streams. There was a difference now in the fact that the country was drier, and that leaf-fall had commenced and was in places appreciable at the time of my second visit, so that the evidence suggested in a remarkable manner that pallidipes, previously to a larger extent scattered sparsely over the face of the Brachystegia area, had now congregated at the morsitans centres. It is perhaps difficult to disentangle this conclusion with certainty from the fact that the cattle always drew, and were now drawing, pallidipes in much larger numbers than natives working without them; but on this occasion the latter were themselves securing a larger proportion of pallidipes than previously. I should say that on the granite-gneiss the presence of pallidipes was in no way dependent on that of woody undergrowth.

West of the Sitatongas, where morsitans does not appear to occur at all, stray individuals of pallidipes were taken in very open bush - and in every type of bushbut it was never taken even two or three together except in Brachystegia and the less tall of the "dense secondary" types. It certainly occurs in small numbers in the dry season throughout the "Oblong" and its northward extension to the Buzi. It is even possible that this great Brachystegia block may be its main permanent habitat here, and it is notable that my cattle sustained a severe attack from pallidipes on 27th July in a limited piece of Brachystegia wooding just north of the Dysart Concession-a wood that had previously supplied a pallidipes or two daily to Dr. Lawrence's grass-cutters just outside it. I also took a few pallidipes between this station and Gogoyo's kraal at a series of small vleis in very dry sandy country carrying a type of Brachystegia bush equal only to the poorest on the granite-gneiss and already losing leaf somewhat heavily, and was informed by a native formerly resident that this fly was exceptionally bad here in the rains. Apart from these instances my only real and repeated successes with this species in the "Oblong" area were in and near the piece of coppice shown in Pl. xvii, fig. 1 and representing a type of wooding that, resulting from native cultivation, is more abundant north of the Mtshanedzi. Here (north of this river) on a few occasions up to half a dozen-even a dozen-together showed themselves in such types as are illustrated in Pl. xi (rather low thicket) and Pl. xvii, fig. 2 (coppice). Largely on account of this predilection, partly no doubt on account of the greater scarcity of brevipulpis and absence of morsitans, pallidipes west of the Sitatongas appeared to be specially associated with the Puizisi-Mtshanedzi area, which carries a very great deal of wooding of these types. The coppice or fern-entwined 
bush might be moderately open (as it was in Makwiana's Makubvu through the trampling of elephants and buffalos). Very frequent-almost constant-constituents of it were the small trees or large shrubs, Brachylaena rhodesiana (ipahla), Markhamia lanata (mubfeya) and Vernonia podocoma (mudambasese), the latter being replaced near the Sitatongas and across them by another woody Vernonia. Bersama niassae (muyahawa), Vitex eylesii (mukubvu) and Conopharyngia elegans were not infrequent, but a great mixture of other species, both of the savannah forest and the primary forest outskirts, were commonly present, and where the tree element overtopped the lower layer the wooding became fit for brevipalpis.

Generally speaking, brevipalpis needs coppice with overwood, while pallirlipes prefers coppice without it, but in the right types - such as rather poor Brachystegin -it can apparently dispense with yat lower growth. Clearing experiment No. 1 (below, p. 373) is of possible interest in this connection. Here pallidipes attacked the cattle somewhat freely in tall primary wooding in which the undergrowth hard been cleared, though before the clearing only brevipalpis had been present; but it may have come direct to the cattle from the wooding ( $\mathrm{Pl}$. xvii, fig. 2) outside. It is curious that in all my special trials on the Buzi for brevipalpis in wooding of the types shown in Pl. xiii, fig. 1, I never took pallidipes either, though I did take it here in places with low growth. It may possibly best be described as a "low-wooding fly," the low wooding varying from mere coppice and bush savannah to poor Brachystegia, etc., though better wooding is to some considerable extent utilised.

All vleis that I came across west of the Sitatongas were searched for male clusters of this fly and the neighbouring-and other--wooding for breeding places, but unsuccessfully. Though stated to be abundant at times in the rains it is generally by far the scarcer of the two flies where it occurs with brevipalpis. The latter often appears to be scarcer through its reluctance to show itself to man. A point to be referred to also is the fact that pallidipes did not occur in all suitable wooding. Much would be passed through without encountering more than a stray fly, if any ; then suddenly a simultaneous attack by three, four, half a dozen or more might take place, as already lescribed. Water (streams or vleis) was usually present not far away, but this part of the country generally is well watered, and similar water in similar woods more often failed to produce pallidipes. A small dry season population in a large area, and gregarious habits, probably sums the matter up west of the hills, but a study of my notes shows also that even stray pallidipes were relatively seldom taken anywhere at any great distance from vleis, glades or streams.

Of Glossina austeni I have in my possession a male fly and about sixty puparia all taken in two localities on the Mtshanedzi, near its junction with the Buzi. Fiftyfour of the puparia, empty and (judging by their muddiness) dating from the late rains, were taken in the (roughly) primary-type forest that lines the Rupisi thermal stream, from under logs. The Rupisi at this point, immediately above its junction with the Mtshanedzi, was still hot enough to give me a pleasant warm bath, and its temperature doubtless influences that of the fringing forest. The latter is of appreciable width, and is here dominated by Khaya nyasica and such trees as Trichilia. It is. to be exact, secondary forest under invasion and still contains fine tamarinds ( $T$. indicus), Kigelia pinnata and other secondary constituents, 
but the primary and primary-like elements-particularly Khaya nyasica, but also Trichilia sp., Lecaniodiscus fraxinifolia, musando (a splendid leguminous tree - unidentified, sometimes erroneously called mukarati), Oxyanthus gerrardi, etc.now so dominate as approximately to reproduce the conditions illustrated in Plate ix. The woody undergrowth is not quite dense, and there is a leaf carpet, not a live one. Great blocks of a crystalline quartzite appear above the surface, and the soil, evidently derived from this rock, is red and finely sandy but compact. Many lianas are present, and it was under an inter-coiled mass of these that the main batch of puparia (30) was found.

Shortly before reaching the Rupisi I had passed the ruined homestead of the late Mr. W. H. C. Coward, formerly a hermit in these wilds. His head-boy, aptly named Long One, had given me much information with regard to the tsetses hereabouts and had accompanied me on to the Rupisi to show me, he said, a forest in which small tsetses, in company with large, were extraordinarily abundant and troublesome in the rains. It proved to be the fringing forest I have described. The small flies, he said, would follow one out of the forest, the big ones (doubtless brevipalpis) often turned back on reaching its edge after humming and settling about one in the forest. He described the attacks of the small flies as surreptitious.

From four to four and a half miles on, near an outcrop of rock that perhaps represented the extreme southern end of the Sitatongas, and already beside the Buzi below the junction of the Mtshanedzi, we came on a great up-rooted tree $3 \frac{1}{2}$ feet thick, lying head downwards in a donga, and beside it the rootlings of pigs. Under it at a point at which it was seven inches from the ground, were found 9 empty puparia of Glossine custeni, in sandy soil. The conditions were sandy, though somewhat less so than on the Rupisi.

The general country between and near these spots was open, and the grass was more or less short with stretches of long grass. The chief savannah tree north of the Rupisi was perhaps Terminalia sericea; a Pterocarpus (near angolensis) also occurred and in places much thicket of Bauhinia galpini and petersiana. Afterwards Bauhinia reticulata came into evidence and. more and more, the upoza (Combretum sp.), together with a general approximation to the conditions of the basalt suitable only for morsitans and pallidipes. Along the rivers the dense forest wooding in many places prevailed.

There is much game in this corner of the country (Gowana's). Buffalo, sable antelope, eland, Lichtenstein hartebeest and roan antelope are all present, also a few wart-hogs, an alleged abundance of pigs and baboons, monkeys (C. pygerythrus in the tree-savannah, C. albogularis in the thicker forest, as also much blue duiker), waterbuck, reedbuck, and plenty of bushbuck and cane-rats. Vleis (not seen by myself) are stated to be present, but not many.

The one fly (austeri) taken by us bit the native who was giving my breeding flies a feed from a goat just outside the edge of the heavy Rupisi wooding, and possibly thereby exhibited a preference for man as against goat.

\section{Moisture and Rainfall.}

Morning mists, very wetting to the leaf, occur not infrequently in the dry season between the Sitatongas and the British border, especially. in the great river valleys. 
In the bare glades and vleis of the Brachystegia bush of the granite-gneiss not only is there a continuous evaporation in the dry season from a considerable underground water supply, but the nightly cooling is such as to produce regular dewsas it does also, to a lesser extent, even in the drier open spaces in the woodland. If, then, the sucking of moisture from wetted grasses which appeared to take place in my tubes should also take place in nature, we should have a probable partial explanation of the attachment of morsitans (and in the same area pallidipes) to the vicinity of vleis and glades. In one instance a large fly-cluster was observed to travel quite a mile and a half in the course of a few days entirely along a connected or but slightly disconnected series of small glades in the bush.

In view of such evidence as is alreadyavailable (page 341) I rather strongly suspect that tsetses will be found to partake fairly frequently of water in one form or another, especially the species that do not rely on heavy shade, in which dew is also less. It is conceivable that the slight occasional snacks of blood taken by male tsetses when travelling are as often for moisture as for food.

At any rate the point with regard to water-drinking deserves investigation, seeing that the practical application of a discovery that tsetses regularly drink dew might lie in the possibility of poisoning at least the male flies at their dry season concentrations--as one of several contributory measures for the flies' destruction there.

Rainfall probably affects the fly here mainly in so far as it influences the nature of the bush, the period of leaf-fall and (for morsitans and pallidipes) the permanence of the moisture in the vleis, etc. I found brevipalpis and pallidipes both east and west of the Sitatongas and on the British border, though we have here, undoubtedly. three different rainfalls. The confinement of morsitans to the smaller rainfall area east of the Sitatongas will be referred to below.

Up to 10th September (the end of the investigation), no matter how apparently suitable the wooding might be, I found no brevipalpis and only once a pallidipes in the immediate neighbourhood of river banks west of the Sitatongas; I refer to such rivers as the Buzi, not mere overshaded streams like the Inyamarimu. Yet on getting a bit back from the river, fly (mainly brevipalpis) was found generally and in quantity and thence up the hills to the limit of the suitable bush. There seemed to be a definite avoidance of the big rivers-possibly a matter of the greater winter cold in their vicinity. With austeni it may be different.

\section{Elevation.}

The effect of elevation was tested for brevipalpis and morsitans. Forty pupae of the latter fly were sent, twenty each, to two friends living in the mountains at about 3,400 (G. D. Otterson) and 3,900 feet (J. W. Scott), respectively. Each batch was placed in a little sand and leaf-mould (taken from the places $I$ found them in) in a wide-mouthed bottle covered with gauze. Each bottle was placed under a slightly raised log in semi-shade, this reproducing the natural conditions, and the temperature was taken daily. I kept a control set in a similar bottle in the lowlands. 
The mountain sets were sent up late in June and more than a month of very cold weather supervened, including, it is stated, the coldest that we have had for some years. Without going into the details here it may be said that the tsetses of the low veld control showed no advantage over those of the highland experiments. The percentage of failures was approximately the same, and the emergences both of the tsetses and of their parasites took place as well in the mountains as below. This is perhaps not surprising when one considers the elevation at which morsitans occurs in Mashonaland.

I could only test brevipalpis observationally. On 27th-28th August, the colder weather being just over, I climbed the hills overlooking the Inyamadzi towards Spungabera up which the continuous Brachystegia bush extends to a considerable elevation, and I found brevipalpis present on the highest points at which bush conditions (except in certain inaccessible kloofs) were suitable for that fly-that is, so far as I could judge from the known elevation of the valley bottom, at an altitude of about 3,000 feet. It was steep and rugged here, but tracks of pigs and baboons were present. I understand that Jack took a pallidipes in August 1917, almost at the level of Spungabera, but the place (pointed out to me by Dr. Lawrence) suggests that it was a "carried" fly stranded there. In these observations on brevipalpis there was no break in the fly's continuity, and from one to several flies attacked from the thickets right along from the Buzi to these high points near the border and back.

I have already referred to my observation at Makwiana's escarpment (fly at the bottom but none at the top), but this was simply a matter of shade versus none. The cattle sustained early morning attacks (before sunrise) from both brevipalpis and pallidipes with the thermometer at $47^{\circ} \mathrm{F}$. and under. G. austeni was taken at an elevation of (probably) six or seven hundred feet.

\section{Shadeless Barriers.}

The isolation of patches of woodland suitable for the tsetse seened of some importance in relation to $G$. brevipalpis in Brachystegia bush on the extreme edge of its area and where the intervening bush was already stripped of shade.

Ascending at the end of August the slopes from the upper Buzi or Inyamadzi, or merely passing along near the bottom of the valley of the latter river with no alteration in elevation, one came out into completely leafless bush (Pterocarpus) or open grass, and I failed to find any fly at all in kloof strips or Brachystegia groves isolated in or by these shadeless stretches, although they were certainly too narrow on the Inyamadzi to act as a definite barrier to either sex.

The obvious explanation seemed to lie in the refusal of brevipalpis to venture outside continuous shady bush except under certain conditions of light not common. in the dry season, and then probably only if it can find a non-human carrier to take it. Unfortunately for this view and the practical suggestion arising from it, throughout the parts traversed of the low-lying crescent (Umzila's guard-area) that descends the Mtshanedzi and swings back up the Puizisi, the smallest patches of dense forest with shrub growth below were very apt to shelter brevipalpis, few or many. The fact that the intervening bush was not yet leafless (in August) doubtless helped, and in places (as on the road east of the Chikambwe) this bush 
itself carried some brevipalpis ; but in Mtobe's area the intervening spaces were largely mere grass or bare Pterocarpus as on the Inyamadzi, yet the scattered darker thickets carried unusual numbers of the big fly. The clue is doubtless given in part by the fact that an actual detached primary-forest clump, diminutive enough, near the Inyamadzi-Chiredza junction did produce a few brevipalpis and that the brevipalpis-producing clumps in Mtobe's, etc., were of the shadier dense secondary or more or less primary types. The temperature conditions in continuous bush are more equable than in isolated patches, and the conditions for the existence of the fly may have been lost in such Brachystegia patches, though retained by quite diminutive clumps of the denser types. The Brachystegia bush on the Inyamadzi is rather poorer in any case in thickets and in fly than that across the Buzi, and it is right on the edge of the fly area with no passage to points beyond. Even if the explanation suggested is the correct one-and it must be noted that the observations it is based on were scanty-splitting up the shelter, as a substitute for complete clearing, on the margin of such an area would (by itself) exclude the fly only during a small portion of the year.

Interesting also was the fact that kloofs ascending towards Spungabera from the infested Brachystegia wooding on the Buzi showed no brevipalpis appreciably above the general margin of that wooding, though much of the wooding in the kloofs was apparently still suitable for it, and I had taken this fly up to a greater elevation near the Inyamadzi. The explanation that this is due to the necessity for a compact breeding population (possibly in part applicable to the occurrence of morsitans centres in some vleis but not others) seems discounted by what I have just related of Mtobe's country; but this principle would doubtless show best on the margin of a fly area and if there were no passage of game to carry the flies to points outside. It was perhaps significant here that below the Spungabera forest a line of precipices divided the general fly-bush below from a wood of Brachystegia above in which there was much leaf and undergrowth but no fly, and that further along northwards the limit of the fly at that moment was not quite that of the Uapaca-Brachystegia bush itself but a little inside it at the foot of a precipitous slope up which the Gogoyo-Spungabera path goes, and on which the above bush terminates. The absence of fly from the Brachystegia bush above the precipice might be explained in any case on the lines that $I$ have suggested for the isolated patches on the Inyamadzi, but the precipice very definitely and the steep slopes to some extent do seem to mark the limit here of the freer wandering of the pigs and other large mammals ; though pigs and baboons are said to come up in numbers in October and November to eat the ripening manzhanzhe (Uapaca kirkiana) fruits, and buffalos come up in the rains (especially from south and north of the more precipitous barrier) and, as the indirect evidence shows, bring up tsetses. I have been interested to hear from Mr. A. J. Orner, who has been along the path there recently in the rains, that even at that season, though he saw brevipalpis all the way from the Umtwadza to the foot of the steep ascent (mostly male queues in the path after sunset), after commencing to climb he saw not one more. In the rainy season there is much leafy wooding with thickets above the Brachystegia also, thus adding to the interest of an observation that is, however, incomplete through the absence of cattle bait to draw the fly out. 


\section{Grass Fires, Grass Growth and Soil.}

The fires scorch the leaves and undoubtedly drive out the tsetses for the time being from the area burned, but on the granite-gneiss, on 27th July, I found morsitans had returned to a patch of ground that had been fired on 5th July. The grass was already 6-8 inches high even in the drier vleis and the trees on their edges, stripped by the fire, were already coming back into leaf.

Of brevipalpis it must be said that of the two types of forest that it inhabits, one (primary forest and its extensions) never burns save along its edges, except in special circumstances which I have referred to already.

With one possible exception, I should say that the tsetse pupa has no necessities such as are not found incidentally in the environment necessary to the adult fly. The nature of the surface soil is, I judge, a matter of nearly complete indifference as a direct factor, for some slight accumulation of detritus is almost always present in such spots as receive the larvae, and I have found puparia on all soils. As an indirect factor it may be far more important, for it is quite certain that at most only an occasional pupa could survive the extraordinarily fierce fires of the heavily grassed dolerite outside the denser woods, when they do not take place too early.

\section{Food supply.}

I have already referred to the rôle of the big game in annually re-distributing the fly. I found no country in which largish mammals (pigs, bluebucks, etc.) were entirely absent, so that I am unable to say from my own observation that the fly can or cannot exist without them. That man must contribute much to the seasonal dispersals of $G$. morsitans I had abundant evidence, and I had plenty of evidence also that it does not avoid native kraals if trees are present.

\section{Two apparent Fly-barriers in Mossurise.}

(1). The Sitatonga Hills. These (except possibly at their extreme southern end) form the eastern boundary of the morsitans area. That this boundary is permanent there can be no doubt. It was the boundary when I visited the area in 1900 and it still is to-day. I failed to find the fly or its pupa west of it, and no morsitans has been amongst the numerous flies (brevipalpis and pallidipes) that have been collected for me during many months by Dr. Lawrence. Mr. Jack, who passed from the Gogoyo (Dysart) station to Mtobe's, under the Sitatongas, in 1917, also took no morsitans.

The Sitatonga Hills are a lofty and uninterrupted "knife-edge" passing right from the Lusitu to the Buzi. There is relatively little back and forth movement of game except at the southern end (where the buffalos have a passage), and it might appear therefore that the ridge acts as a barrier, either direct or (through the game) indirect. On the other hand, at Umtomana's pass and about it the hills are very passable by game and have probably constantly been crossed by them formerly and are crossed to some extent now, and a main native path goes through here. My temperature experiment (above) suggests that the mere height of the hills will not constitute a direct barrier; and (a conclusive argument) the ridge evidently acts in no way as a barrier to the distribution of pallidipes and brevipalpis, which occur freely on both sides of it ; why then should it to morsitans? 
We must look for an explanation to a difference in the conditions. They are as follows :-

1. Smajler rainfall.

G. morsitans present.

2. Surface soil loose coarse sand on gneiss, compact on basalt.

3. On gneiss impervious kaolin sub. stratum bottoming numerous vleis, the latter fringed merely with the Brachystegia of the general wooding.

4. Poor clean-stemmed savannah forest (Brachystegia) on gneiss ; scattered bush savannah on basalt; each type continuous over a great area.

5. Grass mostly short, fires not serere.

6. Much big game.
G. morsitans abrent.

1. Larger rainfall.

2. Soils compact, much humus in denser wooding.

3. Vleis fewer, mostly small and moro of ten with long grass; permanent streams numerous, largely fringed with big trees.

4. Brachystegia savannah forest on sedimentary rock far finer and with, in general, much more undergrowth; on dolerite in widely scattered groves. Here the main wooding is $(a)$ dense secondary types, also primary; (b) highly deciduous tree savannah.

5. Grass of tree savannah immense, fires fierce if late, milder in the denser wooding.

6. Except in "Oblong" less big game, but many pigs, etc.

2 and 6 may be dismissed. I found successfully emerged morsitans puparia on the compactest of soil on the basalt and the other two tsetses seem able to subsist here in numbers in the absence of much "big" game, as morsitans also did after the rinderpest.

4 and 5. If (as is likely) it should be that only the tree savannah of the dolerite is really, as a whole, suited to morsitans, then its high deciduousness, with its fierce fires, should suffice to exclude this fly except as a possible summer visitor carried in on game or man. The scattered Brachystegia groves of the dolerite are utilised by pallidipes, and it is likely enough that it retires to these when the dense secondary wooding loses leaf towards the end of the dry season; but to morsitans, unable to use the bulk of the bush, these Brachystegia groves would stand in the same relation as the outliers of the Brachystegia of the higher Buzi in which I failed to find brevipalpis do to the latter-only they are much farther away from the main block and separated from it by a high hill range and the two narrow and broken strips of dense, unsuitable wooding that fringe its eastern and western foot. To this extent the Sitatongas are a barrier, and doubtless also if they were more freely crossed by game morsitans would appear more frequently on their west side in summer. The apparent absence of morsitans from the generality of the continuous Brachystegia wooding of the "Oblong" (neither Dr. Lawrence nor I have obtained any thence) seems to suggest that the difference in shade and undergrowth between this type of woodland and the poorer type on the gneiss is sufficient to exclude this fly.

To be able to assess the influence of the rainfall here one would require to have figures from many morsitans areas. It certainly seemed to me that morsitans, on the gneiss, was very dependent on vleis of a particular type for its dry-season breeding. Vleis quite of this type are rare, if not absent, on the west side of the hills, but it is again difficult, without an acquaintance with other morsitans areas, to know if these vleis do really represent a vital condition. It may be this factor, rather than that of the wooding, which causes the demarcation, and at present that is rather strongly my opinion. 
In general it does not seem likely that the country west of the Sitatongas, at any rate north of a line drawn through the middle of the "Oblong" and parallel to its greatest length, is in any danger of being invaded by morsitans. Occasional flies might be carried over the hills by Kafirs or game, and the latter would probably happen more frequently were the kraals on the eastern foot of the hills to be removed.

(2). The mountains of and near the British border. These constitute the western and northern boundaries of the pallidipes-brevipalpis areas, and for a clear idea of them the map should be consulted. Generally speaking they form more or less of an escarpment, abutting on to the fly country on these two sides.

The great rise in elevation seems at first sight an adequate reason for the existence of the fly boundary, which, it should be repeated, appears always to have stood approximately where it is now, except when pushed east by Kafir settlement. No doubt the British hills north of the Lusitu (6,000 feet) and the Chimanimani (much higher) would act in this way as a direct barrier, but it is more than doubtful if, from the Lusitu southwards, the elevation (with maximum heights of a little over 4,000 feet) is sufficient to act as a direct deterrent to the fly. On the contrary, a glance at the map shows clearly that it is the great continuous pieces of wooding of the right types that really delimit the fly. Where these ascend mountains, the fly ascends equally ; where they stop short in low-lying valleys (Inyamadzi, Chiredza, Buzi, Lusitu), the fly stops short too. It happens that these great pieces of wooding cross the British border for a short distance only where they touch it. With regard to the wet season fly, which is capable of being established temporarily by game in occasional pieces of wooding such as exist abundantly enough even on the British side of the border, another factor must be mentioned-the white settlers on the border and such native kraals as are present. Our experience shows that these do act quite considerably as a deterrent to the passage of the wandering big game, and that where a white man shoots much or native kraals are numerous a useful "guard" against the fly is thereby established.

In general, however, the summing-up of old Inyabangwa, who long ago herded cattle for the Zulus on the edge of the escarpment, fits the case. "They are barred, sir," he exclaimed, "barred (zi-vimbekile, 'nkosi, zi-vimbekile). They fear the open country (izimbaya) of the mountains and they fear its cold winds."

\section{Waiting Habits.}

\section{XII.-Notes on Habrts.}

I have referred to the tick-like habits of tsetse. I came across no evidence that the flies wander to any extent in search of their prey, though a good deal of local activity is shown by male brevipalpis after sunset, and females then attack from a greater distance. That some of the stray flies found in the country generally are carried, I had evidence in the sudden appearance of my marked flies in native villages immediately after parties of reed-cutters had passed through them from my vleis.

G. brevipalpis may be found in the day-time scattered through all the little thickets in the bush it frequents, two or three or more to each. Just at sunset the males emerge from the thickets in the neighbourhood of game and other paths and (where plentiful) distribute themselves at short intervals along them, sometimes 
for a considerable distance. As one walks each male moves on in front of one for at most a few feet, evidently scanning the walker for any females that may be with him, then falls behind. At one time when a domestic matter called me home from the Buzi, my police boy, left in charge of the work, captured no less than 88 of these flies, every one a male, on three successive evenings without the aid of cattle along the same stretch of path. The path here passed alternately through bush suitable to brevipalpis and more open spaces. On emerging into the latter one ceased to see flies; on entering bush further on one found them in the path. This was a little curious seeing that it was after sunset and rather suggested that they had not come far.

'The males of $G$. morsitans, though occasionally seen like this on game paths, were found mostly crowded together in the short grass beside the path-some of them on the path-and were also (as events each time fully proved) watching for females or carriers to take them to the females. $G$. morsitans usually waited in a crowd, brevipalpis always in a queue.

\section{Travelling Habits.}

G. morsitans utilises man as a carrier far more freely than the big fly does, and as these followers occasionally bite, they would give an unobservant person the impression of persistent attacks by large numbers of tsetse. It is, actually, nothing of the kind, but, in essence, a ride in search of females. This is most clearly seen when the flies are few and on the back of the person in front. I have watched male flies, each with its station on a particular spot on the back of my guide, travel thus for miles. They would keep taking short flights off all the time and at once return to their previous station. Whenever I saw the object of the flight it was another fly, and the fact that the flights were in search of females was sometimes proved by a witnessed pairing.

That these rides on man would be useful even where the females were not feeding on man was supported by the many instances $I$ saw in which flies came out to us and turned back, evidentally rejecting us. (These observations were on brevipalpis.)

Where I have walked slowly the tsetses (morsitans) have some times contented themselves with moving along in the grass beside me. More often they-or some of them-attached themselves to me when I was moving and each time I stopped dropped to the grass again till a movement showed it was time to start. There can be little doubt that when on the grass they watched for females coming to me, for such females were at once assailed. The low position adopted by the tsetses during these waits was doubtless of considerable use in showing them the females against the sky, and in helping them to detect and keep in touch with moving objects generally. Flies that had flown off a man's back to accost another fly always returned flying very low and rose to his back. The principle is that of the nightjar or of the man who stoops to watch crepuscular insects or birds. These clusters of male flies varied greatly from day to day in numbers and position, reductions definitely resulting both from the depredations of birds and from the flies attaching themselves to passers by. With buffalos present the clusters practically became non-existent. They always tended to torm again later, but were not always composed of the same individuals, for experiments with marked 
flies showed that these reappeared in other clusters than those in which they were marked; and the immense preponderance of unmarked flies in clusters that $I$ had taken pains to mark pretty fully suggested that they were being kept up not merely by arrivals brought from elsewhere and from males that had probably been resting, but by new emergences in the neighbourhood, such as were actually noted in searching for pupae. In each case active breeding centres and clusters were never found otherwise than in more or less close contiguity.

There was a certain amount of day-to-day movement on the part of some of these clusters as a whole, but it was gradual. The one nearest my Kanyezi camp was very stationary, its movements being mere fluctuations, and after a three weeks absence $I$ was able to find both this and the other clusters almost where I had left them and to retake in them a few of my marked flies.

Males of brevipalpis waiting on game paths were frequently tempted to attach themselves to the cattle and would then often ride for quite a distance. Sometimes they fell behind them, as they fell behind ourselves, probably because they found that they carried no females.

I measured one of these rides by five male brevipalpis in dull weather, first marking rach of them with a dab of white paint. The flies had come to us just before and were following, not feeding. The greatest distance travelled was $5 \frac{1}{4}$ miles by the one fly that stayed to the end. All five flies were still present at 4 miles and 700 vards. Every kind of country was traversed, brevipalpis bush, simple coppice and open grass.

The flies deserted us on our getting back into their native bush. Elsewhere where brevipalpis had followed us into the open in the daytime it waited before leaving us until it had reached suitable bush, and an individual that once followed far to a camp in the open stayed about for hours (in the evening) before disappearing. All this was interesting in relation to the explanation of outbreaks of nagana in which it appeared that the fly had crossed much open country to bush-patches in the grazing grounds or near a kraal.

I tested similarly the distance to which morsitans will follow man. Twice I obtained rather more than six miles, and many times various less, but still long, distances. On one occasion a journey of over six miles was done in three instalments by a marked fly on three successive days. The riders were almost always interrupted by reaching, sooner or later, another clump of male flies into which the male riders then disappeared. Otherwise, and with more time to experiment, the rides might well have been much longer, and Bevan ( $\mathrm{I}$ think) has recorded an observation of Meikle's in which tsetses were still on his cattle 25 miles outside the fly-belt. A common position was on the load of a native carrier.

In the foregoing experiments and observations the flies that really travelled were invariably the males (marked with a different colour), and it was these only in the case of morsitans and pallidipes that had up to the time of my departure put in an appearance at villages a few miles outside the breeding centre in which they were both captured and released. Hungry flies, including, so far as I saw, all females, came to feed, not follow, and the longest distance travelled in an experiment in which I released a considerable number of hungry marked brevipalpis 
and a few pallidipes behind the cattle was 820 paces quiclly covered. The other flies had already dropped off replete before that, in spite of the kicking and running on the part of the cattle.

The question of the females travelling, even on animals, is an important one in relation to the question of possible control by barrier clearings, and is worthy of more extended special experimentation if long distances have not yet been recorded for it.* In Simpson's experiments with marked male and female flies on the Yapi-Tamale road, in the Gold Coast, only one recaptured fly was found more than two miles from the point of release, and all were retaken near the road, on which there was considerable traffic. Unluckily in stating the result he does not separate the sexes or state the time that elapsed between release and recapture. A female could readily cover two miles on successive journeys on man and animals, especially if much disturbed in her feeding. In Lamborn's experiments only males were retaken.

It is obvious that a fly-belt can only extend definitely, whether its annual extension into highly deciduous wooding is concerned, or a permanent extension into country previously uninvaded, at the same rate as the females. This, if I am right in my present belief that the females do not travel appreciably on their own initiative or to any distance on animals, suggests that the extension will be slow and compact and indicates a possible explanation for the alleged fact that the cause for the division between fly and non-fly country is sometimes not to be found in any difference in the conditions of wooding.

Living in a district that is right up against the fly $\mathrm{I}$ have come across no evidence at all that either sex travels appreciably on its own initiative. There is on the other hand, a very great deal of evidence to connect our local outbreaks of nagana with the movements of big game. I do not think that a fly area will extend seriously in the absence of game.

\section{Migration and Homing.}

The fact that the flies are found still in their centres ili great numbers when food is scarce, and even under such conditions of hunger as have been described by Maugham and as, it is just possible, I saw myself in 1900, $\uparrow$ tells against the theory of unassisted outward migration, though the predilection of the "following" males for joining other fly-clusters they may meet on the road amounts to unassisted migration of a kind. It is also quite certain that in South Melsetter, with the fly right on our border for 20 years past and numerous herds of cattle grazing in and near Brachystegia bush at relatively low elevations, we should have met with much indirect evidence of migration were such to take place.

* Against the obvious suggestion that the barrier could be narrow must belplaced the possibility, to be referred to below, that females as well as males do not dismount readily in uncongenial country once they have allowed themselves to be carried well finto it. This point needs testing also.

† I see from my journal of that time that the tsetses "swarmed and" were very irritating." Game was not quite absent, but, with the exception of duikers, was very scarce, having left this unburned country for the green patches on the basalt that had been burnt earlier. 
That homing occurs, within limits, is to me certain. On 29 th June as soon as I entered a male crowd the flies as usual attached themselves to me and kept pace with me, buzzing about my feet. On my leaving the vlei and entering the Brachystegia their numbers fell off rapidly, only a few following me 50 yards in. I stood still finally when all had left, and after a few minutes returned to the cluster to see if I should pick up the flies along the path, where they had left me. I saw not one fly till I had got to the cluster, in which they seemed as numerous as before. It seemed probable that on leaving me they had flown straight back to the cluster. Natives arriving with loads shortly afterwards passed through the cluster and a number of the flies accompanied them right through to my camp-a further 150 yards-possibly a matter of preference. They stayed for a short time, occasionally biting, then all disappeared.

Similarly whenever we emerged from a cluster, followers would just at first often be numerous, but for the most part would fall off within a very few hundred yards, and on the analogy of the above observation and from certain takings of marked flies, it seemed likely that these short-distance flies had flown back. The numbers of the remainder lessened rapidly with the distance travelled and relatively few followed for some miles. Would these long-distance flies also find their way back unaided? Would they necessarily proceed further than the first useful vlei? And if deposited in congenial surroundings, would they necessarily return at all ? The experiments known to me on the subject of long-distance homing do not (as described) seem to settle conclusively the question as to whether it was unaided. Simpson's were on highways of traffic. His recaptures were many and confined to the vicinity of these highways_road and river. Lamborn's recaptures were few and his general distances longer. From my cattle experience I judge it to be likely that fly will go farther on game than on man. They also, in my observations, tended to travel farther through unattractive country, once there, than through country offering temptations to dismount. This suggests further the need for a closer description of the country searched on the wrong side of the point of release. The question is of some possible practical importance, and it was, therefore, a matter of regret to me that lack of time, with the fact that on first leaving the Kanyezi centre I did not know if I could return to it, prevented me from carrying out long-distance experiments of my own.

My incidental evidence suggested that homing does not always take place at once. The fly that I have described as travelling six miles in three stages reattached itself each time at the spot at which it had left one or other of us the day before, and other isolated instances of the same thing occurred. Of my marked flies that were carried to native villages a few miles off two were reported as staying about for from two to four days before disappearing-when they may merely have moved farther on on natives or have been killed. Further evidence was obtained in investigating a severe and sudden outbreak of nagana in a large herd in British territory, very many miles from fly (permanent or otherwise), which appears to have been caused by male tsetses carried by game. It had taken place at the commencement of the dry season. The native in charge and the herd boy, interviewed separately, each picked out tsetses (from amongst my specimens) as having been on the cattle before and during the outbreak and stated that they had appeared suddenly and stayed three weeks or rather more. They disappeared "when the leaves fell "—a spontaneous 
piece of evidence which, coming from high-veld kaffirs previously unacquainted with tsetse, seemed rather convincing. Whether they then "homed" or died it is impossible to say. Old natives who herded cattle in the earlier davs of Umzila's experiment had previously given me similar instances of long stays by the fly. Of course there was an attraction, but the seasonal spread of the fly into other deciduous areas ( $v$. Sections ix and xvii) will itself, if fully confirmed, constitute strong evidence against the universality of homing, as the well known recent spread of many fly areas already does against its completeness.

\section{Hours of Activity.}

G. brevipalpis, as I found, attacks in the shade of the bush at any hour, but does not fly appreciably outside its own thicket to do so except in the early morning, after sunset and on dull or rainy days. Having attacked, even in sunny weather, it completes its object of feeding or riding, unless its victim emerges into the open. In this event it usually leaves. In a special experiment that I carried out with the aid of a lantern occasionally lit and turned on I found that both this fly and pallidipes attacked right up to dark. Then every fly suddenly disappeared. On moonlight nights they continue their attacks, and all three flies come to light, including firelight, and, once there, bite freely. G. morsitans I found, as have other observers, to be most active in the rather warmer hours and least on cold or dewy mornings, but it too attacked up to dark. It is probably dependent on shade to retire to occasionally when blood and water are not available, for I captured several male flies that had been resting under logs in the wooding adjoining vlei edges frequented by male clusters. The frayed wings of some showed that they had not just emerged.

\section{The Bite, and the Attack; Methods of Marking.}

Nothing struck me more than the frequency with which a fly would steal a feed from the back or (especially) leg of a kafir walking in front of me and fly off replete before the man noticed it. Very frequently the first intimation of the fly's presence comes with the final withdrawal of the proboscis: sometimes even that is not noticed. At other times a bite is noticed instantly and felt acutely. The natives who converse on the phenomenon hold that a bite over a bone hurts and in a fleshy prrt does not, but it is obviously a matter of local presence or absence of the specific sensory nerve-terminations. I have myself had both painful and painless bites quite close together on my forearm.

The practical bearing of the fact is in relation to the criticism (based on the success of observers' pet animals) that flies will not make good their feeds on baboons, etc., and that such animals need not therefore be seriously considered in relation to the effect of game destruction. A second fact to be remembered here is that captive animals have abundant leisure for fly-catching. A wild baboon is often absorbed in raiding. hastily cramming his pouches, quarrelling, keeping up with the troop, or participating in shouting contests. Especially where tsetses are present all the time, he can hardly attend to them except incidentally. The black man in thes circumstances brushes the fly he notices away-commonly, if walking, by a wrist movement that brings the butt of his assegai sharply to the point on his back that was litten-and the fly at once returns; he makes an etfort to capture it chiefly when 
he is idle. When watching tsetses in my net experiments I relatively seldom noticed the approach of any that attacked, though their attentions were sufficiently annoying to make me wish to do so. A male in search of females approaches boldly enough and is not silent, but the attack of flies intent only on feeding is often remarkably surreptitious.

I was never bitten through my clothing by $G$. morsitans, but very frequently indeed by hungry G. brevipalpis, both through thin shirt and vest and strong khaki trousers, though I occasionally watched flies probe for a time as though unable to penetrate. The scrotum (when one squatted) was almost always the point of attack, and this accorded well with this fly's habit in relation to cattle. It always attached itself to their bellies, more or less in the median line, or between the fore or hind pair of limbs. The kicking of its belly by a beast in brevipalpis country almost invariably indicates that it has been attacked by that fly. The position chosen has probably as much to do with considerations of shade as with the thinness there of the skin, and some very hungry brevipalpis released by me behind running cattle fed at the first points reached, including the flanks, whence one was seen to be licked off-suggesting a further reason for the selection of the belly by a fly that is less active in avoiding such reprisals than is G. morsitans. The smaller tsetses attacked more on the flanks and forequarters and lower down.

I carried out an experiment in trapping tsetse by fastening skins smeared with bird-lime on the goats and under the animals' bellies. The fly-catching properties of the lime, made from Loranthus berries, were excellent, but it speedily became so masked with leaves and grass blades as to be useless.

I have referred alread $y$ to the low poise and sidelong, running, almost Olfersialike movements of the fly in evading reprisals. This is well seen when the natives try to catch it, as they frequently do, by "treading on its toes" with the edge of an assegai or knife. Occasionally a leg is damaged in the process and this, with the attacks of birds, makes unreliable the method of marking by snipping off a portion of a leg tha1. was adopted at first. I later used paint from water-colour tubes, placing with : small brush a dab of white or colour on the back of the thorax and varying its position and size. This proved excellent. It enabled me in some cases to recognise individuals again and again, and the conspicuousness of the mark brought me reports from the natives as to the spots at which such flies reappeared. It doubtless also carried with it the disadvantage of laying the flies open to detection by birds - a consideration that is of less importance in relation to the males, which, in any case, trust more to activity and less to concealment than the other sex.

\section{XIII.-Proportion of THE SEXes.}

The following statements represent the result of day-to-day observation and analvsis in the field-the only reliable method.

(1). Wherever we had to deal with male crowds or queues awaiting females or, in the case of brevipalpis, the bush immediately bordering on the path on which the male flies would line up at sunset, we took, as might be expected, practically nothing but males. 
(2). Elsewhere, using cattle bait, we found usually either an approximate equality of the sexes or a preponderance of females.

(3). Many more females proportionally came to cattle than to man and goats.

The cattle were with me only during my last four days in the morsitans area (three at Kanyezi centre), but the proportion of females rose abruptly on their arrival. It amounted now to from 35 to 40 per cent. in spite of the fact that the cattle were used very largely at a strong male cluster in order to obtain the material for certain experiments. Previously 7 per cent. had constituted a good day, the only day on which I had surpassed this figure being one (1st July) on which the already weakened male cluster at and near which we were catching had temporarily been obliterated by the passing through it of a buffalo. The percentage of females for that day only was 30 , and it was also the one day on my first visit on which pallidipes (taken one here, one there) predominated, but the total was in any case diminutive, not exceeding my daily catch minus morsitans males.

Bagshawe's result (more male palpalis where crocodiles were present, more females where not) and McConnell's (more palpalis females on the small tributaries -where food is doubtless scarcer-more males on the main Nile) appear to be completely explained by observation No. 3, above. Bequaert's observation (more males in uninhabited regions, where non-human food would be more abundant) would appear to be the same, had not Graham (quoted by Bagshawe) noted that, in Ashanti, palpalis prefers human blood to that of cattle. But both Graham and Zupitza (also quoted by Bagshawe) observed that when flies bite readily males are not in excess.

In spite of a heavv preponderance of males in my total takings-the inevitable result of following paths and of special attention to all male crowds or queues with a view to obtaining material for my marking and other experiments-I came across no evidence at all which, properly analysed on the spot, suggested an actual preponderance of the male sex. Rather the reverse; and it was likely, both in view of the systematic attack by birds which I found taking place on a conspicuous male crowd and from a consideration of the breeding habits (which are such as to allow for much male wastage), that, at a given moment and apart even from the freer dispersal of the males, the females are more numerous than the latter, though they will show themselves in their true proportions only when hungry.

Dr. Lawrence's numerous small sendings of flies, lasting over many months, showed (in pallidipes) a remarkable equality of the sexes even in the individual sendings. Here we have a locality in which game generally is rather scarce and even wild pigs, it is stated, unusually so; also no male fly crowds, in so far as I have seen or heard, but mere individual attacks by single flies on natives passing or working. In the stray individual flies of pallidipes and morsitans taken by myself over a far greater variety of country both east and west of the Sitatongas, some of it with much game, the females amount approximately to one-third, but a few stray flies taken on cattle (on Ist Aug.--females over 50 per cent.) are included here. 
Attacks by several pallidipes together (except at the waiting male crowds of the granite-gneiss) were very different. Here the tendency to equality was great, and on at least one occasion, to judge by the captures, only females were present. But we had no such attacks except on the cattle.

The above results from pallidipes may usefully be contrasted with those obtained from brevipalpis - a fly which is very loth to feed on man; and it must be remembered again that the female sex comes primarily to feed. In Dr. Lawrence's sendings (mainly flies taken on natives) practically all the brevipalpis are males. Except in the pig observation (p. 337) this was my own result also, till I used cattle bait.

My results would seem to place Lloyd's suggestion outside the category of theory and further to show clearly that the apparent scarcity in the presence of game of the females of the three flies chiefly investigated is probably due to a relative dislike of man.

The fact that morsitans and pallidipes might be found about native villages where the shade was suitable, was, as I shall show, the natural result of villages being centres of arrival from the surrounding country, together with the fact that these flies do attack and (in particular) follow man. It does not invalidate their probable preference for game.

\section{XIV.-Observations on Breedint: Habits.}

\section{Glossina morsitans.}

Wherever I went I searched diligently for pupae with all the natives at my disposal, including often a number of local natives ineited by the offer of rewards. Special halts were made at likely or typical spots or at mere fallen logs, and the normal halts were fully utilised. My general lack of success was remarkable, and the two or three solitary, evacuated, muddy, wet season pupae found corresponded with the sparsely scattered character of the actual fly in most of the morsitanspallidipes area. Only one small find of puparia (evacuated) was made on the basalt in spite of a week's exhaustive search in the country round my camp, both in river bush and bush savannah, by a large and quite keen gang.

At some of the better vlei-series (by no means at all) the indications were very different, and at one of these (shown on the map as Kanyezi's) I stayed at the end of June and again at the end of July, for about a week each time. Buffalos had been present here in very great numbers in the late rains, but had left two months before my first arrival. During my stay a small herd of Lichtenstein hartebeests, small droves of wart-hogs, and latterly a solitary buffalo bull were about the only large mammals present, except an occasional duiker, a leopard and three passing lions. The buffalos had left some heavily trodden-out game paths, now used mainly by ourselves and once by the solitary bull. Thorough searches for puparia were made both near the game-paths and away from them and near the vleis and away, and I took many hundreds of full and evacuated puparia in all from more than a hundred breeding places. The puparia were not, like Lloyd's, necessarily connected with the game paths, though it was not easy to get very far away from these; but the muddy ones were more or less confined to areas well grazed by the buffalos, and all were confined to the wooding in the immediate vicinity of open vleis and glades, 
to the borders of which and the old game paths traversing them the male flies were obviously betaking themselves on emerging. The soil was sandy, the formation was granite-gneiss, and the wooding was the Brachystegia-dominated savannah forest of that formation.

The females when not feeding certainly spent their time in hiding away-from the males (as Lamborn has suggested) and, I am certain myself, more especially from birds and the sun. The indirect evidence showed clearly that it was mostly when thus hiding-in a spot which suited their own convenience but by no means necessarily that of the pupa ( $c f$.also Lloyd)-that they dropped their young, sometimes (as my indirect evidence again most strongly suggested) from several feet from the ground. Most of my puparia were found under prostrate trunks and branches, raised little or much from the ground, but batches were also found in the angles of root-buttresses, under mere leaning trees, under fallen palm leaves, and below and between the outleaning dry leaf stems at the bases of palms (Hyphaene ventricosa), in holes in trees and in holes made by animals in banks, and where the hoof-marks of passing animals had broken the slight crust of a sandy stream-bed immediately under light overhanging grasses. I failed, in spite of much search, to find tsetse pupae in the leaf-sheaths of palms, though I took Lepidopterous and often other Dipterous pupae there. The situation was usually dry, but some of my sand-stream pupae were in a moist situation, and I took a pupa-case that had emerged successfully under a fallen Eugenia log in very damp ground on the edge of a vlei.

I also carried out an experiment, lasting many weeks, with the pupae taken. Some were exposed to conditions as normal as I could make them, some were in soil exposed to day-long sunlight and others were in ground kept always moist and either warm or cold. It was wonderful how well those exposed to the extremes (perhaps less extreme than the conditions used by Roubaud) emerged, but less so when one remembers the continuous state of the ground in such a wet season as 1917-18 or so dry a one as 1912-13. Pupae placed in a calabash of sand exposed continuously to the sun failed, but in travelling they worked right down under the sand in any case and many of them showed definite crushing by it. It is worth noting that in the moister situations (in the vleis) practically no trees grow except on the ant-heaps, consequently logs and other dark hiding places are relatively seldom found there. Otherwise it is probable that pupae would have been taken there more frequently.

One other condition should be mentioned. The vast majority of the pupae were in the nearest suitable hiding place to a spot in which big animals had been lying down-buffalos (mainly), wart-hogs, hartebeests, etc. This seemed to accord with the fact that we ourselves were attacked by feeding flies (as opposed to males utilising us as vehicles) mainly when we were stationary and especially when we were squatting down searching for pupae. Again, of two sand-streams, otherwise not dissimilar, one that was used as an occasional game path yielded a number of pupae; the other, used only by small carnivora, yielded only one pupa-in a highly placed hole where a duiker had lain on the edge of the bank just above. It was frequent for the puparia to be near ant-heaps, but this was the result of the fact that the buffalos had chosen the sheltered sides of ant-heaps to lie on during the rains. 
Provided that the hiding-place itself afforded shade to the mother, overhead shade (as an analysis showed) was a matter of complete indifference, and the ground in which puparia lay was commonly reached by the sun during part of the day.

The puparia were usually close beneath the surface of the earth, and the evidence suggested that the maggot had wandered but little from where it was dropped. Under each log was usually harder ground, interspersed with softer pockets where babblers (Crateropus) or small mammals had previously scratched. The puparia tended to be congregated in these pockets, but they appeared in some cases to give evidence also of gregarious settling by their mothers.

I carefully identified all logs, old or fresh, under which puparia were found and was most interested to note that the very great majority of them were of two species, chiwhanga and mukarati (Ormosia angolensis and Burkea africana), which were by no means the commonest trees in the woodland. It was not that the fly chooses these out, for all evidence (and there was a great deal) showed that it goes after feeding to the nearest shelter, in some cases very diminutive. The reason was that these are actually the commonest logs on the ground, and they are so because they are the most durable timbers present and also do not readily burn. Some of these logs had quite likely lain for twenty or thirty years, very gradually dwindling, whereas a fallen Brachystegia may disappear in three. The eventual exploitation of these areas will result in the early clearing out of these two useful trees (the Ormosia for fencing posts) and the consequent confinement of the fly for its log breeding places to species that are attacked by insects and burn. This is one of the various facts that show how concentrated human activity assails the fly from several different directions.

The localisation of the breeding centres in this area suggests that the possibility of attacking the fly on the lines suggested by Lamborn might require consideration. Some of the logs at the Kanyezi vleis that were cleared by me of pupae at the end of my first visit (early July) had already many fresh pupae under them when I came back at the end of the month, where hartebeests had been present. Breeding was going on both in June and July and in some quite cold weather, but emergences from the pupae secured only began taking place in numbers with the advent of really warm weather in early September, and continued into November. The pupae. like those of Lepidoptera, will apparently stand a small amount of damage. Out of 15 that I put aside as damaged in the finding on 30th July two afterwards produced flies.

\section{Glossina brevipalpis.}

I obtained no live pupae of brevipalpis, but found a few batches of pupa-cases in the Brachystegia bush on the Buzi east of Spungabera, one of which contained nearly a hundred puparia. In the case of this fly the batches were beside lying places of buffalos and wild pigs, and the flies at the moment of dropping the maggot had in the biggest find ( $\mathrm{Pl}$. xiv, fig. 1) evidently been resting for the most part on the undersides of the coils of large rough lianas (Cissus, Landolphia and Bauhinia), apparently favourite resting places. Some of the puparia were found under logs and some of the replete gravid females taken during the bush-pig incident (p. 337) were resting on the lower surface of fallen Uapaca sansibarica 
stems, under which the pigs had been lying. The ground (shale) was in two cases exceedingly hard and compact, but humus was present in the situations in which the pupae were found. There seemed to be no such localisation of the breeding centres as I found with morsitans.

\section{Glossina pallidipes.}

I have referred to the puparia of this species elsewhere (p. 346). They wer taken with those of $G$. morsitans and under the same logs, but in very small numbers indeed. None were found west of the Sitatongas.

\section{Glossina austeni.}

I have already given some details of this species (p. 348). The very distinctive puparia were all under four logs. One, more or less rotten-with only two puparia-was beside a game path used by bushbucks and waterbucks. Another with 30, showed many blue duiker "forms" about it, but these were too recent ; leaf-carpet does not preserve traces well. The third, with 23 puparia, was also in dense shade and exactly at the junction of the primary-type forest and some heavy Markhamia bush (mubfeya). Right up to the log, in the latter bush, were the old tramplings and lying places of elephants. A similar log in similar shade lay 18 rards away; it was away from the tramplings, etc., and covered no puparia. The fourth $\log$ is described sufficiently elsewhere (p. 349).

\section{Resting Surfaces.}

XV.-NeT EXPERIMENTS.

When studying morsitans, and, later brevipalpis, I erected (Pl. xv, fig. 2) a large mosquito net, 9 feet high, over cut-back tree-trunks, shrubs, etc., and furnished it with stems having different kinds of bark, stones, etc., in order to study the resting habits of the flies. These I turned into the net in some numbers-well over a hundred in the case of brevipalpis. Some pallidipes were also included in each experiment, and each was continued for from three to four days. None of the three species used confined themselves to the few feet next the ground; they settled, colour conditions being correct, up to the full height available. I have noticed unconfined morsitans resting up to at least six feet from the ground.

The rough-barked stems were selected in preference to the smooth, and large and small holes in the trunk and grooves in the bark were freely utilised for hiding in. A completely smooth-barked trunk was entirely neglected. Diplorhynchus mossambicensis was a favourite with the large tsetse, and a distinct colour-harmonisation took place also, the blacker tsetses (morsitans) choosing blacker bark, the greyer grey bark, the brown ones (brevipalpis) brown bark and the underside of rough or knobby lianas, on which they easily passed as one of the knobs.

For the morsitans experiment, in pyrophytic wooding in which the trees always show, on one side especially, blackening by the grass fires, the Diplorhynchus trunks were specially selected on account of the strong contrast between the colours of their two sides. Shade conditions were about equal (as the result of overhead shade) and, the position of the branch being also suitable, the female flies in particular always tended on settling to select the blackened side. On this side, furthermore, they settled chiefly where the black of the raised cork ridges alternated with pale 
brown grooves and this was at 3-4 feet from the ground. Below this area the bark was uniformly black, above it rather more uniformly pale ind uncharred. The females also settled, the colours being right, mainly on the lower side of a branch or log, the males settling as frequently on the upper sides. A raised stone and clods of earth were also used for resting under in the brevipalpis experimint. Leaves and thin twigs were used by active, not resting flies; these flies were readily disturbed. The majority of the brevipalpis remained quiet during the heat of the day, but began to move freely and to buzz against the gauze at sunset. It was then chiefly that this fly, including its females, settled appreciably on non-protective surfaces-leaves and twigs, etc. Those definitely at rest on protective surfaces on the other hand, or in holes, were hard to flush, some (females, and particularly more or less gravid or replete females) even allowing me to tap on the bark beside them. The excellence of their concealment was shown when I finally cleared the net. Both $\mathrm{I}$ and two smart natives searched every inch of its contents most thoroughly, as we thought, until we could not find another fly. I then passed my hand over the various surfaces and in this way flushed four more flies, all femeles, from the Diplorhynchus trunk. It would seem that Bagshawe's suggestion-that fly does not haunt shady papyrus on account of the contrast in coloration-may well be correct.

A certain number of flies were generally to be found on the net and restless ; these were always males. When the net was cleared and the flies examined one by one this observation was fully confirmed. The hiding flies were mostly, but by no means entirely, females. From my observations in the field also, it seemed lear that in Glossina, as in so many other animals, the female trusts mainly to concealment for defence against enemies, the male more largely to activity, and that the difference in the requirements of the sexes and their methods of meeting them is the chief reason for the female's special seclusion, though Lamborn's factor (avoidance of males) may be operative also. The smallness of the meals usually taken by the males in the field-commonly mere snacks-bore a relation no doubt to their need for activity ; not so much to relation to enemies, for the male flies were quite capable of hiding, if necessary, but in relation to tre velling and the capture of females. It seems certain also that the males need for food must be far smaller than that of the female. The results generally suggested the consideration of a contributory method of fighting the fly which I shall refer to below (p. 379).

\section{Distance of Attack.}

Another point tested was the distance from which brevipalpis and pallidipes will attack passing animals. It was undertaken at the end of my stay and I was unlucky in the matter of wind, light variable airs prevailing during the main experiment. However, rushes to the side of the net next the cattle occurred at 6 and 8 yards distance, and once, just before sunrise, at 18 yards, the shrub growth that blocked the view on this occasion showing clearly that it was a matter of scent. When the net was to windward of the cattle no general excitement took place, though a very few flies might fly towards them. The short distance from which attacks by brevipalpis took place in the sunny hours was illustrated in my clearing 
experiments also. If I was right in believing that in the experiment on the Inyamarimu (described fully on p. 373) the individuals of pallidipes that attacked the cattle did so from outside the clearing, the small number that came to the cattle compared with the considerable number of these flies outside suggested that about 30 yards may be the extreme limit of this fly's attack under favourable conditions.

A live goat tied inside the net attracted little attention. The flies bit occasionally, but allowed themselves to be driven off easily, and none fed to anything like repletion, yet the two oxen, when brought close up to windward, always attracted a great rush, even on the part of females that had been resting quietly on protective bark surfaces and had not been in the least attracted by the goat. I should say that I was myself much more readily attacked in the net than the goat. The liver of a cow was also not specially attractive.

\section{XVI.-Natural Enemies.}

During my first week at the Kanyezi vlei I was camped 150 yards or rather more from a considerable cluster of male flies. These were preyed on daily,* sometimes continuously and for a long time, by half a dozen to eight birds belonging to three species-Dicrurus afer (African drongo), Bradyornis ater (mimetic fly-catcher) and Bradyornis murinus (mouse-coloured fly-catcher). From the continuous nature of the attacks, and the immense number of house-flies (Musca domestica) that tame drongos of my own have shown themselves capable of devouring in a very short time, there could be very little doubt that the birds were making considerable inroads into the male fly population, and it was likely that the practical disappearance sometimes of this cluster was in part due to them. The birds perched on the low trees bordering the vlei and dropped to the tsetses in the grass below.

In my general experiments I found that many birds disliked Muscid flies, including Stomoxys, replete or empty (actual Glossina not tested), but that drongos, flycatchers, stonechats, swallows, bee-eaters and some commoner small searching birds (Crateropus, Phyllastrephus, Apalis) liked them much; drongos and swallows (certainly also fly-catchers) continued to feed on them when so replete as to refuse all non-Dipterous insects. The digestion in at least two of these last three groups is so rapid that (in my experiments) even when the birds were replete three or four minutes' rest made room for two or three or more flies. These birds must be relatively formidable enemies to a fly the males of which display themselves so freely, and it is a pity that the population of such enemies must be limited by the dry season food supply. I have sometimes seen swallows hawking continually after insects on grass-stems and grass-blades, picking them off while flying, so that male morsitans is a likely enough object for attack by these birds. Birds are in the habit of paying special attention to insects, otherwise acceptable, that are present in numbers together, so that in localities in which male morsitans is being kept scattered by the presence of much game it must lose a far smaller proportion of its population through the attacks of birds.

* The presence of the birds at this spot was noted practically daily ; they were only continuously watched on about two days. 
Crateropus kirki (Kirk's babbler) and the two guinea-fowls, Gutlerce edouarli (crested) and Numida mitrata (East African), were observed once or twice (out of many times) scratching in positions like those in which tsetses deposit their larvae, as was also the bristle-necked bulbul (Phyllastrephus capensis).* A more interesting observation was made on an elephant shrew (presumably Petrodromys tetradactylus) in a dry but shady donga entering the Buzi at the south end of the Sitatongas. We had searched for and found puparia (austeni) under a large fallen tree and, going on to search under other logs and stones, found we had been anticipated by a small animal. For a distance of 47 paces along the donga every hiding place that would have been used by tsetse had had the surface soil scratched out and the spoor and the droppings were, I should say (and the natives also were certain), distinctly those of one of these elephant shrews. I have actually watched the above elephant shrew in the wild state scratching thus for slightly buried insects and, having kept individuals in captivity, am tamiliar with their droppings, etc.

The natives stated that ox-peckers (Buphaga) regularly prey on tsetses that are feeding on game animals, and that from the movements of the birds it is obvious that the flies employ against them the sidelong movements I have referred to in relation to attack by knife and assegai. The flies also no doubt continually come within the ken of the birds that carefully search tree-trunks and twigs, and it is no doubt in relation to these that their choice of protective resting surfaces is of use. Such birds form a very large proportion indeed of our small bird population.

Spiders of various bark-haunting species that hide in crannies and leap on their prey accounted for a number of the flies I had under observation in the net, and it is probable that these are the female tsetse's most important enemy. One tsetse (morsitans) was seen caught in the net of a web-making spider. Dragonflies on several occasicns in fly country inspected the backs and necks of my companions. A wasp once did the same. On one occasion, travelling from the Buzi to the Mtshanedzi, five brevipalpis were under the cattle, four being under the leading ox. We ran into some dragonflies, which at once began passing to and fro immediately under the belly of that ox. I saw no captures, but these four brevipalpis had disappeared when the dragonflies left us. The one survivor travelled with us for over one and a half hours and remained about our camp for long afterwards. Dragonflies were exceptionally and extraordinarily numerous in 1918, but the tsetse population remained large. I do not remember seeing any AsILIDaE. They only become abundant here in October.

\section{XVII.-TSETSE CONCENTratrons.}

Iy closer observations on this subject, which may be of high practical importance, were limited to a single morsitans centre, but I searched and studied much country in which there was no concentration, both before and after the commencement of leaf-fall, and secured much native information also. I obtained, I believe, a fairly clear idea of the conditions obtaining in this particular fly-area. I spent a fortnight in all at the Kanyezi fly-centre. This was a large and very definite breeding

* The existence of soft pockets of earth, breaking the harder crust under most of the logs examined, constitutes indirect evidence also of the scratching of some animal or animals in these places. 
concentration in country relatively devoid of the fly. Secondly, my native expedition reported coming across several such concentrations north of the Lusitu, with the same male crowds at the edges of similar vleis, the same ease in finding puparia and the same relative dearth of tsetses in the similar country between. They brought me both morsitans and pallidipes and puparia of the former. Thirdly, the Masando vleis and some vleis east of the Mapapa (see Map) were both stated by the local natives to be the sites of concentrations, how great I do not know, and to have been so in the present season. I had myself found a concentration at the Masando in 1900 , but in 1918 we found the flies on the grass of the vlei-edges only in parties of three or four-as at Kanyezi's, when a male crowd had been dispersed. Buffalos and elands were present in small parties. We were led to the more easterly vleis by a native (subsequently in my service and apparently reliable), who stated that he had seen the flies there in great numbers only a week or two before. I had no cattle with me and only two flies were taken, but a large herd of buffalos had arrived meantime. These two sets of vleis and Kanyezi's are all within a very few miles of each other.

\section{Leaf-fall Concentrations.}

When I left Kanyezi's on 1st Angsut it seemed likely on the whole, though uncertain, that this scattered, unconcentrated fly was even somewhat sparser than it had been in June. The few that the cattle picked up on that particular day were at vleis or glades-not that this was unusual. Natives on the Umvuazi River had reported an increase in the flies about their villages, and one way in which the insects might travel thither appeared to be illustrated by the fact that the flies that were attaching themselves to us left us (one of them after following for $5 \frac{1}{2}$ miles), not in the rather barer bush, but on our reaching the somewhat shadier wooding beside streams. The natives stated that this tendency to collect at the streams becomes more marked rather later, but not (Kanyezi said-and I think we saw) at the expense of the vlei population, which also increases.

The natives attributed the streamward movement of the fly in the later dry season to the fact that the general drying up of the country forces the game thither. "The int-hesi then congregates there to feed on the game." While this explanation is not quite accurate, it is certainly to be judged from what I have said above that game, or natives, either going to the streams or merely travelling across them, will tend to deposit there at this time any flies that they may have picked up either in the drying-up country generally or at vleis, etc. These leaf-fall (and soil-moisture?) concentrations, whatever they may amount to here, are evidently to be distinguished from the more permanent breeding centres, although these also will doubtless receive accessions from outside at this time.

\section{Primary Concentrations.}

- That the concentration of the fly in the last-named centres is not purely the result of dry season concentrations there of the game seemed certain. There was no conceniration whatever of the game at Kanyezi's vleis, where I stayed a fortnight in all and at which fly was plentiful and breeding, nor had there been since the rains. There was even less of a concentration at the Masando in June 1900, when I found 
tsetses there in great numbers and very troublesome, but could find nothing to shoot. The concentration (in this case merely the arrival of a large herd of buffalos) at the more easterly Mapapa vleis in 1918 took place when the flies were (according to the natives) already abundant there, and the small parties of buffalos that were apparently keeping down the numbers of the visible fly at the Masando in 1918 could hardly be described as a concentration. It was certain from the detailed distribution of the large number of muddy puparia taken at Kanyezi's vleis that the fly concentration was already in being here in the late rains, when also a great buffalo herd was temporarily present; and as my flies and pupae were indubitably largely the descendants of the depositors of these puparia, it might be said that fly concentration found in the dry season may be the result of game concentration either then or previously. Even this (as accounting for the presence of a fly centre, apart from the mere question of its population) was negatived by the native statement that this fly concentration is permanent though variable in numbers, that it had been there before the buffalos came (as it had also survived their departure), and that the animals had stayed a very few days only. In testimony to the great size of this herd my guide, Kanyezi, who lives near and had seen them, pointed out strong paths that had been beaten out and vleis that had been heavily pitted with spoor in a single day. The natives said that the other centres seen or heard of by me were also present each dry season, though again with a varying population. The conclusions that I would draw from all I saw and heard, including the fact that away from these centres we failed to find any but very stray pupae, even when buffalos and other game had been abundantly present, are that what Shircore has called "primary centres" undoubtedly exist; that their actual (not their apparent) population no doubt varies with the immediately preceding food supply; and that in their situation beside vleis they have hit off the best obtainable combination of the three desiderata of food, moisture and shade (for vleis, generally speaking, and their neighbourhood are attractive to game and other animals, and the wooding bordering them is quickly back in laaf). It is even possible (in an area in which morsitans happens to be dependent on the larger mammals) that a kind of selection is continually taking place by which those vleis that for any reason have become neglected by the game for a considerable period cease to be fly centres. It was certainly strange that Gundoda's vleis, well watered, midway between Kanyezi's and the Masando and quite near each, and in the same wooding, uncleared, but carrying a human population and a more permanent shortage of game therefore than the others, should have been shown by fairly exhaustive examination to be practically devoid of pupae and to have produced few flies. Some of these few, latterly, were marked flies released by me in the Kanyezi vleis, and it is likely that the great number of flies said to be at Gundoda's in the rains come first from this and other vlei series.

\section{Village Concentrations.}

A concentration of another kind than the two referred to above, and presumably one of a very shifting nature, is that which appears to take place at native villages, even in the rains, and particularly whenever the fly is abundant. Gundoda (whose village, besides affording good shade and being situated at the edge of a well-watered vlei, is a tempting dismounting-place for $\mathrm{fly}$ ) Pdescribed to me well how in the 
spring and early rains, as they would be sitting in the shade by the water, attended it might be at first by a merely reasonable number of tsetse, every newcomer or passer-by would bring with him an accession of flies till their numbers became unbearable. Some would go again with departures, more would stay, and they tended to increase in numbers from day to day. At that time every one, sitting or travelling, carries a leafy switch and uses it incessantly. The probability that the great majority of the flies of these village concentrations are males was suggested further by my failure to find puparia at Gundoda's.

\section{Leaf-fall in relation to Concentration.}

It would seem that in one of the three forms of concentration I have referred to, leaf-fall must be a highly important factor. That there are other factors producing concentration is however certain; for on my first arrival in the morsitans country in June, concentration at the vlei centres was already in full operation, yet leaf-fall (the season being late) was not yet noticeable. The same would apply to my visit at the end of May and beginning of June in 1900, when also high concentration was present. When I left on 1st August 1918, leaf-fall was in many places producing a visible effect, and it is possible that this may have brought about the apparent increase in the numbers of pallidipes at the Kanyezi morsitans centre. Otherwise things had not. to all appearance, been so very different in June from what they were in August, Whatever the factors that bring about these "primary" concentrations, the possibility is suggested that measures against them might, not have to be confined to the very brief period of maximum leaf-fall. All would really depend on the value of the "scattered" fly for the local survival of the species, and $I$ am inclined for the moment to suspect that this may be greater in the case of pallidipes-everywhere seemingly a rather scattered fly-than in that of morsitans.

The Kanyezi centre was certainly, to judge from its puparia, a focus of morsitans rather than pallidipes, and it is conceivable that these primary centres may be a vital point in this fly's social organisation.

The rural population of brevipalpis, as I saw it, was much heavier and more evenly distributed than that of morsitans and therefore less easily distinguished from its rather more populated patches, in the primary thickets. In a less generally suitable area (such as the granite-gneiss actually is) or in a season (if such occurs) which really stripped the Brachystegia wooding of the "Oblong," it would doubtless undergo leaf-fall concentration.

\section{XVIII.-The Recent Outbreaks of Nagana in Mossurise.}

The fly, driven from a large piece of deciduously wooded country by Umzila's measures, never greatly abandoned its permanent haunts except on the Sabi and in the cleared portion of Gogoyo's, the Mwangezi, etc., and within 7 or 8 years after the relaxation of the measures in 1889 it was found re-occupying its old (and its present) wet season quarters in so far as bush conditions and travelling facilities then allowed. Since then, within my own observation, the wooding of the heavily deciduous areas hes increased greatly, and areas close to the British border that 
18 years ago were relatively bare are now very fully wooded and capable of giving a temporary support to tsetse.

Up to a very few years ago cattle were still kept successfully in Mossurise within a few miles of the British border from the Puizisi to Maruma, and from Spungabera to the Inyamgamba. These, except the Spungabera cattle, which have suffered, have been largely wiped out by successive attacks of nagana, especially during the last three years. At the same time isolated outbreaks, here and there, have taken place on farms just on the British side of the border. In a remarkable proportion of cases a connection has appeared to exist between the outbreak and the wanderings of buffalo.

The incursions of buffalo into the cattle-carrying areas have undoubtedly increased greatly in the years concerned. The northern outbreaks coincided with or followed the invasion of Mafusi's country by considerable numbers of buffalos from the south and their coming in contact with the brevipalpis-pallidipes area there. In the section opposite Spungabera (across the Buzi) these animals are certainly far more in evidence, and in far larger numbers, than they were some years ago, as I know from shooting trips on the Upper Mtshanedzi in 1901 and 1902.

Elands have also greatly increased, as have pigs; and it is likely enough that the fly itself has increased within its permanent haunts in consequence of the great and progressive increase in its food, and of the earlier burning of the grass. This would contribute to the menace, and it is by no means incompatible with the fact, of which I am convinced, that such destruction of the big game as might be easily feasible would not alter the fly's permanent boundaries, though it would certainly prevent it from being carried into contact with the cattle.

The great increase in the wandering game has undoubtedly been the main factor in the outbreaks of the past few years. But it may be said that it is especially hard to distinguish the separate original infections where natives' cattle are concerned, owing to the likelihood of infection by mechanical transmission by other biting flies that is incurred through their placing the survivors in the herds of their neighbours, and by their movements of cattle in connection with their matrimonial affairs.

\section{XiX.-Clearing Experiments.}

These were carried out only to ascertain the effect on the fly of the clearing of undergrowth (Pl. xvi).

Experiment 1. To ascertain the effect of clearing the undergrouth in primary forest. The whole width of the dense undergrowth of the Inyamarimu forest strip was cleared to a length of 80 yards. The width varied from 40 to 70 yards. It was incidentally open to penetration and passage from the sides by any flies there might be in the Brachystegia-Uapaca bush on either side of it. At 11.30 on the following day the two oxen were driven into the middle of the clearing. They carried in with them one fly, a male brevipalpis picked up in passing near some of the uncleared bush, and this was at once removed. They were stood in the centre of the clearing and from time to time moved across it a little though not to its edges. They had been placed many times before in this spot and had never failed to be attacked by large numbers of brevipalpis. This time in three hours only four came to them. 
G. pallidipes and Tabanus had never before been noted on them in this dense wooding, though they occurred in the bush outside. Yet in these three hours nine pallidipes (all but one females) and 31 Tabanus were taken on them.

I then turned the two oxen just into the uncleared undergrowth alongside and they were at once attacked by brevipalpis. My collector captured 15 on one of them here in fifteen minutes and no pallidipes or Tabanus were seen at all.

The effect of clearing the undergrowth alone in banishing the big fly was, I think, well demonstrated. It is perhaps more likely that the other flies were attracted to the cattle from the bush outside than that they had taken up their abode in the forest as the result of the clearing of the undergrowth. This would suggest that attacks of pallidipes in the sunny hours are undertaken from a greater distance than those of brevipalpis, being equivalent rather to the latter fly's evening attacks.

Experiment 2. To ascertain the width of undergrowth clearing necessary to protect a strip of road from attacks by brevipalpis in sunny weather. In Brachystegia bush on the Buzi, the cattle in passing along a certain track four times in all had on each occasion been attacked by brevipalpis all the way along from the thickets passed closely or passed through. I cleared the dangerous undergrowth, but none of the overwood, for a paced length of one mile and a width of 25 to 40 yards with the track in the middle. I left three small points not fully cleared-some small Diplorhynchus trees with low-hanging branches and Bauhinia, a small primary-type thicket, and a piece of uncleared sapling growth. I put the cattle through and they were attacked at the first two of these places-nowhere else at all. I brought them back just outside the clearing and they got flies all the way. In the afternoon, having cleared these spots, I put them through again, bringing them back this time along the track. They got no flies at all either way until driven out beyond the cleared strip at each end. They were then each time attacked at once.

It was to be expected that this narrow clearing would be of use only in sunny weather and this point was tested later on an overcast day. The cattle were driven along the cleared mile and 32 brevipalpis were taken at them, coming in all the way along. They still failed to be attacked here in sunny weather.

Obviously then, very little clearing is needed to safeguard a given piece of road from this fly, provided that the cattle pass along it in sunshine. A considerably wider clearing would be needed to render it safe at all hours and in all weathers.

Clearing by Arsenite of Soda. I had previously carried out successful experiments in poisoning with arsenite epiphytic figs in forest on my own property. This suggested its use in clearing for tsetse, for the difficulty in ordinary axe-clearing is that the stumps at once (and repeatedly) send up fresh growths and form coppice that is even more suitable for the fly than the growth cleared. A recent examination of some of my experiments shows that the strength of an ounce of arsenite to a pint of water (the maximum strength tried) is insufficient to be generally effective, though it killed some trees and inflicted damage on many others that may enable the fires to burn them out. I hope shortly to be in a position to state the best strength for this sort of work. Given this and the amount of liquid required per acre for particular kinds of bush, one can estimate very rough'y the cost of this kind of clearing. 
Mere ring-barking - with an upward-pointing frill-is required instead of cutting down and this will economise part of the extra cost of the arsenite.*

The balance of extra expense will doubtless in particular cases be justified by the fact that the work will not have to be repeated, but it will be seen that where great areas of dense undergrowth are concerned this will be considerable. Naturally cattle should not be run where arsenic has been used in the last few months.

\section{XX.-Measures for the Control of Tsetses in Mossurise.}

The parts of the Mossurise district which are more especially suited to white settlement are the two dolerite areas ( $a$ ) that between the Lusitu and the Mtshanedzi, and $(b)$ the Gwenzi country from Spungabera to Mount Singunu. These areas would split up into a very great number of 1,000 hectare farms, practically all good. The soil is for the most part rich and particularly adapted to Arabian coffee (a good close settlement product, if the labour should be sufficient), the natives raise fine crops even when crops are more or less of a failure elsewhere, the rainfall is considerable and reliable, and a good deal of local labour is available; the grazing throughout is good and the grass early. It was pitiable to see my bait-cattle being followed for miles like a circus by the children of some of the villages we passed in a country that should be carrying its thousands of head. There are good permanent streams everywhere.

If there should be an unwillingness to sacrifice the Mafusi rubber forests--which will always carry fly and be a menace - there might still be a large number of farms in the remaining area. If the outlet to a market is not through British territory, there is, for produce, the Lusitu-Buzi waterway investigated by Snr. Roma Machado and capable of being opened as part of the settlement scheme. The eventual creation of a safe winter route for cattle along the south of the Buzi is also not improbable. $\dagger$

The Umzila results, already described, show clearly-and it cannot be too much emphasised-that settlement properly planned will protect itself. As settlement is bound to be the eventual policy, no matter how long deferred, it cannot be said that the ultimate future of the more delectable of the Mozambique Company's infested areas is necessarily seriously compromised by the presence in them now of fly. Umzila's results even suggest that some day in the very far distant future the question will be settled by the natural increase of the now protected native population. "Properly planned" settlement in fly will not consist in the giving out of isolated farms, scattered over the face of the country. The failure to keep cattle at the Dysart Concession is a case in point.

There must be a definitely planned settlement scheme, affecting a large block of country together, on some sound agricultural basis. The closer the settlement can feasibly be the better, and first and foremost amongst the conditions of occupation must stand the effective clearing of the less freely deciduous types of woodland.

* I have tried boring, both by auger and by down-slanting strokes with a narrow native axe, but find that this leaves unaffected areas of bark between the holes and kills only particular branches, the poison (as might bo expécted) taking effect in a verticial, not horizontal direction.

† Later information suggests that the Sabi even now offers a safe route. 
These will be inferred sufficiently from what I have said in this report, but I will add here that in the piece of country in question, along the streams and rivers and in larger blocks on the Lusitu, first-class timber trees-mahogany (Khaya), musando, mowana (Adina) and others-are present in quite unusual numbers. These, floated down the Lusitu, might in some cases help much to defray the cost of clearing.

Secondly, no ingress of large game must be allowed from areas still under fly. The best barrier - with the elephants away - might be a strong, patrolled fence; but if the fringes of the area are sufficiently closely settled it is likely, even from our present imperfect success on the lightly settled border, that this fact alone, with shooting, will suffice to keep off the elephants, buffalos and elands. It is these three animals that probably chiefly matter.

Umzila's principle-the settling and clearing of the low-lying guard-area only, the enclosed hill mass then taking care of itself and being perhaps disposed of later at an enhanced value-would be well worth consideration and investigation. Under such a scheme, carried out with thoroughness, it seems at present fairly certain that cattle could, after a few years, be kept safely and in numbers on the dolerite.

If, on the other hand, the settlement should have to be a gradual growth from small beginnings, its safest base would be the deciduous part of the British border, a block at a time being settled and special measures being taken against the buffalos.

The settlement of the two permanent fly-areas themselves would mean the end of the menace. The great strip on the Lusitu that is now occupied by rubber forest, both east and west of the river's southward turn, represents some of the finest agricultural ground in the country and is in immediate touch with the Lusitu-Buzi waterway. Much clearing is necessary, but the farms here could be small. The "Oblong" offers greater difficulty. The soils on the whole are distinctly useful, though less rich than in the other brevipalpis-area, but there is relatively little permanently running water away from the big rivers. Pools, however, persist in most cases and water should be obtained in this formation at no great depths by boring and sinking.

\section{XXI.-Discussion of General Methods of Tsetse Control.}

\section{Game Destruction.}

In view of the evidence I have already alluded to (p. 336 and elsewhere) we are bound to keep an open mind with regard to the possibility that even $G$. morsitans might survive the destruction of all large mammalian life. Yet the fact that under present conditions game-paths are the regular rendezvous of the sexes, and that the connection with game appears generally to be an essential point in their rather complicated social scheme, makes one hesitate to reject the alternative view: Lamborn (Bull. Ent. Res. vii, 1916, p. 37) has argued well for the view that it need not be a large game population that will support $f y$, and this might be a sufficient explanation of Umzila's continued trouble in the rubber forests.

In a relatively clean-stemmed area like that on the granite-gneiss, in which also bush-pigs are not over-abundant, it is to me very conceivable that wholesale game destruction might banish the fly. An obstacle, however, would be that the wbole territory is one vast game area, so that the game would pour again into a given section of it as soon as the persecution was relaxed-unless an effective barrier 
were created such as could probably only be made a permanency with settlement behind it. Whether the returning game would bring fly in again would depend on (1) whether the whole continuous fly area had been cleared of fly, or (2) whether the portion cleared had been split off from the uncleared portion by an effective barrier against the fly itself.

West of the Sitatongas the country is much more jungly, and wholesale game destruction is proportionately more difficult. In addition this country abounds in bush-pigs, which are difficult to destroy and which in anything approaching their present numbers can probably alone support the fly, with baboons, abundant cane-rats and other animals which may all contribute to its sustenance. I consider that it will be impossible to starve the fly at all generally by ordinary game destruction here, at any rate before the country is very fully settled, though buffalos and elephants might be banished by adequate and persistent shooting.

What can be done is to protect particular places, like Spungabera and the British border, that are outside the fly and are threatened only by the wanderings thence of the bigger game. Fencing, the judicious placing of native kraals and shooting are amongst the possible measures, and organised and repeated drives might be undertaken locally. I have suggested similar means of keeping the fly from being carried into any areas that may in the future be settled.

Again ( $c f . p$. 355) it seems to me that game destruction should check the advance of a fly-belt, whatever its effects on the ground already infested. No problems are at present better worthy of study than these-(1) the extent to which tsetses will travel independently of game, and (2) the distances that the female will travel on game.

\section{An Attack on the Concentrations.}

At first sight, the weak point of morsitans in the area in which I have seen it would appear to lie in its most striking attachment to the vicinity of more or less moist spots and in the great numbers in which it breeds there. One is strongly tempted thereby to suggest that for areas in which this is the rule further experimentation should be carried out on these distributing, and probably receiving, centres; experiments in local clearing of varying widths, in planting vleis and their margins with the heavy wooding avojded by morsitans,* poisoning and gassing the male clusters (torpid on dewy mornings) and the bush just immediately adjacent, catching with the aid of cattle, pupa-destroying or any other methods against either sex or either stage however remotely promising, suggest themselves as worthy of trial before the idea of attacking morsitans at its concentrations is finally given up.

The essential point to ascertain, however, supposing such measures to be capable of exterminating the fly at the concentrations, is the value or otherwise of the "stray" flies (which comprise both sexes) for the survival of the species, and whether these would continue indefinitely to escape the measures applied at the centresalways supposing that, in the area concerned, they are not and cannot be driven in

* To check radiation, introduce shade conditious inimical to the fly and spoil the game's early grazing, also if the trees that succeeded were of a definitely " drying " type, like Eucalypts, to help to dry the ground. Such a measure, even if locally succesiful, would luubtless be too expensive to use except under special circumstances. 
completely by leaf-fals or simultaneous burning. It would be difficult to ascertain their value until one had already successfully applied the local measures.

There are other difficulties also to be faced in dealing with the individual centres. Their probable large number in a given area-though in the area visited they occupied only a small number of the places that appeared suited to them-gives rise to difficulties (1) in relation to finding them all, (2) in relation to the number of white workers that it might be necessary to employ when simultaneity seemed important and time short, as in work that might be planned against the emerged flies. Here the period.when emergence is already rapid, but the fly not yet greatly scattered, might be of special importance. There is also the fact that the game must first be banished from each centre before the flies will present themselves for treatment in anything approaching their full numbers.

Broader lines of work are undoubtedly preferable if any should be found effective, and it will be most interesting to see the result of the Southern Rhodesian Government's present measures against morsitans, planned, as I understand they are, on game removal and large measures of bush destruction.

To discuss one or two of the points, nevertheless, it may be said that the great reinforcement of the visible fly sometimes called out by the presence of my cattle showed that ordinary collecting by hand is a very inadequate method, especially with game about. Collecting round cattle would be far better, but their length of life under continual attack is a point to be considered in relation to the financial feasibility of the scheme. It might well be prolonged by antimony injections, but would otherwise (to judge from my experience) be a matter of a very few weeks indeed. Better still would it be if the flies coming to the cattle could be automatically poisoned. The effect of frequent arsenical spraying, although it seems quite unlikely to be useful. might be tested experimentally, for it has not been my experience that a tsetse keeps its proboscis buried to the bulb all the time it is feeding, and a possibility I have referred to elsewhere (p. 341) might also be worth a trial.

If the breeding concentration seen by me at the Kanyezi centre should be typical, it suggests that in areas where such concentrations are the rule it might be possible to devise useful measures against puparia. Artificial breeding places, unless scattered nearly as freely as the present fallen logs, though with a regularity that would make them more easily found, would not, I think, be useful ; for my indirect evidence all pointed to the probability that the heavily pregnant female does not fly many yards from where she last fed.

The present situation at Gundoda's vleis suggests that the placing of Kafir villages at the fly-centres might break these up through the effect on the game, but with so many apparently eligible sites vacant the concentrations would presumably reform elsewhere. This measure alone would only be useful if it were possible to plant a population at such places through the area generally.

So far as $G$. brevipalpis is concerned, the observations spoken of on p. 351 would require to be greatly added to before we could assume that this fly's permanent boundary could be put back merely by the splitting up of the bush on its western margin. The point is worth looking into further. In any case the game would require to be destroyed or excluded in order that the fly might not be carried back in the rains. 


\section{Assistance to Natural Enemies.}

Natives destroy great numbers of birds, in both the adult and nestling stages, but I fear it would be impossible to make protection effective. It perhaps matters less here, as the native population is in parts not great and in the "Oblong" it is almost non-existent. The same difficulty applies to elephant-shrews which are greatly trapped. It is a pity that these useful animals cannot be protected, the more so as they are put to death in a peculiarly cruel manner.

Rewards for the skulls of small carnivora brought in might be useful in better populated fly areas, probably not here. There would in any case be a doubt whether the natives, who trap freely for these animals already as articles of food, could be stimulated very much more by a prospective reward. The greatest enemies of nestling birds here are the tree-snakes (Dispholidus) and probably the only effective remedy against these lies in severer fires.

Indirect assistance to birds would take the form of destroying trees, etc., the bark of which is specially protective to the tsetses. This method is inapplicable to morsitans and pallidipes because so large a proportion of the trees in Brachystegia bush have suitable bark, grey and somewhat charred, that wholesale clearing would be necessary. In a brevipalpis area the destruction of Diplorhynchus mossambicensis and all rough barked lianas would probably be distinctly useful and should form an essential part of any hand-clearing scheme; not but what other species I could specify are of probable use to this fly in varying but usually less degree.

\section{Protection of Stock and Riding Animals passing through Fly.}

I have already described my clearing in this connection (p. 374). In addition I found that very frequently the animals were not attacked if the carriers were walking immediately ahead of them, without an interval. I sometimes walked at the head of the carriers myself and then noted flies (brevipalpis) coming out to me and turning back-rejection, evidently, after inspection.

Again, when I divided the cattle into two lots (two in front, one after an interval behind-I never had more than three) I found that the first lot drew off all the fly, the last animal commonly getting none.

In the following experiment both these principles were called in. I wished to protect a donkey in passing through the heavily infested three mile strip following the Inyamarimu. I placed two oxen in front; the four goats followed them at from forty to eighty yards behind ; then (just behind) came myself and a native, then the donkey with its rider, a native walking in each side of it and one behind; next, at some distance, came a cow. The oxen both carried fly all the way and were sometimes assailed by many ; the goats' driver captured a brevipalpis on himself, but the goats escaped entirely; one only came to the cow. On emerging from the dangerous bush, the oxen were turned sharply into the grass and took their flies with them; the other animals, which now passed ahead, getting none. The control experiment, if such were needed, had been provided two days before when, on the same path, the donkey was sent on a detour to avoid a bad bit of forest. It ran into a thicket and sustained quite an attack and had to be brought back behind the cattle.

This suggests that a mob of cattle might be protected in travelling by placing the less valuable animals a little ahead. Naturally a mob of cattle is a bigger mark 
than my animal or animals that marched second, but that relative and perhaps nearly complete protection would be afforded I am convinced.

I have heard it stated at second hand from a man who had had some experience of running cattle through fly that it was chiefly the outside animals of a mob that were attacked. It may be possible to prevent even this.

I failed to carry out any experiments in the matter of spraying or wiping animals with paraffin or other deterrent liquids, though it had been my intention to do so. Against brevipalpis the animals' lower surface should be sprayed.

When biting flies are abundant it is a common experience to have them attack the cattle at once on their emerging from an arsenical dip. An internal tsetsefuge might, however, be experimented for and be used where the number of cattle was not too large for treatment. During our first epizootic of African Coast fever, in 1900, when I was already losing stock seriously, I tried dosing the surviving cattle each morning with a double handful each of garlic, crushed and given in a bottle of wateras we had then no dipping tanks. I am inclined to attribute the fact that $I$ saved a much larger percentage of our small herd than did any of our neighbours (who lost nearly everything) in part to the deterrent effect of the garlic on the ticks. I do not know its effect in relation to biting flies, but it might be tested, and if it were successful, garlic-eating might become a useful if obnoxious habit in sleepingsickness areas.

\section{Clearing Measures.}

(1). Clearing by cutting doun. Where not followed up, the good effect of this measure must be very transient, for the stumps quickly produce coppice of a type that is specially liked by pallidipes ( $\mathrm{Pl}$. , fig. 46)-or, under shade, by brevipalpis. Where, on the other hand, clearing by cutting down is followed by very late annual burning, its effect, very generally speaking, is likely, when the grass is sufficient, to last as long as the late burning is kept up. It is said that a large proportion of Uapaca cut down during the rainy season does not grow again. I have no observation on this myself beyond the fact that Uapaca trees are more easily killed in native gardens by burning than are various other trees. The reaction of each of our commoner tree species to the cheaper methods of clearing would be worth ascertaining by special experiments.

(2). Clearing by arserite. Experiments that I carried out on pieces of wooding selected as representing an average of a type that was well infested with brevipalpis did not suggest that the clearing by arsenite of such continuous Brachystegia bush as fills the "Oblong" and runs north to the British border past Spungabera would necessarily run to a prohibitive figure for this class of work, though the full strength to be used remains uncertain. Naturally the clearing of great areas is in any case certain to be expensive.

Superintendence and transport of water, etc., have to be considered. While native police might superintend the actual working groups, general supervision by a European would be necessary both for the efficient organization of the water transport and of the work generally, and because it would be unsafe to leave large quantities of poison in the sole care of native police. The best effects from poisoning would probably be obtained when the sap is up, that is in the spring and summer. Water 
would doubtless give much difficulty in some localities in the spring months, but the country generally has water in streams or pools.

It will be gathered from this that poisoning offers certain difficulties in addition to its possible high cost. It could be put into effect most easily and cheaply round a settled station like Spungabera, where there are also mere patches of wooding to be dealt with ; but here the greatest care would have to be taken to keep all stock from treated areas until all possibility of their obtaining poisoned leaves had passed. The method would be still more useful to occupiers of farms under a settlement scheme in the fly, for cattle would not yet be present.

Killing by arsenite, followed by a course of late fires, should be exceedingly effective in removing woodland, and the finality of it, with the fact that it requires vastly less labour than the other radical method, stumping, would be worth the expenditure that a considerable increase in the strength of the poison might entail.

A local point to be remembered is that my observations were carried out in a year in which bush generally tended to carry leaf in the dry season better than usual owing to the heavy preceding rainy season. Brachystegia wooding has this tendency at all times, except when exposed to relatively rigorous conditions, but if it should be found later that in certain dry seasons the Brachystegia-dominated bush of the "Oblong" generally does become too leafless to harbour brevipalpis, the clearing of the ravine-type thickets might suffice-if at any time in the future the handclearing of this area comes to be considered.

(3). Clearing by judicious native settlement. The first lesson to be drawn from Umzila's results seams to be that we can make a seasonal fly-area safe by broadly (perhaps narrowly) clearing its margin and preventing passage of game.

In the permanent fly-area and portions of another permanent fly-area that he cleared of fly the result was brought about, apparently, mainly by bush destruction, though game also was greatly reduced.

It is perhaps a pity that the humane methods of the white man make difficult the wholesale transportation of populations for the elimination of tsetse areas, even in the interests of the population in question. Our methods would be less wasteful than Umzila's. We should begin with a close botanical and oecological study, and we could produce Umzila's result with a half, a quarter or an eighth of the force used by him.

On a small scale, with such an inducement to settle as the remission of their tax (meaning much to the native, and to the Government a great saving in the cost of clearing by other methods), the plan is still very feasible. When examining the Spungabera problem I was struck by the impression already made in a single season by the native Umgazaza on a piece of wooding that constitutes one of the special dangers of the place. With a few more Umgazazas settled here this piece of wooding would go-at a small cost to the Company. The soil to be cleared is rich, the natives would raise good crops, and they could dispose of their surplus grain a mile away at Spungabera. Other wooding on the Spungabera hill could be treated in the same way.

The pity is that the cultural operations of our natives do not include the taking out of tree-roots. If, however, they left all stumps standing-and they leave a 
very great many in any case- these, in secondary bush, could be treated with arsenite by the owners themselves under the supervision of police, who might be sent round with it for that purpose. This should render the clearing permanent-at a cost. Surviving primary-forest stumps are killed by the grass fires after the cessation of cultivation.

(4). Clearing by regulated burning. Of the probable good effect of this measure I can speak with an assurance that is based on nearly twenty years of interested observation and experiment; interested, because my own land has been in question, and I have had to study there the effect of early, late and no burning on pasture and afforestation respectively.

I have already (p. 325) contrasted the effect; of early and late burning on thicket and sapling growth. The following quotation is from a paper of mine, read in 1917 and published a year later, and written with no thought of tsetses in my mind.

"The fact is," I wrote (S.A. Journal Sc., June 1918, p. 16), "that land from which fire is excluded tends to go back to dense bush. Even the more open grass-veld here is full of stumps that seldom get further than a one season's shoot. The very fires that have rendered their existence on that ground possible, by driving the [primary] forest off it, keep them from growing up until, some year, a poor burn, it may be, or no burn, allows of a second season's growth being superadded to the first and gives a more fire-resisting bark to the latter. . . . Keep the fire from such a piece of ground-or burn too soon-for several years, and these shoots grow up and eventually in places become so dense as to reduce the grass and the severity of the fires and to allow semi-forest types as Markhamia lanata and Albizzia chirindensis to spring up amongst them, as I shall describe below, and eventually to replace them. The result [even] when this occurs so far from high forest as not to obtain seeds from it, is a form of dense thicket." On my own land Uapaca-Brachystegia areas burned regularly and more or less late have failed to develop appreciable undergrowth, while areas which, for winter grazing, have been burned irregularly and early, have developed it (Pl. xvii, fig. 2). The latter areas, which were clean-stemmed when I came here, would now carry G. brevipalpis; the former would not. Elsewhere in the irregularly burnt area new coppice wooding has sprung up in open ground from long suppressed underground stumps and roots and could already shelter pallidipes.

The converse statement-that late fires will destroy already existent growth-is true also. It is particularly true of a late fire following a year in which burning was omitted; and I have sometimes been much struck-the last instance was late in 1917-by the large size of the pyrophytic saplings that such a fire has killed down. On occasions even large pyrophytic trees are definitely killed by it, at any rate in such a season as 1913. Of the effect on primary-type thickets I have given an instance on p. 325 and have seen further instances myself.

With regard to the statement that late burning was a practice under the Zulu regime, I can say from personal observation that there was less wooding, and less undergrowth under existing wooding, in the Northern Mossurise district even when I lived and travelled in it from eighteen to nineteen years ago than there is now after a further period of unregulated burning. It is likely that this probable result of their late burnings contributed much to the Zulus' success, particularly of late, in 
the margins of the "Oblong," and it is unfortunate that such fires should necessarily have ceased at the very moment when whole districts of native gardens were abandoned to grow up into coppice growth.

The effect on reproduction of burning at a time when a large proportion of the trees are in flower must also not be overlooked. I wrote on 5th December 1906 on examining a late "burn" between Chibabava and Arucate and observing that the flower crop generally had been destroyed, "it will be interesting to note to what extent this late burning will effect the seeding, and consequent replacement of dead individuals." There can be little doubt that it will affect it considerably in the lower types of wooding.

Late burning is no emergency measure against fly. In some areas especially, where the grass is already well reduced, its full effects may take long to show. Again, its abandonment will mean the return of the old conditions, for the underground stumps and roots of pyrophytes are extraordinarily tenacious of life. It must be regarded as a piece of administrative policy and be kept up annually. That its adoption is necessary I am quite convinced, if only for the reason that the country generally is at present reverting more and more to wooding and becoming increasingly fitted for tsetse, even in those areas in which the cover has hitherto been sparse and light. The recommendation of the measure, in face of its having to be kept up indefinitely, must be that the fires take place in any case and that the annual cost of regulating them will be trivial. The latter may even be met by the fines imposed on unauthorised burners, and the actual burning, being done at a signal by the kraal natives themselves, will cost nothing.

A part from the prophylactic value of the measure just mentioned, its effect, grass conditions being equal (which they are not), should show first and chiefly in relation to G. brevipalpis and (in the area in which this fly depends mainly on coppice) pallidipes. It will not affect the grown pyrophytic trees in any wholesale manner (unless in a very exceptional season or unless they are weakened by ring-barking). Its effect in relation to morsitans might even be regarded as problematical, for that fly and pallidipes in the same wooding appear to be independent of undergrowth. The systematic burning back of smallish growth will assuredly tell as the established trees pass maturity and eventually go, with nothing to replace them, but the time involved will be long.

The objections that may occur should be discussed. One is that the loss of the wooding at springs may dry these up. Many of the springs rise already in open vleis, and wooding on damp ground (including big Khaya and Adina) is in any case not easy to destroy by burning, except occasionally in such a season as 1913. But better an occasional spring lost than a continuance of the tsetse; and the Zulu clearings, sufficient to remove the fly, do not seem to have caused any shortage of water. At worst, occasional lost spring-heads could be allowed to revert to wooding after the tsetse had been eliminated. The exposure of the ground to wash by burning shortly before the rains is not an effective objection, as it has been our experience here that the growth of spring-burned grass rapidly overtakes that of winter-burned grass, which itself affords little protection to the soil in October. Loss of, or damage to, the secondary wooding generally-unless of the very finest Albizzia-MilletiaPterocarpus monsoon types-need not be regretted, for reasons which I have stated 
in the paper from which I have already quoted. It comprises types that are relatively useless from every point of view. As for rainfall, the merits of wooding in bringing about this kind of condensation are in dispute, and at best only the bigwooding area of the Lusitu would need consideration; but all local evidence goes to show that it is the mountains, not the wooding, that perform this service for us here. The objection in any case is applicable to any clearing measures.

Another difficulty is administrative. Even on the British side of the border, where unauthorised fires are forbidden by legislation, such fires still take place. This will happen also here, but the local set-backs involved will weigh lightly in the balance against the benefit that should accrue from the general success. The penalty for unauthorised burning should be severe, and even if it should be necessary to employ a few extra police-boys for four months in the year, the measure would be a very cheap one. There should be no discontent over it amongst the natives, as late burning represents their own old custom, and, whatever their infringements, they still speak of it as the correct method. Dr. Lawrence, speaking of the fact that native huts and granaries must have the grass round them burned at an early date to protect them against the grass fires, has suggested that it will be more difficult to protect against late fires, and that it will also be difficult, when one of the guard fires gets away, to discriminate between real accidents and pretended ones. It seems to me that the real accidents and cases of hardship will be reduced to a minimum-along with the carelessness or lack of adequate hoeing preparation that produce most of them-by a refusal to excuse them. The natives adapted themselves successfully to the late burning of the Zulu regime and even now have sometimes to meet late, fierce fires, as they had to in some of Gwenzi's heavy grass-jungle country in 1918. Naturally they would receive ample warning.

Another difficulty that has been raised in conversation-but it is no difficulty at all-is that late burning is supposedly bad for the pasture. The excellent grasses left us here by the Zulus, who burned late and regularly, are a sufficient reply. It is true that continued burning checks the development of a "close sole" of still better grasses that otherwise follows on heavy stocking by cattle; but if you stop proper burning before you stock, you lose your pasture altogether. The land goes to dense wooding, as it is now fast doing everywhere in Mossurise. Wholesale late burning is in any case not being recommended for country that is already carrying cattle.

Simultaneous burning off of the infested country-and more or less simultaneity would in any case result from postponement-would probably discommode the flies on the wing in a more direct fashion. It would banish the game for the time being. and in the case of brevipalpis in the "Oblong," it would probably force the fly either to take refuge in the ravine-type thickets which a course of late burnings should eventually destroy, or, in part at least, to perish. Its probable effect on morsitans seems more doubtful in view of this fly's relative independence of shade, but observations by Lamborn (Bull. Ent. Res. vii, p. 39) and others show that it is usual even for this fly to desert burnt areas.

Unemerged pupae would no doubt remain in any event to repopulate the area, but Lloyd took a greater percentage of dead pupae from burnt areas than from unburnt; and if $I$ am right in my expectation that the heat of the October fire 
will reach a considerably higher proportion of pupae than those of the earlier fires, the anticipated effect on the flies on the wing would be well worth obtaining also. Birds, again, as I have shown already, probably attack tsetses most when these are in numbers together, and the temporary clearing of the game from a large area will remove the agency that keeps the smaller tsetses scattered, while hunger and the black background should increase the flies activity and visibility.

The one thing that has made me hesitate to recommend simultaneous burning is a slight doubt as to its exact effect on the insectivorous bird population itself. October burning in any case encroaches somewhat on their breeding season, but not to an important extent-that is, the early nesters that have had their nests destroyed have still plenty of time before them, and even in ordinary years an amazingly large proportion of them has to make a fresh start as the result of the depredations of enemies that are likely to be adversely affected by late burning. Again, a fire and the few days following it are feast days, for a very large proportion of the winged insect population escapes it and, being then more conspicuous against the universal blackening, is more readily detected by the birds, which may sometimes be seen searching the burnt ground in parties. The real point is whether the wholesale destruction everywhere of the insects' own food will so much reduce their numbers as to react adversely on the birds. I think that there will be no difficulty here at all, for in this district at that time of the year the response of the vegetation after burning is immediate and most rapid, and a burn gets repopulated with wonderful speed, the new brood of grasshoppers even showing colour adaption to the scorehed surroundings; but the effect of simultaneous burning on the insectivorous birds should be noted nevertheless.

In short, the effects of simultuneous burning, while very promising, have yet to be accurately observed; but the good effects of late burning have actually been demonstrated.

I wish, therefore, to make it the one outstanding recommendation of this report that late burning - with, very frequently indeed, a year of no burning-should be given a trial over a considerable number of years; also that, in the first season at any rate, an effort should be made to have the burning as simultaneous as possible over a large block. The rubber forests and finer Lusitu wooding generally could, if desired, be left out of the scheme. Early burning thereabouts, every year, will save them. It will also unfortunately spread both them and the fly. The fine timber there must be considered also; and against the reduction of the cost of clearing which late fires might have effected by the time this section comes to be settled, must to some extent be placed their destruction of the surface humus. Elsewhere this is being destroyed in any case by the useless fires; it may as well therefore be destroyed by useful ones. The very deciduous areas at the higher elevations need not necessarily be included either, but they are not sufficiently extensive to be worth excluding, especially as their wooding (for the most part of little value) will remain a great annual danger so long as any permanent fly survives below.

To give the measure a definite experimental value sample plots or areas in each type of wooding should be selected, described, charted and photographed. These, examined from time to time, would afford a measure of the success or failure of the experiment. 


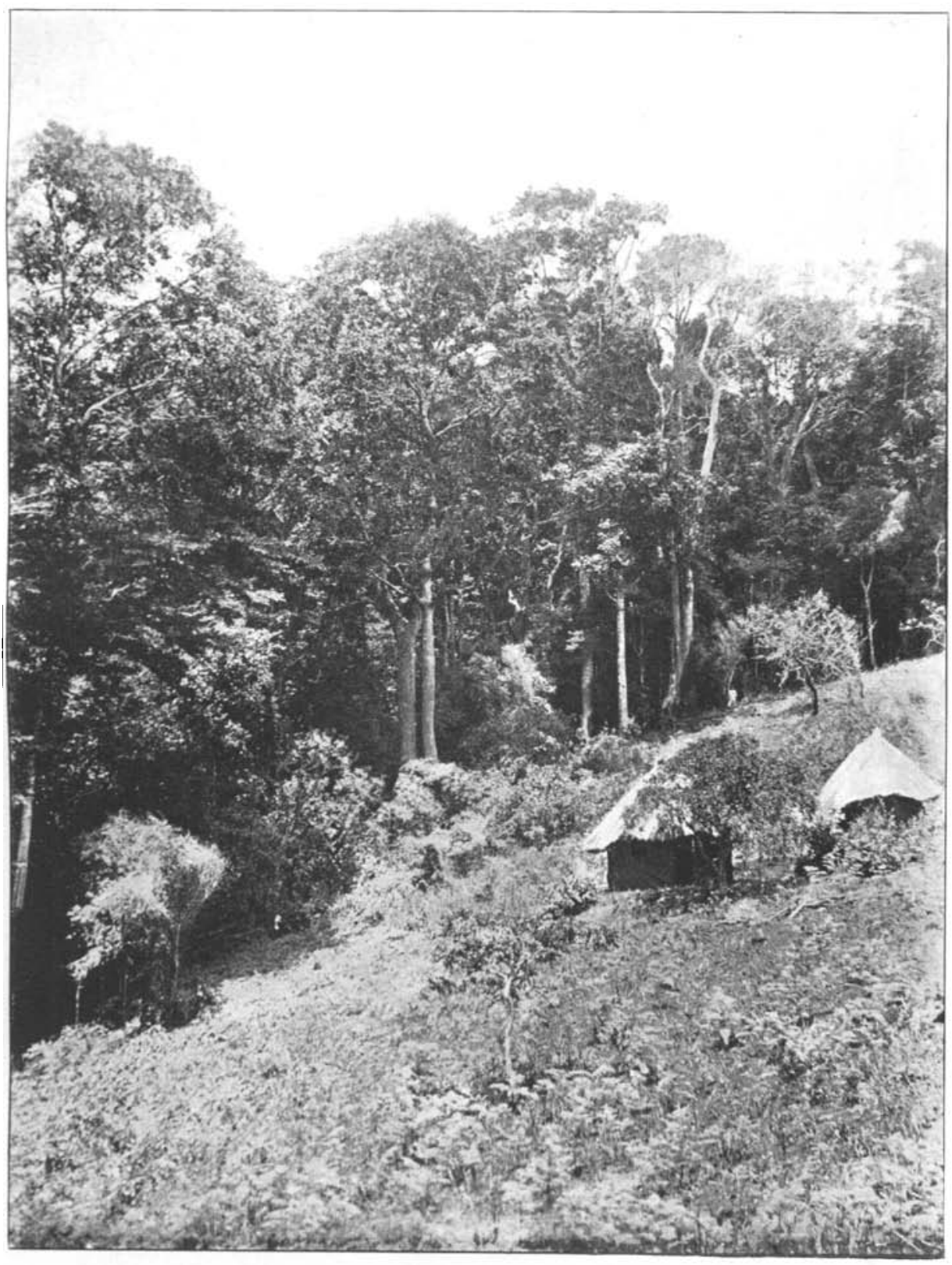

Primary "rain" forest; the large trees are African mahogany (Khaya nyasica'. At suitable elevations this type of forest harbours Glossina brevipalpis in the dry season. 


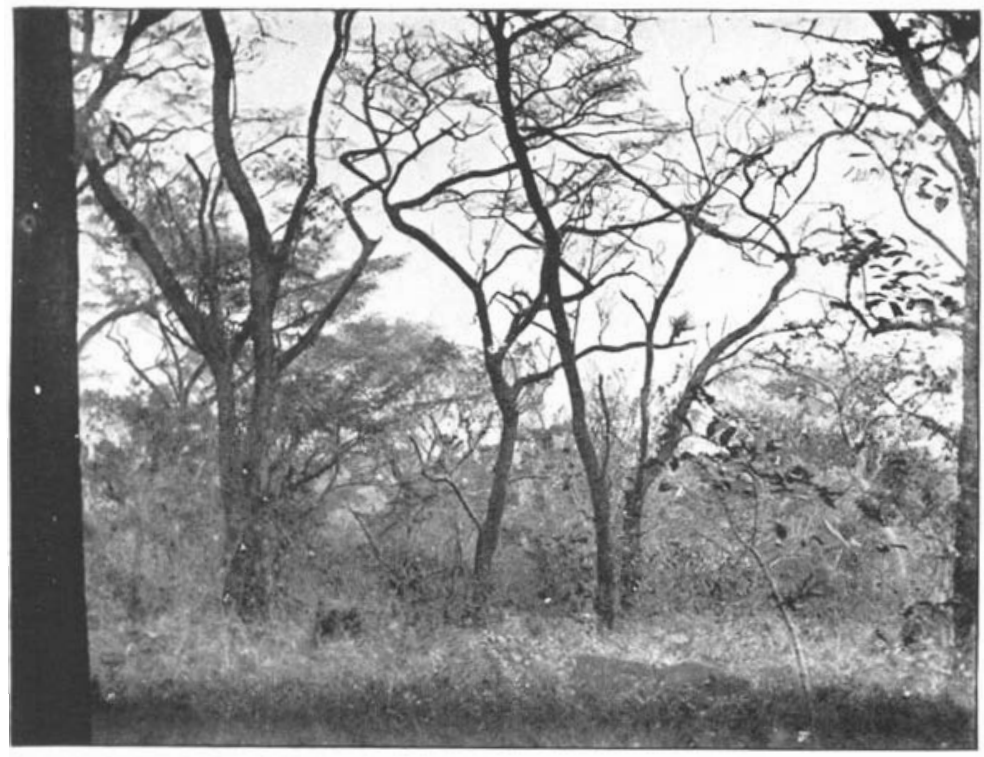

Fig. 1. Highly deciduous secondary forest on Mount Umtareni in August, with Pterocarpus anqolensis and Terminalia sericea. Capable of sheltering Glossina brevipalpis and G. pallidipes in the wet but not in the dry season.

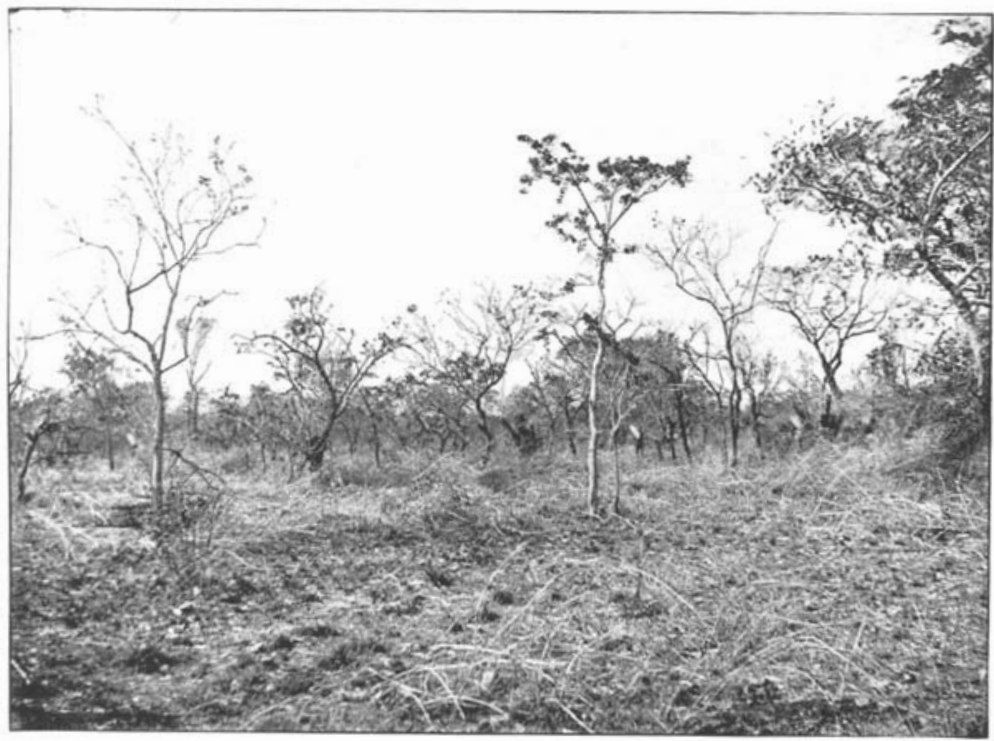

Fig. 2. Lowland bush-savannah on the basalt at the younger Gunye's, Combretum dominating; harbours the overflow of $G$. morsitans from the Brachystegia for much of the year. 
Bull. Ent, Research. Vol. XI. Part 4.

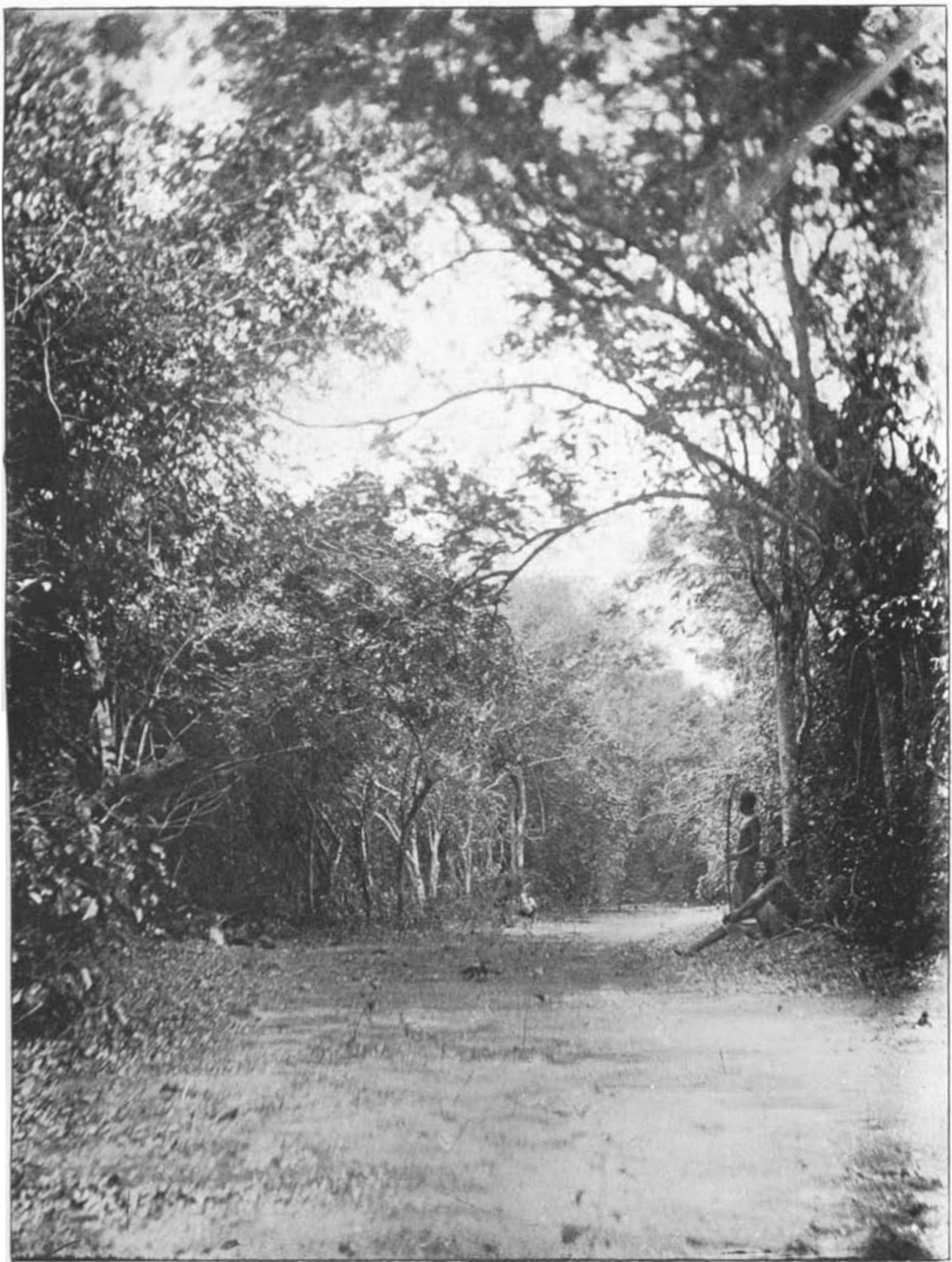

A typical scene in the Madanda rubber forest. An Erythroxylon-Landolphia invasion of tree-savannah and savannah-forest, capable of harbouring G. brevipalpis and G. pallidipes. 

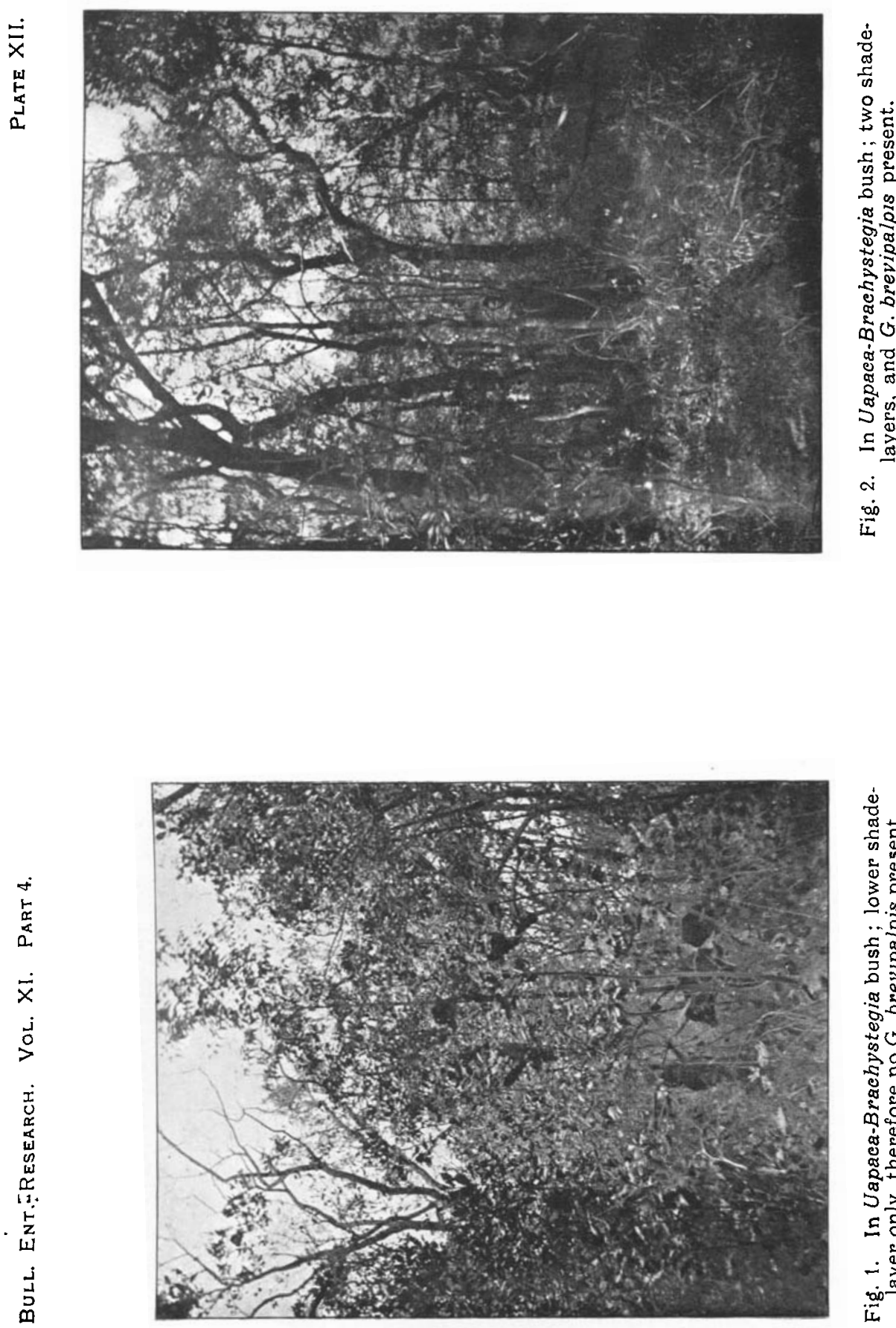

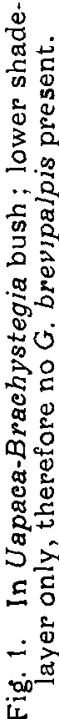




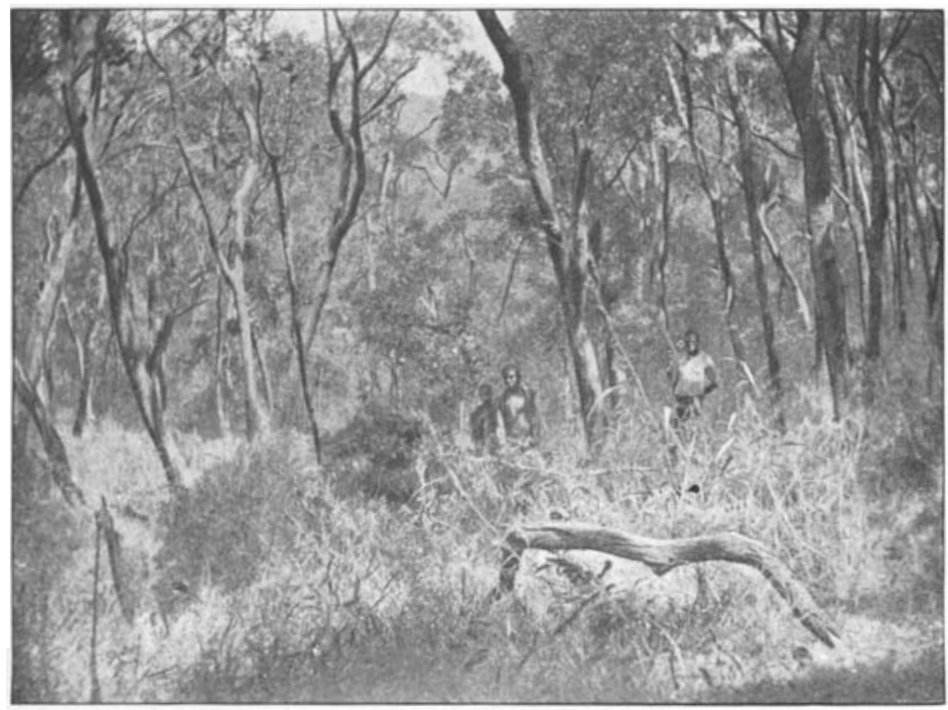

Fig 1. In Uapaca-Brachy'stegra bush: only an upper shade-layer, and therefore no $G$. brevipalpis.

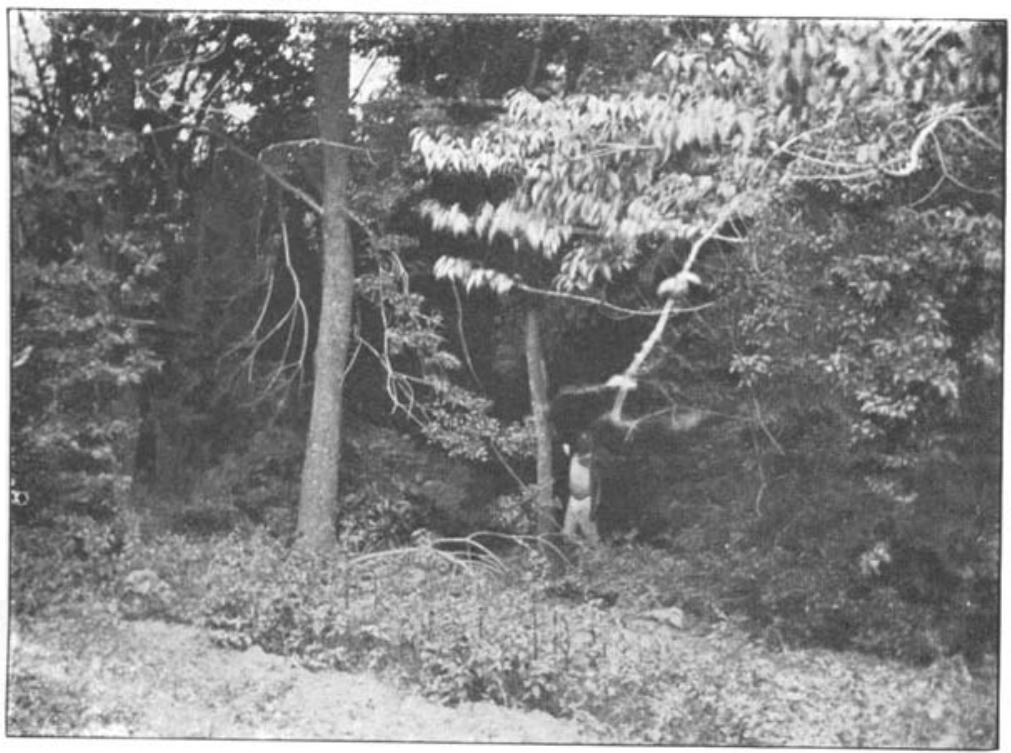

Fig. 2. Landolphia wooding of the Lusitu rubber forest type; with a lower shade-layer of this high, very dense type G. brevipalp1s was present even when the higher trees were leafless. 
Bull. Ent. Research. Yol. Xi. Part 4.

Plate Xiv.

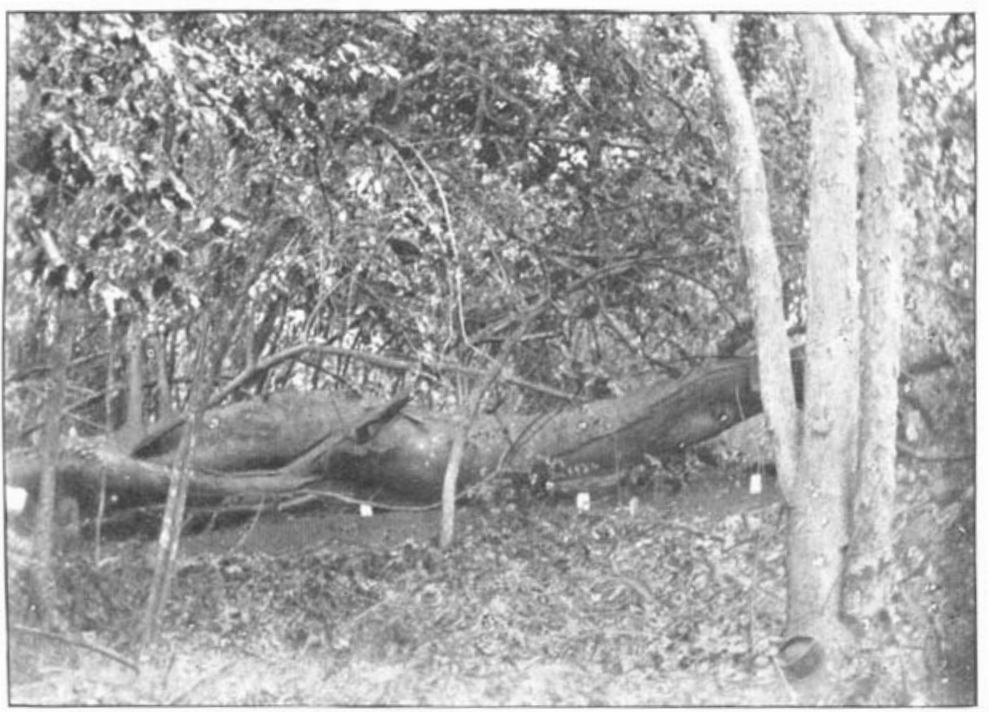

Fig. 1. Nearly 100 puparia of G. brevipalpis were taken under this fallen Piptadenıa buchananı at the spots indicated by the papers.

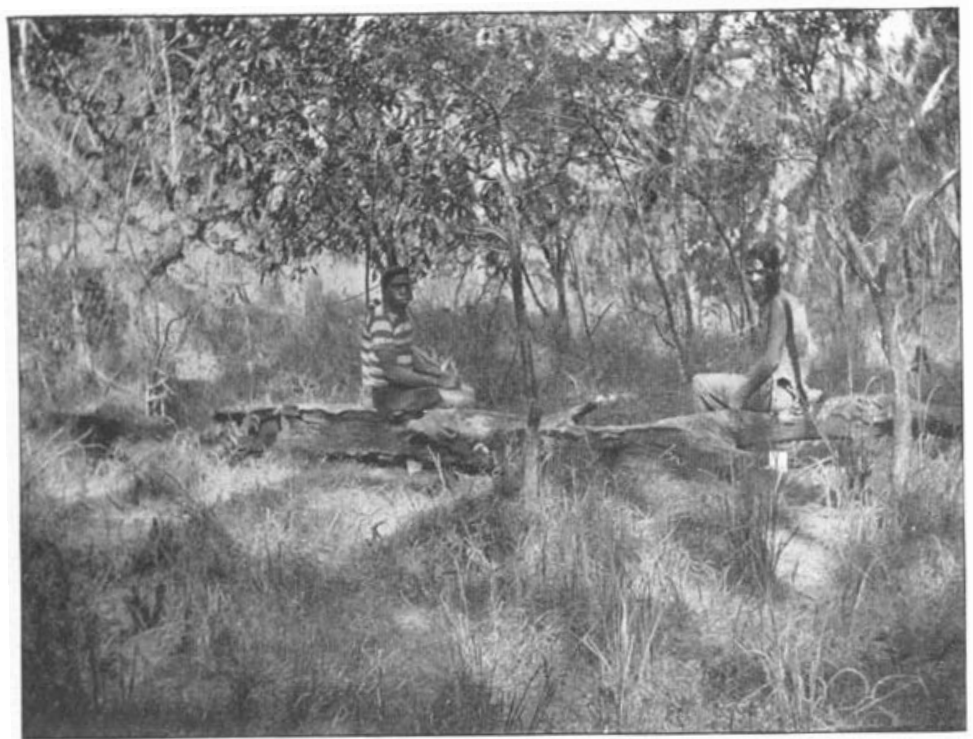

Fig. 2. A lery typical breeding-place of $G$. morsitans under a long-fallen trunk of Burkea africans. 
Bull. Ent. Research. Yol, Xi. Part 4.

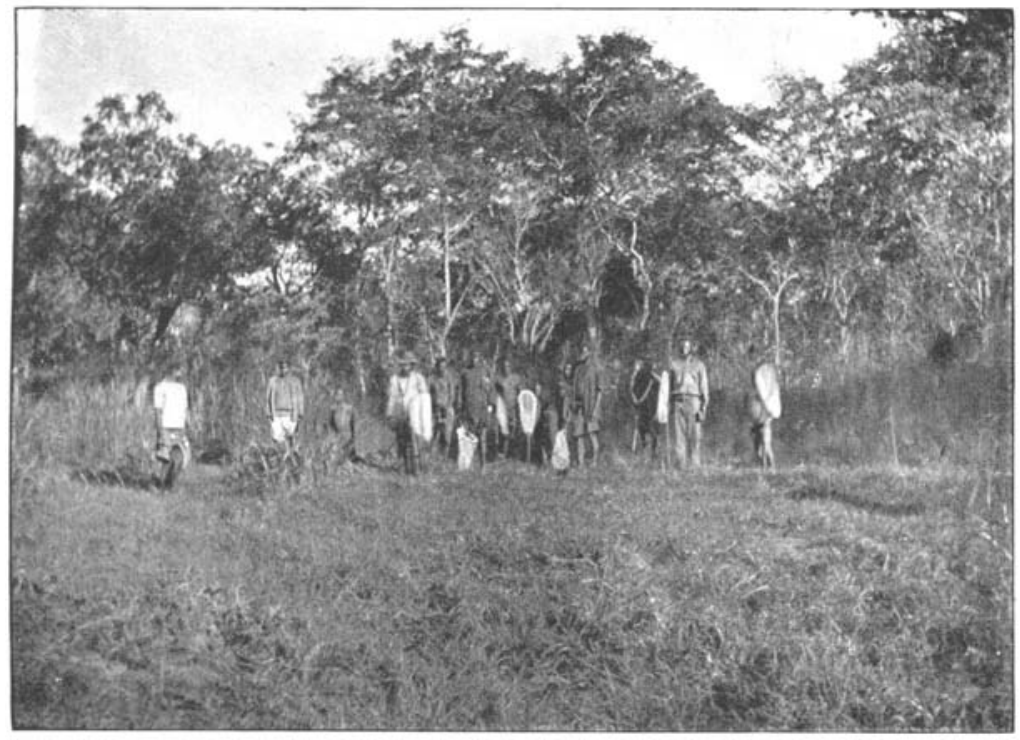

Fig. 1. Site of a male cluster of G. morsitans; the short grass was very green and luscious, and the flies occurred both on it and on the longer grass near.

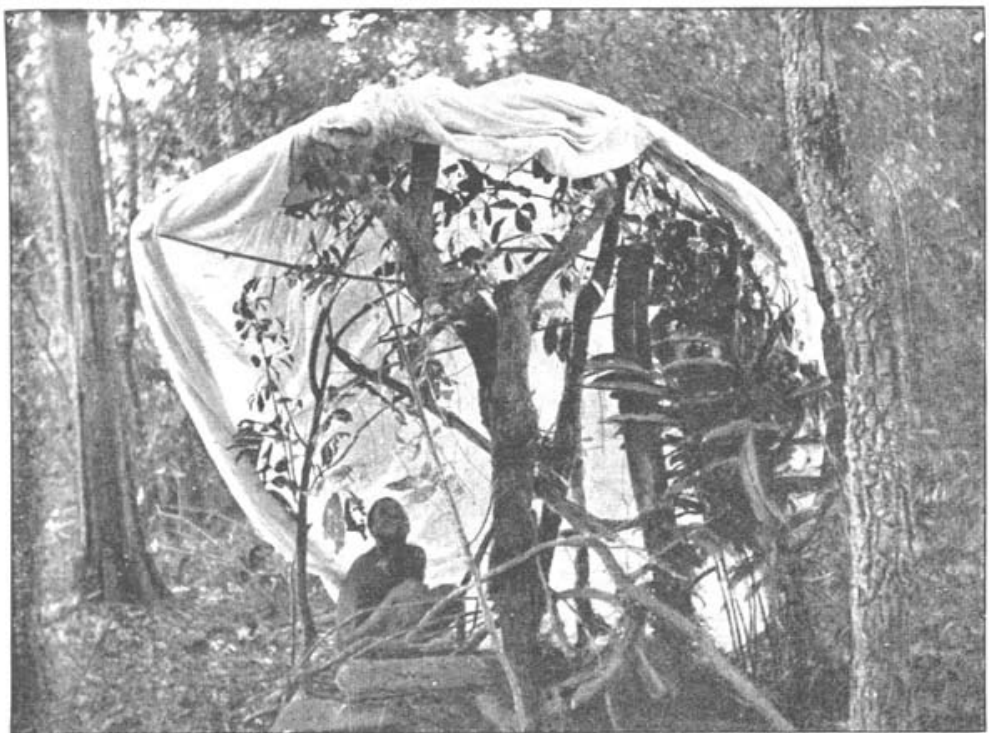

Fig. 2. Experimental net and its furniture, as used for G. brevipalpis and G. pallidipes. 
Bull. Ent. Research. Vol. XI. Part 4.

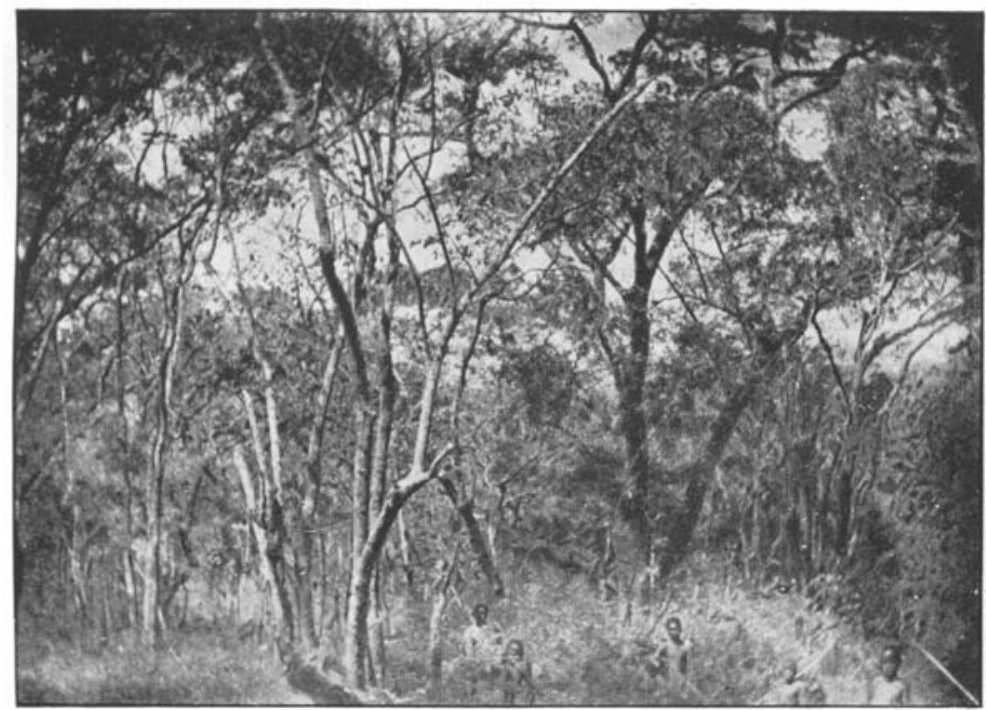

Fig. 1. Clearıng experiment ¿No. 1. Undergrowth uncleared; G. brevipalpis present in abundance.

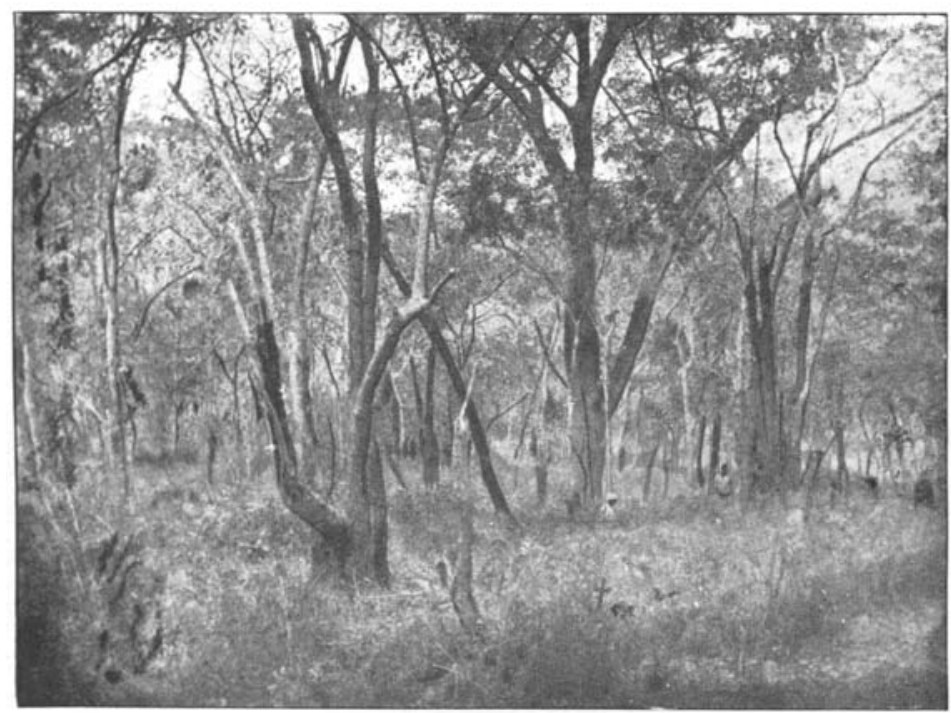

Fig. 2. The same spot with the undergrowth cleared; G. brevipalpis has entirely disappeared. 


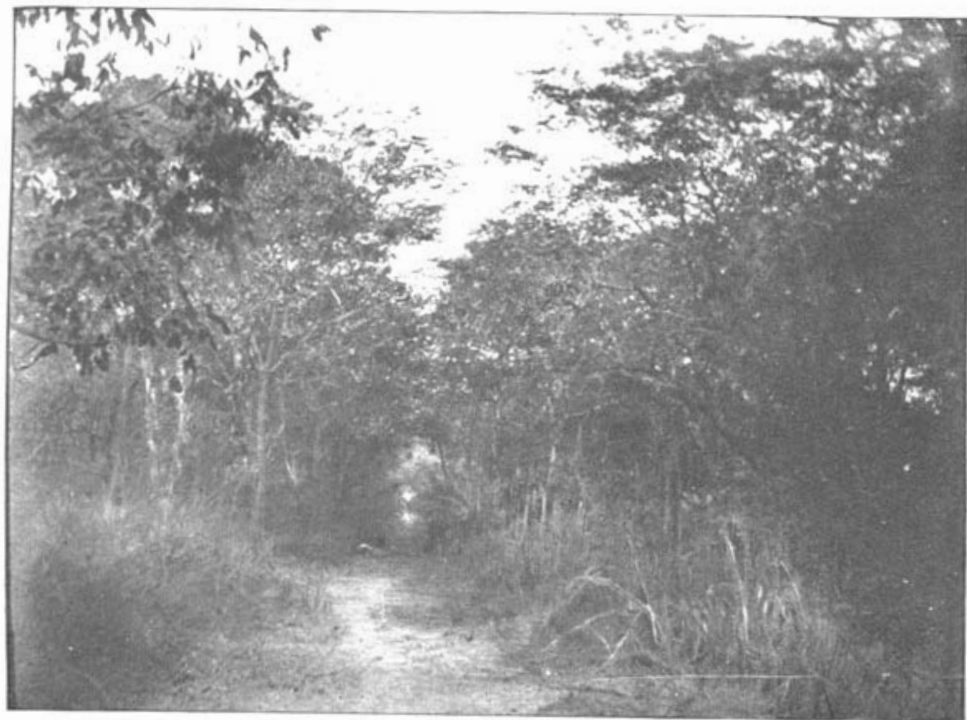

Fig. 1. Coppice type of secondary bush, strongly favoured by G. pallidipes west of the Sitatonga Hills. This bush has grown up in 12 years on deserted native gardens.

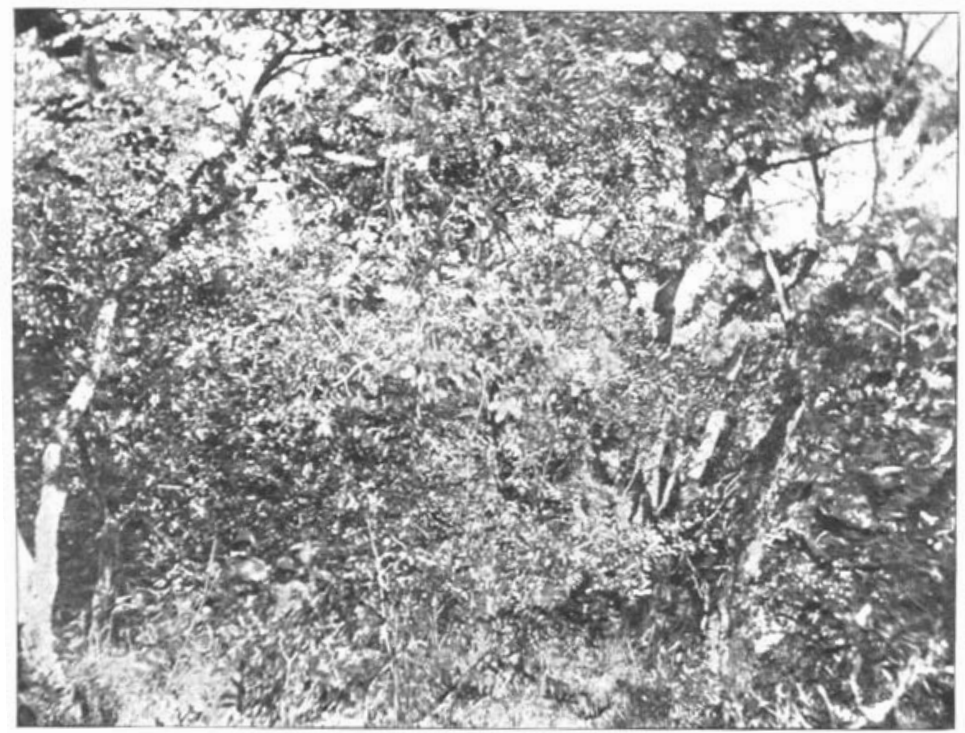

Fig. 2. A thicket on a piece of land belonging to the writer resulting from early and irregular burning for a good many years; it was previously clean-stemmed wooding. 


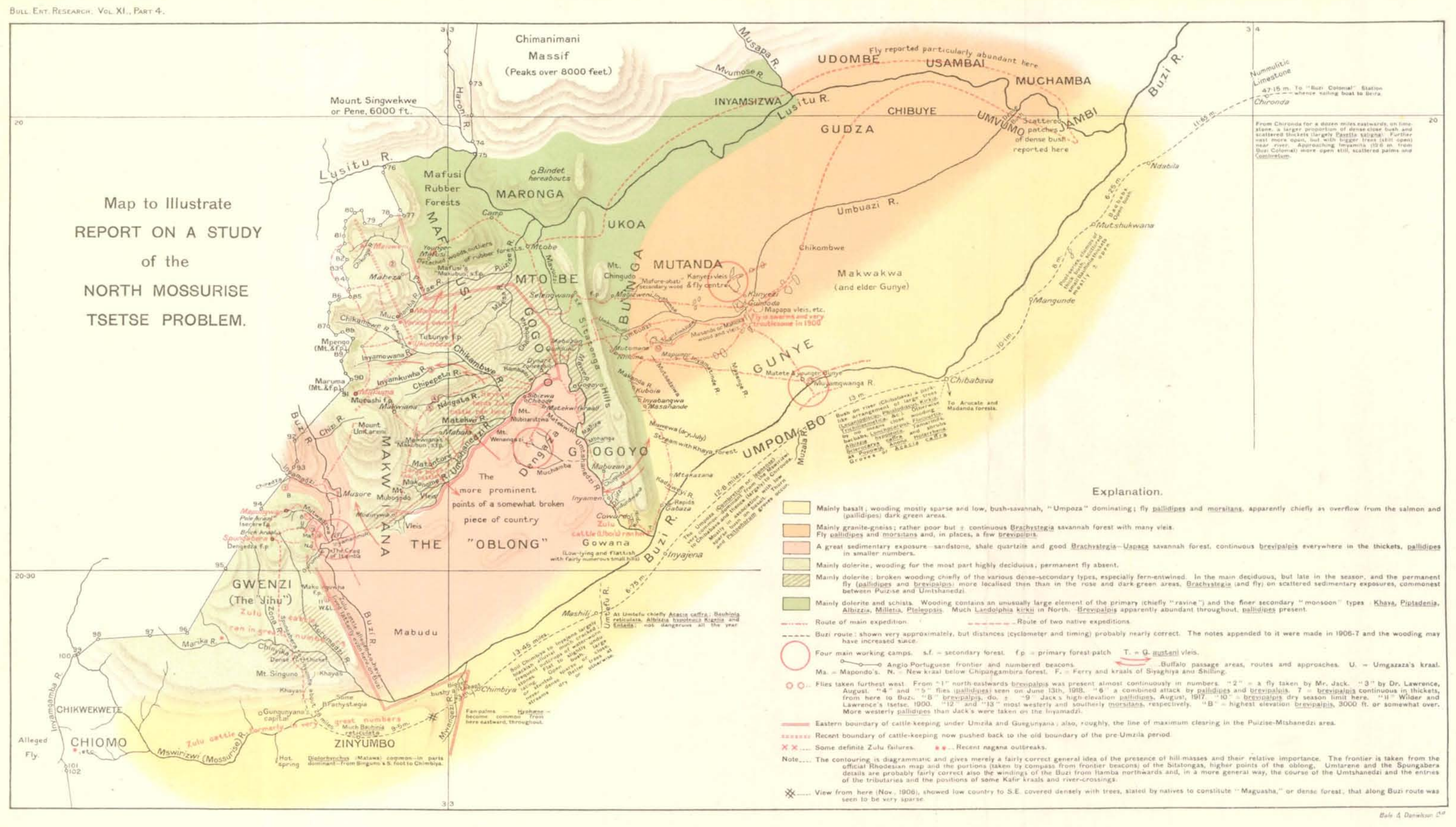

